\title{
Energy Efficiency Improvement and Cost Saving Opportunities For Petroleum Refineries
}

\author{
An ENERGY STAR ${ }^{\circledR}$ Guide for Energy and Plant Managers
}

\section{Ernst Worrell and Christina Galitsky}

\author{
Energy Analysis Department \\ Environmental Energy Technologies Division \\ Ernest Orlando Lawrence Berkeley National Laboratory \\ University of California \\ Berkeley, CA 94720
}

February 2005

This report was funded by the U.S. Environmental Protection Agency's Climate Protection Partnerships Division as part of ENERGY STAR. ENERGY STAR is a government-backed program that helps businesses protect the environment through superior energy efficiency. The work was supported by the U.S. Environmental Protection Agency through the U.S. Department of Energy Contract No.DE-AC02-05CH11231. 



\title{
Energy Efficiency Improvement and Cost Saving Opportunities for Petroleum Refineries
}

\author{
An ENERGY STAR ${ }^{\circledR}$ Guide for Energy and Plant Managers
}

\author{
Ernst Worrell and Christina Galitsky \\ Energy Analysis Department \\ Environmental Energy Technologies Division \\ Ernest Orlando Lawrence Berkeley National Laboratory
}

February 2005

\begin{abstract}
The petroleum refining industry in the United States is the largest in the world, providing inputs to virtually any economic sector, including the transport sector and the chemical industry. The industry operates 146 refineries (as of January 2004) around the country, employing over 65,000 employees. The refining industry produces a mix of products with a total value exceeding $\$ 151$ billion. Refineries spend typically 50\% of cash operating costs (i.e.,, excluding capital costs and depreciation) on energy, making energy a major cost factor and also an important opportunity for cost reduction. Energy use is also a major source of emissions in the refinery industry making energy efficiency improvement an attractive opportunity to reduce emissions and operating costs.

Voluntary government programs aim to assist industry to improve competitiveness through increased energy efficiency and reduced environmental impact. ENERGY STAR ${ }^{\circledR}$, a voluntary program managed by the U.S. Environmental Protection Agency, stresses the need for strong and strategic corporate energy management programs. ENERGY STAR provides energy management tools and strategies for successful corporate energy management programs. This Energy Guide describes research conducted to support ENERGY STAR and its work with the petroleum refining industry. This research provides information on potential energy efficiency opportunities for petroleum refineries.

This Energy Guide introduces energy efficiency opportunities available for petroleum refineries. It begins with descriptions of the trends, structure, and production of the refining industry and the energy used in the refining and conversion processes. Specific energy savings for each energy efficiency measure based on case studies of plants and references to technical literature are provided. If available, typical payback periods are also listed. The Energy Guide draws upon the experiences with energy efficiency measures of petroleum refineries worldwide. The findings suggest that given available resources and technology, there are opportunities to reduce energy consumption cost-effectively in the petroleum refining industry while maintaining the quality of the products manufactured. Further research on the economics of the measures, as well as the applicability of these to individual refineries, is needed to assess the feasibility of implementation of selected technologies at individual plants.
\end{abstract}




\section{Contents}

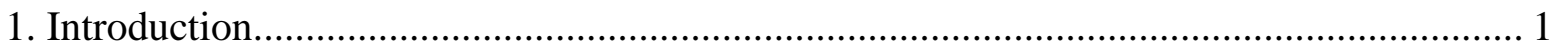

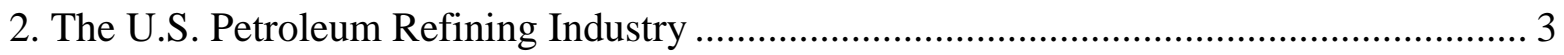

3. Process Description ................................................................................................. 9

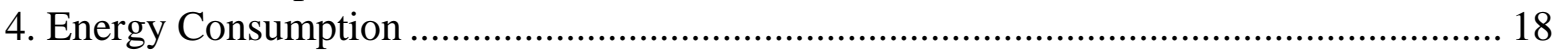

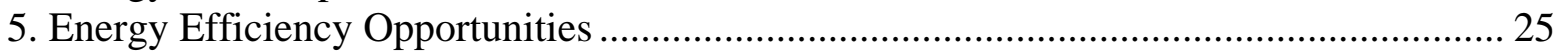

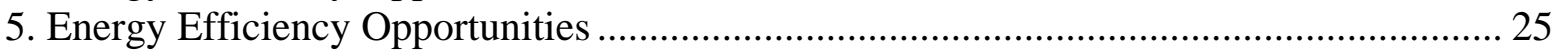

6. Energy Management and Control ................................................................................ 28

6.1 Energy Management Systems (EMS) and Programs.................................................. 28

6.2 Monitoring \& Process Control Systems ………………............................................... 30

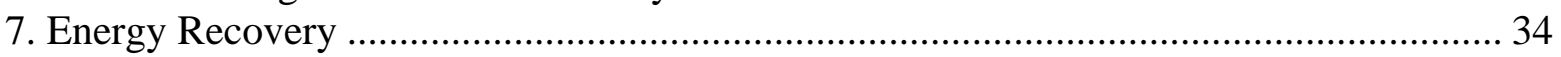

7.1 Flare Gas Recovery ............................................................................................. 34

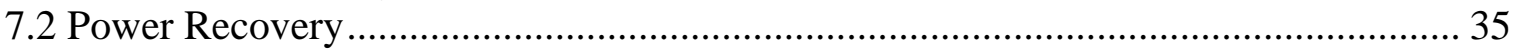

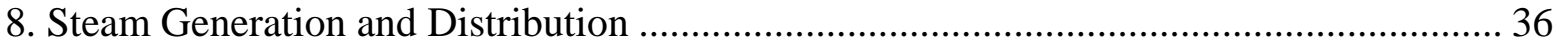

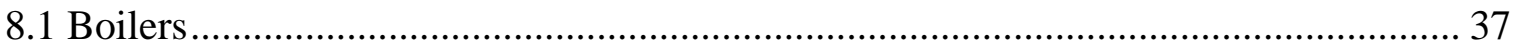

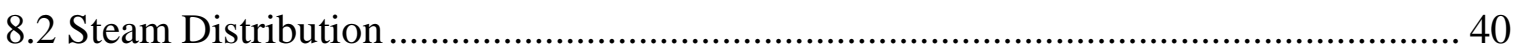

9. Heat Exchangers and Process Integration........................................................................ 43

9.1 Heat Transfer- Fouling ........................................................................................... 43

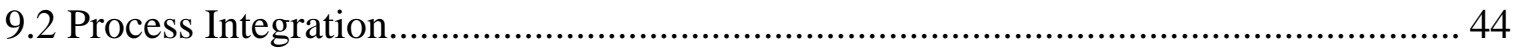

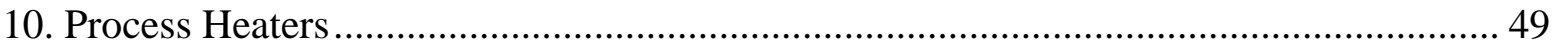

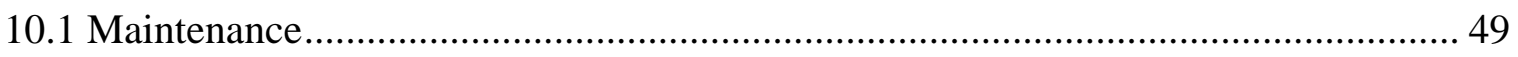

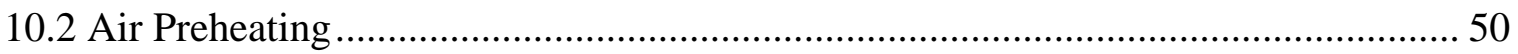

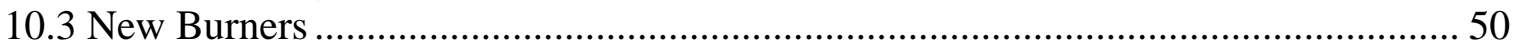

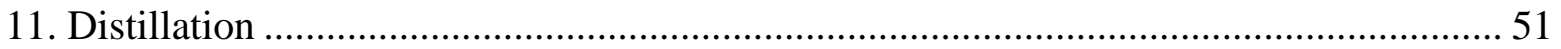

12. Hydrogen Management and Recovery ............................................................................. 53

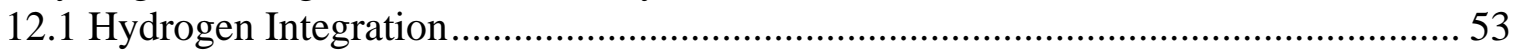

12.2 Hydrogen Recovery …………………………….......................................... 53

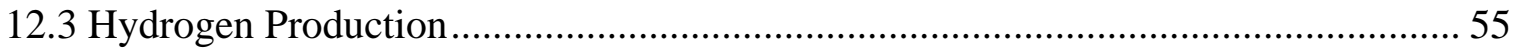

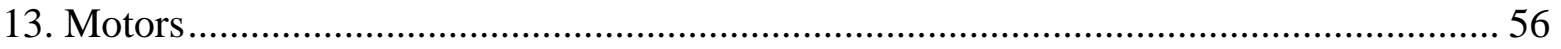

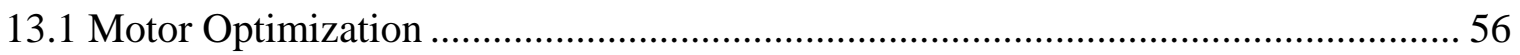

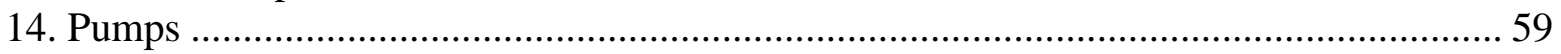

15. Compressors and Compressed Air............................................................................... 65

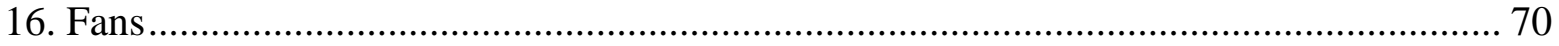

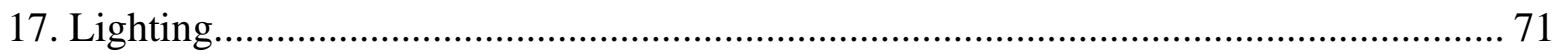

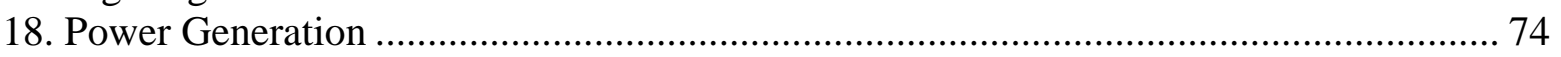

18.1 Combined Heat and Power Generation (CHP) ………........................................... 74

18.2 Gas Expansion Turbines ..................................................................................... 75

18.3 Steam Expansion Turbines. ............................................................................... 76

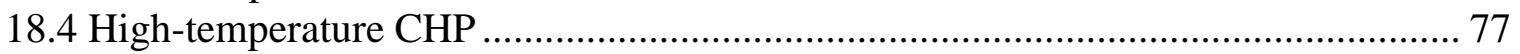

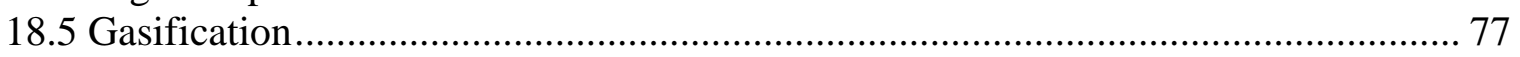

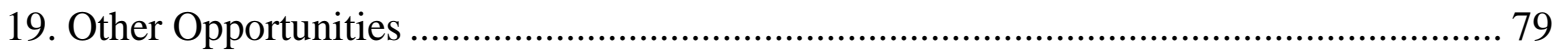

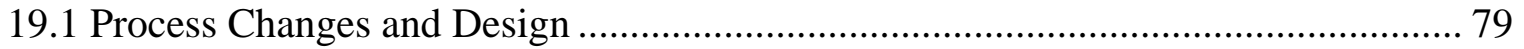

19.2 Alternative Production Flows ............................................................................ 79

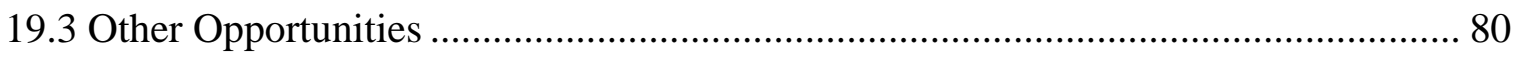

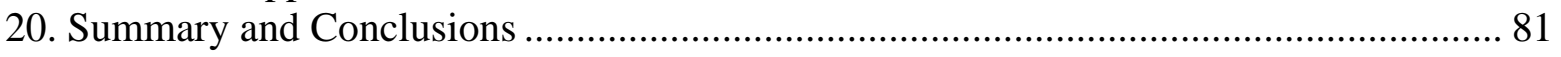


Appendix A: Active refineries in the United States as of January 2003 ............................ 94

Appendix B: Employee Tasks for Energy Efficiency ….................................................. 99

Appendix C: Energy Management System Assessment for Best Practices in Energy

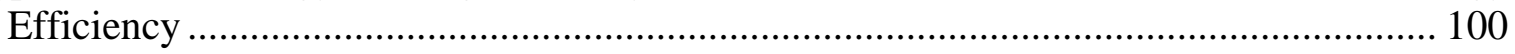

Appendix D: Energy Management Assessment Matrix ................................................ 102

Appendix E: Support Programs for Industrial Energy Efficiency Improvement ................ 105 


\section{Introduction}

As U.S. manufacturers face an increasingly competitive global business environment, they seek out opportunities to reduce production costs without negatively affecting product yield or quality. Uncertain energy prices in today's marketplace negatively affect predictable earnings, which are a concern, particularly for the publicly traded companies in the petroleum industry. Improving energy efficiency reduces the bottom line of any refinery. For public and private companies alike, increasing energy prices are driving up costs and decreasing their value added. Successful, cost-effective investment into energy efficiency technologies and practices meets the challenge of maintaining the output of a high quality product while reducing production costs. This is especially important, as energy efficient technologies often include "additional" benefits, such as increasing the productivity of the company.

Energy use is also a major source of emissions in the refinery industry, making energy efficiency improvement an attractive opportunity to reduce emissions and operating costs. Energy efficiency should be an important component of a company's environmental strategy. End-of-pipe solutions can be expensive and inefficient while energy efficiency can be an inexpensive opportunity to reduce criteria and other pollutant emissions. Energy efficiency can be an efficient and effective strategy to work towards the so-called "triple bottom line" that focuses on the social, economic, and environmental aspects of a business ${ }^{1}$. In short, energy efficiency investment is sound business strategy in today's manufacturing environment.

Voluntary government programs aim to assist industry to improve competitiveness through increased energy efficiency and reduced environmental impact. ENERGY $\operatorname{STAR}^{\circledR}$, a voluntary program managed by the U.S. Environmental Protection Agency (EPA), highlights the importance of strong and strategic corporate energy management programs. ENERGY STAR provides energy management tools and strategies for successful corporate energy management programs. This Energy Guide describes research conducted to support ENERGY STAR and its work with the petroleum refining industry. This research provides information on potential energy efficiency opportunities for petroleum refineries. ENERGY STAR can be contacted through www.energystar.gov for additional energy management tools that facilitate stronger energy management practices in U.S. industry.

This Energy Guide assesses energy efficiency opportunities for the petroleum refining industry. Petroleum refining in the United States is the largest in the world, providing inputs to virtually all economic sectors, including the transport sector and the chemical industry. The industry operates 146 refineries (as of January 2004) around the country, employing over 65,000 employees, and produces a mix of products with a total value exceeding $\$ 151$ billion (based on the 1997 Economic Census). Refineries spend typically 50\% of cash

\footnotetext{
${ }^{1}$ The concept of the "triple bottom line" was introduced by the World Business Council on Sustainable Development (WBCSD). The three aspects of the "triple bottom line" are interconnected as society depends on the economy and the economy depends on the global ecosystem, whose health represents the ultimate bottom line.
} 
operating costs (i.e., excluding capital costs and depreciation) on energy, making energy a major cost factor and also an important opportunity for cost reduction.

This Energy Guide first describes the trends, structure and production of the petroleum refining industry in the United States. It then describes the main production processes. Next, it summarizes energy use in refineries along with the main end uses of energy. Finally, it discusses energy efficiency opportunities for U.S. refineries. The Energy Guide focuses on measures and technologies that have successfully been demonstrated within individual plants in the United States or abroad. Because the petroleum refining industry is an extremely complex industry, this Energy Guide cannot include all opportunities for all refineries. Although new technologies are developed continuously (see e.g., Martin et al., 2000), the Energy Guide focuses on practices that are proven and currently commercially available.

This Energy Guide aims to serve as a guide for energy managers and decision-makers to help them develop efficient and effective corporate and plant energy management programs, by providing them with information on new or improved energy efficient technologies. 


\section{The U.S. Petroleum Refining Industry}

The United States has the world's largest refining capacity, processing just less than a quarter of all crude oil in the world. Although the major products of the petroleum refining sector are transportation fuels, its products are also used in other energy applications and as feedstock for the chemical industries.

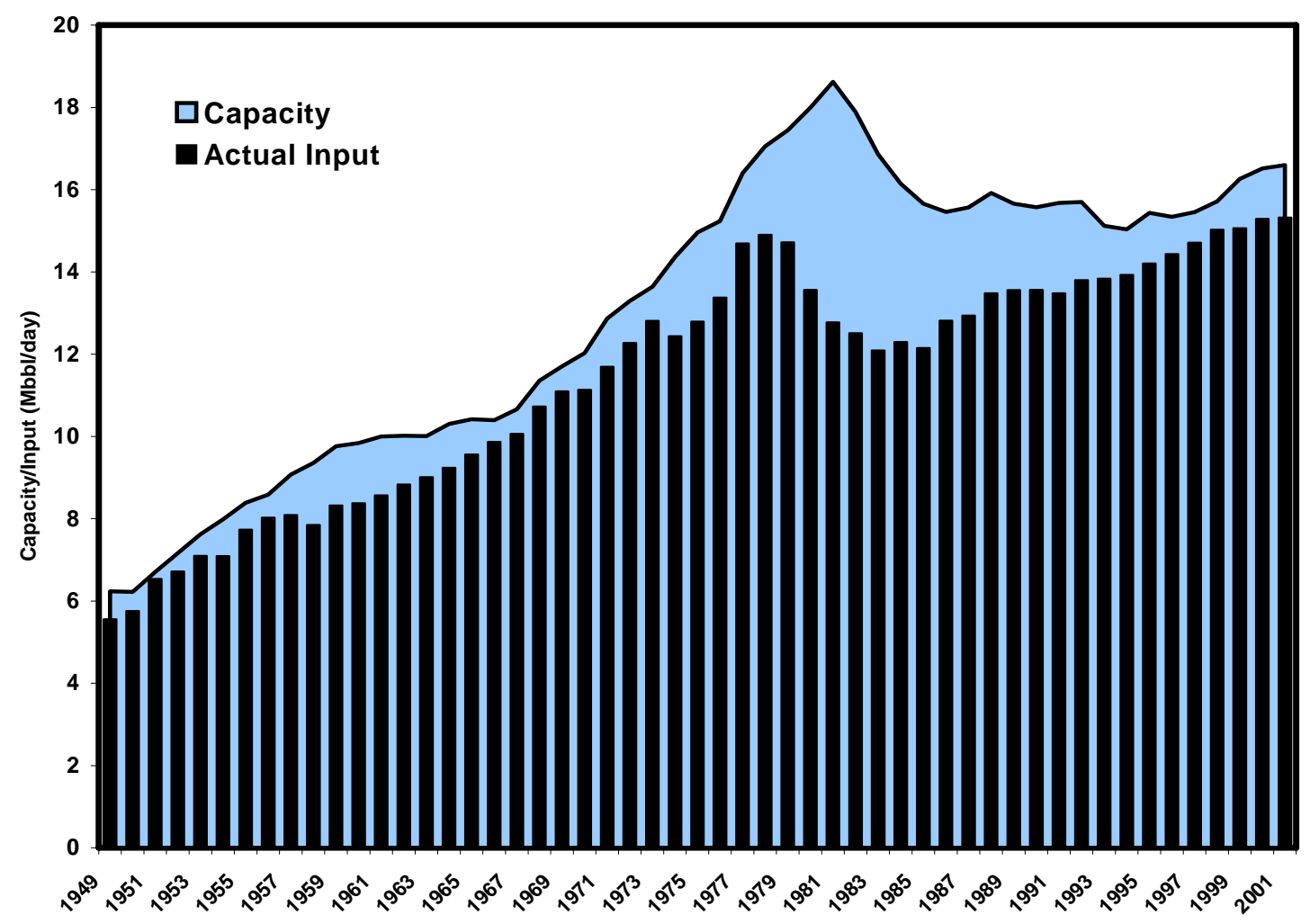

Figure 1. Capacity and actual crude intake of the U.S. petroleum refining industry between 1949 and 2001, expressed in million barrels/day of crude oil intake. Source: Energy Information Administration.

The U.S. petroleum refining sector has grown over the past 50 years by about 2\%/year on average. Until the second oil price shock, refining capacity grew rapidly, but production already started to level off in the mid to late 1970s. This was a period where the industry started to reorganize. It was not until after the mid-1980s that refinery production started to grow again. Since 1985, the industry has been growing at a somewhat slower rate of 1.4\%/year. Figure 1 shows the developments in installed capacity (expressed as crude intake capacity) and actual crude intake in the U.S. refining industry since 1949.

Figure 1 shows that capacity utilization has been pretty steady, with exception of the period between the two oil price shocks. Following the first oil price shock, federal legislation favoring domestic production and refining subsidized the construction and operation of many small refineries (U.S. DOE-OIT, 1998). As shown, this led to a reduced capacity 
utilization. Figure 2 shows the number of operating refineries in the United States since 1949.

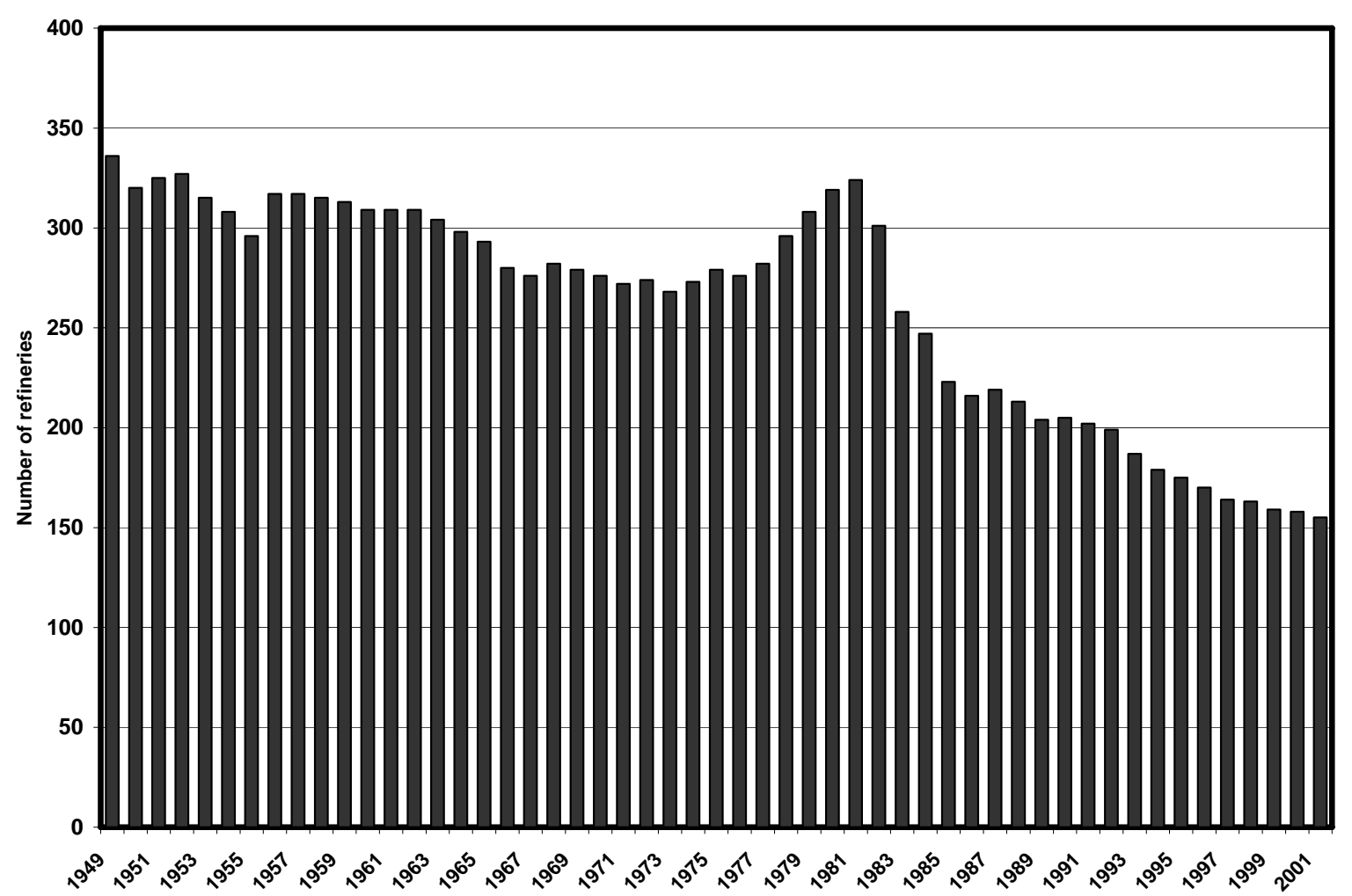

Figure 2. Number of operating refineries in the United States. Source: Energy Information Administration.

Figure 2 clearly demonstrates the increasing number of refineries after the first oil price shocks in the 1970s. The small refineries only distill products, and are most often inefficient and less flexible operations, producing only a small number of products. Increasing demand for lighter refinery products, and changes in federal energy policy, have led to a reduction in the number of refineries, while increasing capacity utilization (see Figure 1).

These market dynamics will also lead to a further concentration of the refinery industry into high capacity plants operating at higher efficiencies. The number of refineries has declined from 205 in 1990 to 147 in 2002. The current refineries have a higher capacity utilization and are generally more complex, with an emphasis on converting technology. This trend will continue to increase the ability to process a wider range of crudes and to produce an increasing share of lighter petroleum products. Also increasing is the need to produce cleaner burning fuels to meet environmental regulations (e.g., reduction of sulfur content). Appendix A provides a list of operating refineries in the United States as of January 2003.

Petroleum refineries can be found in 32 states, but the industry is heavily concentrated in a few states due to historic resource location and easy access to imported supplies (i.e., close to harbors). Hence, the largest number of refineries can be found on the Gulf Coast, followed by California, Illinois, New Jersey, Pennsylvania, and Washington. Some of the 
smallest producing states have only very small refineries operated by independent operators. These small refineries produce only a very small mix of products, and are ultimately not expected to be able to compete in the developing oil market. Figure 3 depicts refining capacity by state (expressed as share of total capacity crude intake) in 2002.

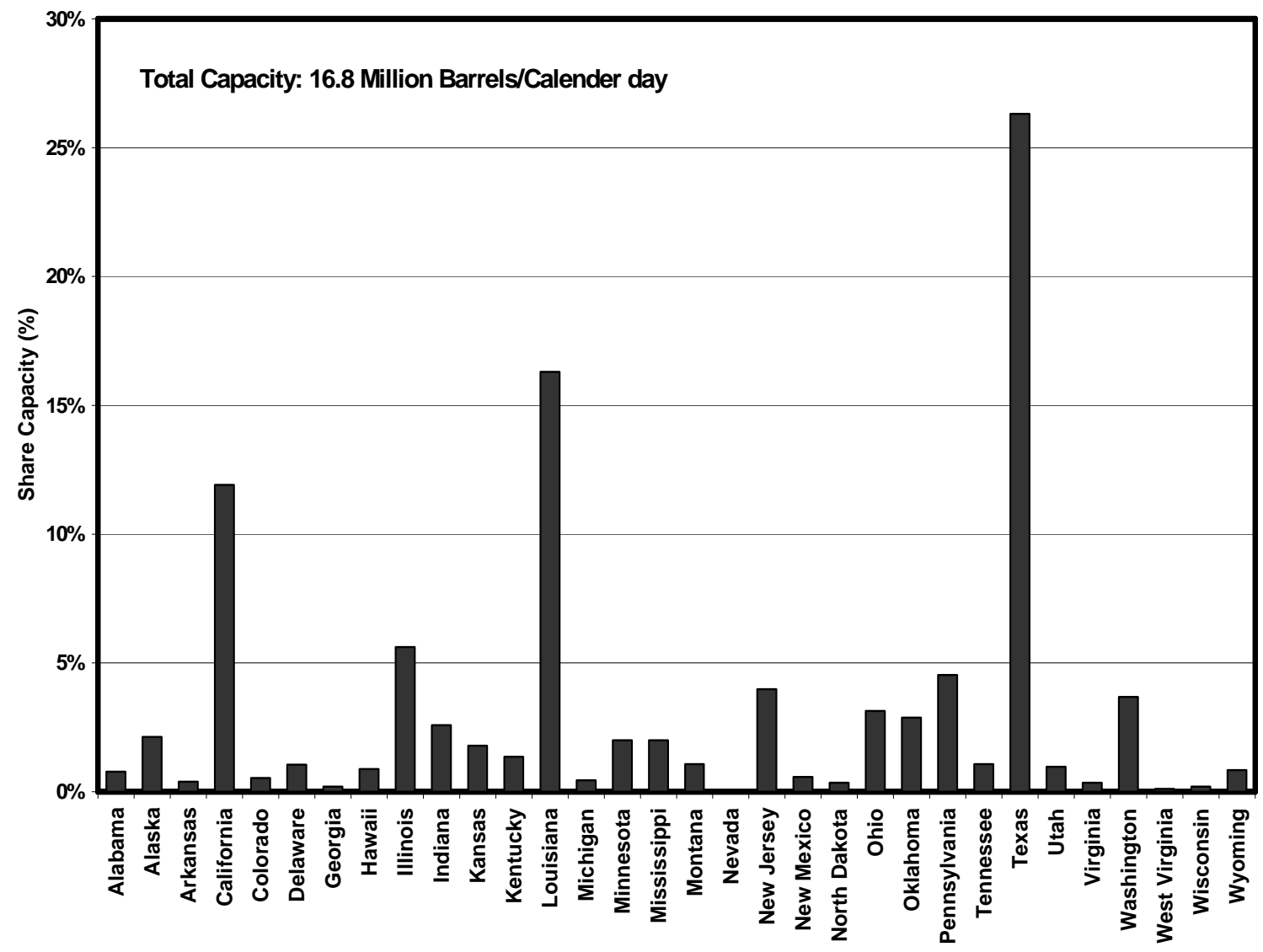

Figure 3. Refining capacity by state as share of total U.S. refining capacity in 2003. Capacity is expressed as capacity for crude intake. Source: Energy Information Administration.

The refineries are operated by 59 companies. Although there are a relatively large number of independent companies in the U.S. refining industry, the majority of the refining capacity is operated by a small number of multi-national or national oil processing companies. The largest companies (as of January 2003) are: ConocoPhilips (13\% of crude capacity), ExxonMobil (11\%), BP (9\%), Valero (8\%), ChevronTexaco (6\%), Marathon Ashland (6\%), and Shell (6\%), which combined represent 59\% of crude distillation (CDU) capacity. Each of these companies operates a number of refineries in different states. Figure 4 depicts companies operating over $0.5 \%$ of CDU capacity in the United States

The small refineries produce a relative simple mix of products. Small refineries may often use high cost feedstocks, which may result in a relatively low profitability. As a result, small companies' share of total industry economic value is smaller than their share of total industry production capacity. 


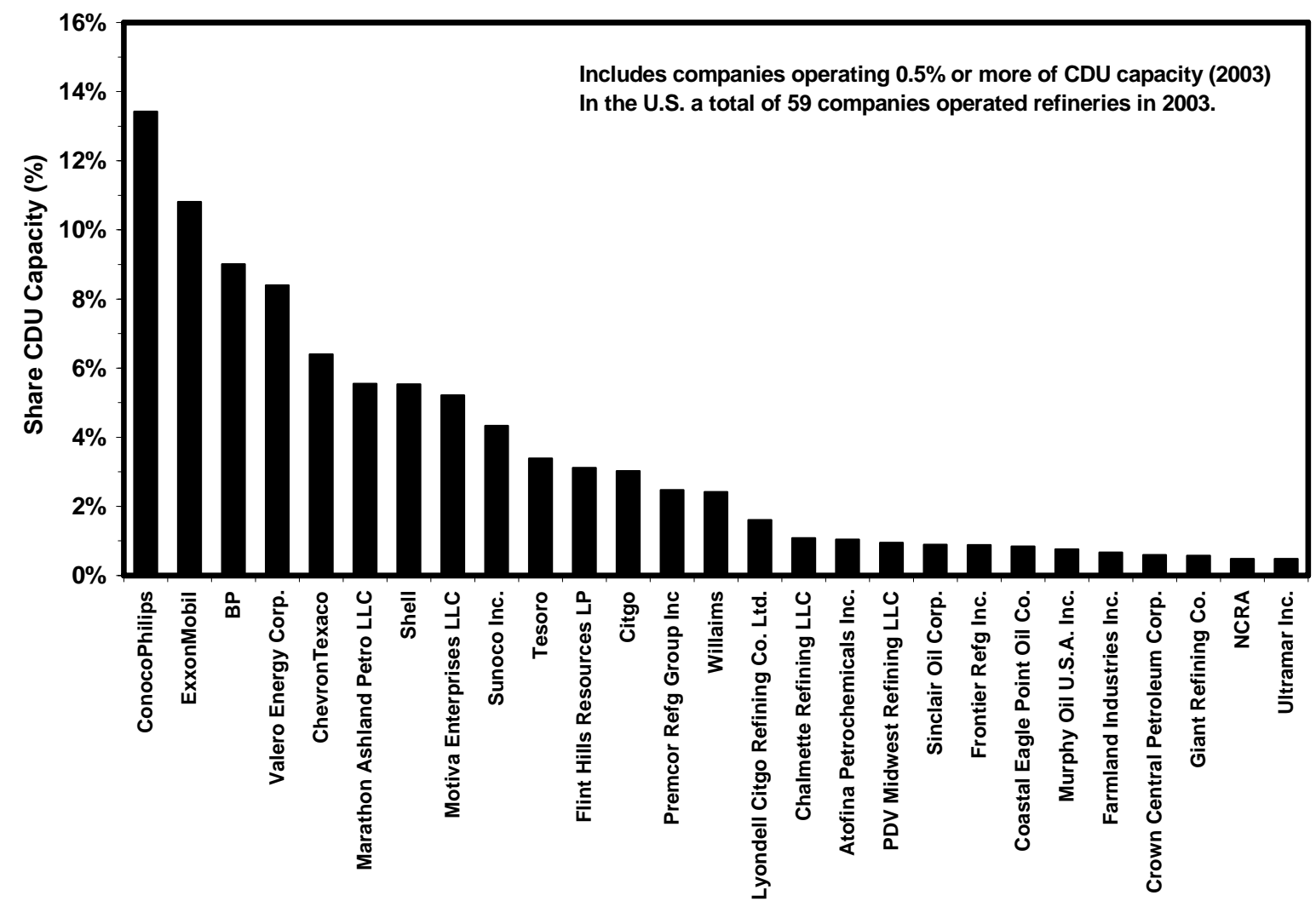

Figure 4. Refining capacity (expressed as percentage of CDU capacity) for companies operating over $0.5 \%$ of CDU capacity in 2003. The depicted companies operate $94 \%$ of total national capacity. Companies operating less than $0.5 \%$ of CDU capacity are not depicted. Source: Energy Information Administration.

The further concentration of refineries in the United States has contributed to a reduction in operating costs but has also impacted refining margins (Killen et al., 2001). The Western United States market is more or less isolated from the other primary oil markets in the United States. Although overall market dynamics in the United States and the Western United States market follow the same path, the operating margin from Western refineries is higher than that in other regions. Between 1995 and 2000, the operating margin of West Coast refineries has grown from $\$ 3$ to a high of \$8/bbl crude in 2000 (Killen et al., 2001), compared to 1 to $4 \$ / b b l$ in other U.S. markets.

U.S. refineries process different kinds of crude oil types from different sources. Over the past years, overall there has been a trend towards more heavy crudes and higher sulfur content (Swain, 2002). These effects vary for the different regions in the United States, but overall this trend has been clear over the past 10 years. This trend is likely to continue, and will affect the product mix, processing needs, and energy use of refineries. This trend will also result in a further expansion of conversion capacity at U.S. refineries. 


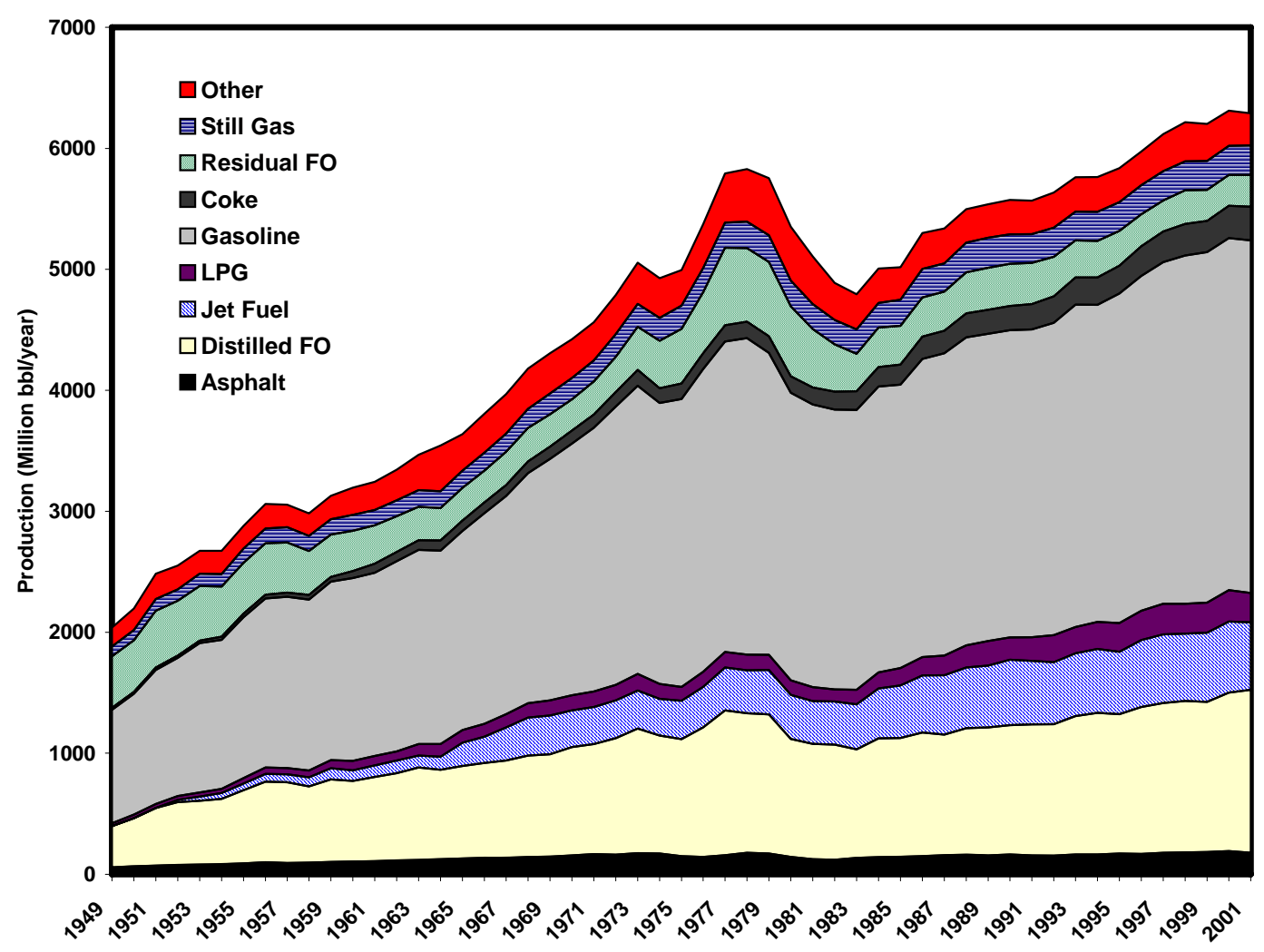

Figure 5. Petroleum refining production, by major product categories in the United States, 1949 - 2001. Source: Energy Information Administration.

While the type of processed crude oil is becoming increasingly heavier and higher in sulfur, the demand for oil products, and hence the product mix of the refineries, is changing towards an increased share of lighter products. Figure 5 depicts the past trend in production since 1949 by product category. Figure 5 shows an increase in the production and relative share of lighter products like gasoline, while the share of heavier fuels like residual fuel oil declined over the past 50 years.

Figure 5 does not show the changing quality demands of the product categories. Started in California, increased air quality demands in many parts of the United States will result in an increased demand for low-sulfur automotive fuels (gasoline, diesel). This will result in an increase of hydrotreating capacity at the petroleum refinery, as well as alternative desulfurization processes in the future. Small refineries will most likely not be able to invest in this type of expansion, and will further lose market share. With limited markets for the hydroskimming refineries, a further concentration of refineries is likely to take place over the next few years. Expansion of existing refineries will provide the increased demand, as no greenfield refineries will likely be built in the next few years within the United States

At the same time, the dynamic development of the petroleum industry faces other new challenges and directions. Increasing and more volatile energy prices will affect the bottom line of refineries. Commodity markets, like that of most oil products, show smaller and smaller margins. Both factors may negatively affect the profitability of petroleum refining. 
Increased needs to reduce air pollutant emissions from refinery operations as well as increased safety demands will drive technology choice and investments for future process technology. However, environmental compliance alone has not been the major factor affecting profitability (EIA, 1997). Instead, a combination of the above factors is the driver for reduced profitability of refinery operations. This trend is expected to continue, and in the future the above challenges combined will affect the industry and technology choice profoundly.

The continued trend towards low-sulfur fuels and changes in the product mix of refineries will affect technology choice and needs. For example, the current desulfurization and conversion technologies use relatively large amounts of hydrogen. As hydrogen is an energy intensive product, increased hydrogen consumption will lead to increased energy use and operation expenses, unless more efficient technologies for hydrogen production and recovery are developed and applied. In the long-term, new desulfurization technologies may reduce the need for hydrogen. At the same time, refineries are faced with challenges to reduce air pollution and other energy related issues (e.g., regulatory changes of power supply). The petroleum refining industry will face many other challenges. Climate change, new developments in automotive technology, and biotechnology are posed to affect the future structure of refineries. Table 1 summarizes the challenges to the petroleum refining industry.

Table 1. Key drivers and challenges for the petroleum refining industry. The order in the table does not reflect an order of priorities.

\begin{tabular}{|l|l|}
\hline Challenge & Key Issues \\
\hline Safety & Safety incidents, refineries now mainly located in urbanized areas \\
Environment & Emissions of criteria air pollutants (NOx, VOC) and greenhouse gases \\
Profitability & Commodity market, further concentration of the industry \\
Fuel Quality & Sulfur, MTBE-replacement \\
Feedstock & Increasing demand for lighter products from decreasing quality crude \\
Energy & Costs of power and natural gas \\
\hline
\end{tabular}

Katzer et al. (2000) explored the forces of change and the impacts on the future of petroleum refining. They see important new development needs in catalysis, optimization and control, reaction engineering and reactor design, biotechnology for desulfurization, increased use of natural gas as feedstock, and power generation. In the view of Katzer et al., the refinery of the future will look more like an automated chemical plant that will maximize high-value products (e.g., engineered molecules for specific applications) and integrate into the total energy-infrastructure. 


\section{Process Description}

A modern refinery is a highly complex and integrated system separating and transforming crude oil into a wide variety of products, including transportation fuels, residual fuel oils, lubricants, and many other products. The simplest refinery type is a facility in which the crude oil is separated into lighter and heavier fractions through the process of distillation. In the United States, about $25 \%$ of refinery facilities are small operations producing fewer than 50,000 barrels/day (U.S. DOE-OIT, 1998), representing about 5\% of the total industry output. The existence of small, simple and relatively inefficient refineries is in part due to legislation subsidizing smaller operations following the first oil price shock. These small operations consist only of distillation capacity (i.e., no reforming or converting capacities) and make a limited number of products.

Modern refineries have developed much more complex and integrated systems in which hydrocarbon compounds are not only distilled but are also converted and blended into a wider array of products. The overall structure of the refinery industry has changed in recent years because of a growing demand for lighter products. This has led to more complex refineries with increased conversion capacities. Increased conversion will lead to an increase in the specific energy consumption but will also produce a product mix with a higher value. These dynamics will continue in the future, as demand for heating (fuel) oil is decreasing.

In all refineries, including small less complex refineries, the crude oil is first distilled, which is followed by conversion in more complex refineries. The most important distillation processes are crude or atmospheric distillation, and vacuum distillation. Different conversion processes are available using thermal or catalytic processes, e.g., using a catalytic reformer, where the heavy naphtha, produced in the crude distillation unit, is converted to gasoline, and the fluid catalytic cracker where the distillate of the vacuum distillation unit is converted. Newer processes, such as hydrocrackers, are used to produce more light products from the heavy bottom products. Finally, all products may be treated to upgrade the product quality (e.g., sulfur removal using a hydrotreater). Side processes that are used to condition inputs or produce hydrogen or by-products include crude conditioning (e.g., desalting), hydrogen production, power and steam production, and asphalt production. Lubricants and other specialized products may be produced at special locations.

The principal energy using processes in refineries (in order of overall energy consumption in the United States) are the crude (or atmospheric) distillation unit, hydrotreaters, reformer, vacuum distillation unit, alkylate production, catalytic crackers, and hydrocrackers.

The main production steps in refineries are discussed below, providing a brief process description and the most important operation parameters including energy use (see also Chapter 4). Figure 6 provides a simplified flow diagram of a refinery. The descriptions follow the flow diagram, starting with the intake of the crude through to the production of the final products. The flow of intermediates between the processes will vary by refinery, and depends on the structure of the refinery, type of crude processes, as well as product mix. 


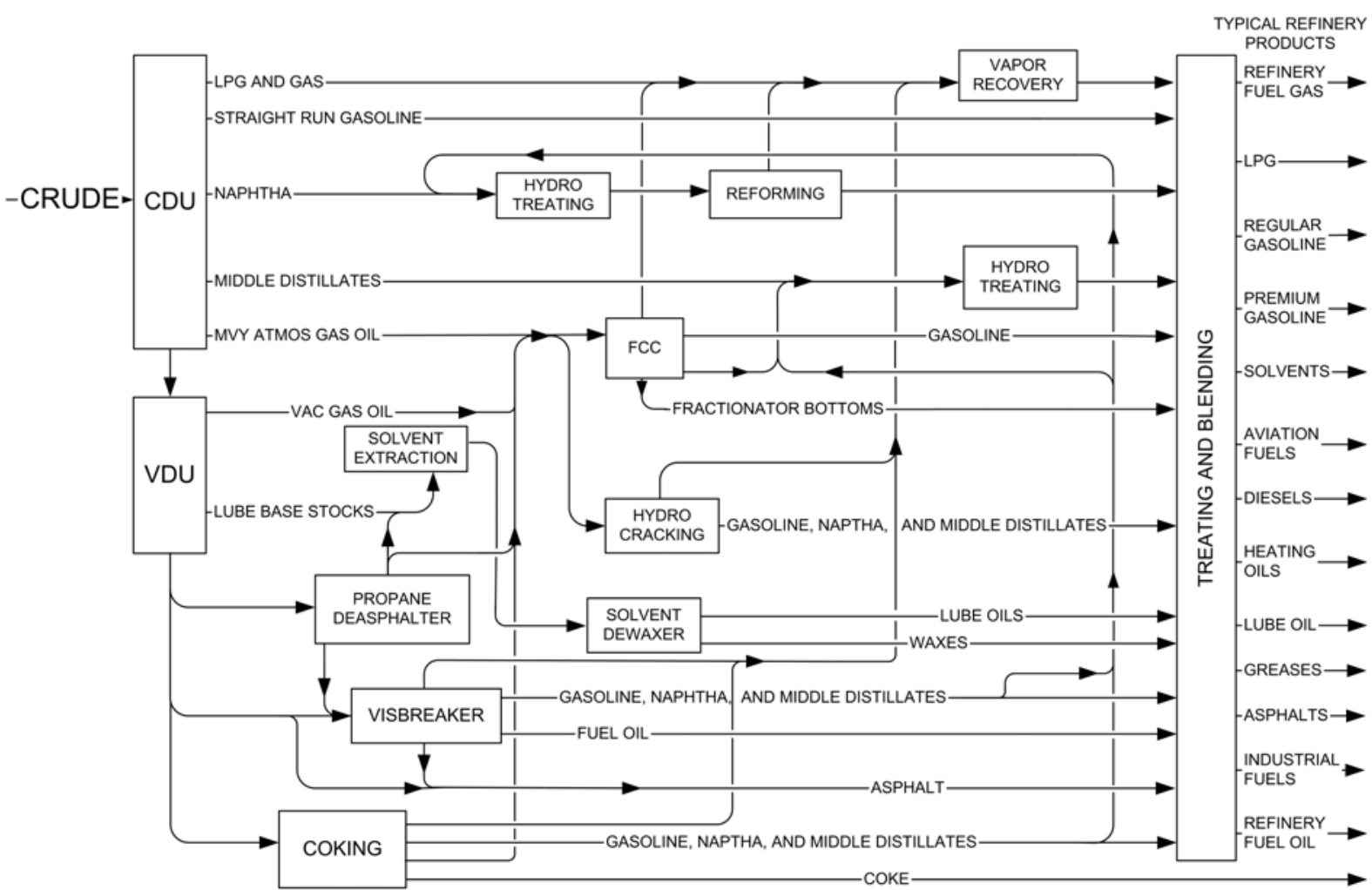

Figure 6. Simplified flowchart of refining processes and product flows. Adapted from Gary and Handwerk (1994).

Desalting. If the salt content of the crude oil is higher than $10 \mathrm{lb} / 1000$ barrels of oil, the crude requires desalting (Gary and Handwerk, 1994). Desalting will reduce corrosion and minimize fouling of process units and heat exchangers. Heavier crudes generally contain more salts, making desalting more important in current and future refineries. The salt is washed from the crude with water $\left(3-10 \%\right.$ at temperatures of $200-300^{\circ} \mathrm{F}\left(90-150^{\circ} \mathrm{C}\right)$. The salts are dissolved in the water, and an electric current is used to separate the water and the oil. This process also removes suspended solids. The different desalting processes vary in the amount of water used and the electric field used for separation of the oil and water. The efficiency of desalting is influenced by the $\mathrm{pH}$, gravity, viscosity, and salt content of the crude oil, and the volume of water used in the process. Electricity consumption of desalting varies between 0.01 and $0.02 \mathrm{kWh} /$ barrel of crude oil (IPPC, 2002).

Crude Distillation Unit (CDU). In all refineries, desalted and pretreated crude oil is split into three main fractions according to their boiling ranges by a fractional distillation process. The crude oil is heated in a furnace to approximately $750^{\circ} \mathrm{F}\left(390^{\circ} \mathrm{C}\right)$, and subsequently fed into the fractionating or distillation tower. Most CDUs have a two-stage heating process. First, the hot gas streams of the reflux and product streams are used to heat the desalted crude to about $550^{\circ} \mathrm{F}\left(290^{\circ} \mathrm{C}\right)$. Second, it is further heated in a gas-fired furnace to $400^{\circ} \mathrm{C}$ (Gary and Handwerk, 1994). The feed is fed is to the distillation tower at a temperature between 650 and $750^{\circ} \mathrm{F}\left(340-390^{\circ} \mathrm{C}\right)$. Energy efficiency of the heating process can be improved by using pump-around reflux to increase heat transfer (at higher temperatures at lower points in the column). 
In the tower, the different products are separated based on their boiling points. The boiling point is a good measure for the molecule weight (or length of the carbon chain) of the different products. Gasoline, with relatively small molecules, boils between 70 and $140^{\circ} \mathrm{C}$, while naphtha, which has a larger molecule, has a boiling point between 140 and $180^{\circ} \mathrm{C}$. The distillation towers contains 30-50 fractionation trays. The number of trays depends on the desired number and purity of product streams produced at the particular CDU.

The lightest fraction includes fuel gas, LPG, and gasoline. The overhead, which is the top or lightest fraction of the CDU, is a gaseous stream and is used as a fuel or for blending.

The middle fraction includes kerosene, naphtha, and diesel oil. The middle fractions are used for the production of gasoline and kerosene. The naphtha is led to the catalytic reformer or used as feedstock for the petrochemical industry.

The heaviest fractions are fuel oil and a bottom fraction, which has the lowest value. Fuel oil can be further processed in the conversion unit to produce more valuable products. About $40 \%$ of the products of the CDU (on energy basis) cannot be used directly and are fed into the Vacuum Distillation Unit (VDU), where distillation is performed under low pressure.

Because the CDU processes all incoming crude oil, it is a large energy user, although the specific energy consumption compared to the conversion process is relatively low. Energy efficiency opportunities consist of improved heat recovery and heat exchange (process integration), improved separation efficiencies, and other smaller measures. Integration of heat from the CDU and other parts of the refinery may lead to additional energy savings.

Vacuum Distillation Unit (VDU) or High Vacuum Unit (HVU). The VDU/HVU further distills the heaviest fraction (i.e., heavy fuel oil) from the CDU under vacuum conditions. The reduced pressure decreases the boiling points making further separation of the heavier fractions possible, while reducing undesirable thermal cracking reactions (and associated fouling). The low pressure results in much larger process equipment. In the VDU, the incoming feedstream is heated in a furnace to $730-850^{\circ} \mathrm{F}\left(390-450^{\circ} \mathrm{C}\right)$.

Vacuum conditions are maintained by the use of steam ejectors, vacuum pumps, and condensers. It is essential to obtain a very low pressure drop over the distillation column to reduce operating costs.

Of the VDU products, the lightest fraction becomes diesel oil. The middle fraction, which is light fuel oil, is sent to the hydrocracker (HCU) or fluid catalytic cracker (FCC), and the heavy fuel oil may be sent to the thermal cracker (if present at the refinery).

The distillation products are further processed, depending on the desired product mix. Refinery gas is used as fuel in the refinery operations to generate heat (furnaces), steam (boilers), or power (gas turbines), while some of the refinery gas may be flared. Parts of the refinery gas may also be used to blend with LPG or for hydrogen production. Hydrogen is used in different processes in the refinery to remove sulfur (e.g., hydrotreating) and to convert to lighter products (e.g., hydrocracking). 
Hydrotreater. Naphtha is desulfurized in the hydrotreater and processed in a catalytic reformer. Contaminants such as sulfur and nitrogen are removed from gasoline and lighter fractions by hydrogen over a hot catalyst bed. Sulfur removal is necessary to avoid catalyst poisoning downstream, and to produce a clean product. The treated light gasoline is sent to the isomerization unit and the treated naphtha to the catalytic reformer or platformer to have its octane level increased. Hydrotreaters are also used to desulfurize other product streams in the refinery.

Although many different hydrotreater designs are marketed, they all work along the same principle. The feedstream is mixed with hydrogen and heated to a temperature between 500 and $800^{\circ} \mathrm{F}\left(260-430^{\circ} \mathrm{C}\right)$. In some designs, the feedstream is heated and then mixed with the hydrogen. The reaction temperature should not exceed $800^{\circ} \mathrm{F}\left(430^{\circ} \mathrm{C}\right)$ to minimize cracking. The gas mixture is led over a catalyst bed of metal oxides (most often cobalt or molybdenum oxides on different metal carriers). The catalysts help the hydrogen to react with sulfur and nitrogen to form hydrogen sulfides $\left(\mathrm{H}_{2} \mathrm{~S}\right)$ and ammonia. The reactor effluent is then cooled, and the oil feed and gas mixture is then separated in a stripper column. Part of the stripped gas may be recycled to the reactor.

In the hydrotreater, energy is used to heat the feedstream and to transport the flows. The hydrotreater also has a significant indirect energy use because of the consumption of hydrogen. In the refinery, most hydrogen is produced through reforming (see below). Some hydrogen is also produced as a by-product of cracking.

Catalytic Reformer. The reformer is used to increase the octane level in gasoline. The desulfurized naphtha and gasoline streams are sent to the catalytic reformer. The product, called reformate, is used in blending of different refinery products. The catalytic reformer produces around $30-40 \%$ of all the gasoline produced in the United States Because the catalytic reformer uses platinum as catalyst, the feed needs to be desulfurized to reduce the danger of catalyst poisoning.

Reforming is undertaken by passing the hot feed stream through a catalytic reactor. In the reactor, various reactions such as dehydrogenation, isomerization, and hydrocracking occur to reformulate the chemicals in the stream. Some of the reactions are endothermic and others exothermic. The types of reactions depend on the temperature, pressure, and velocity in the reactor. Undesirable side reactions may occur and need to be limited. The reformer is a net producer of hydrogen that is used elsewhere in the refinery.

Various suppliers and developers market a number of reforming processes. In principle all designs are continuous, cyclic, or semi-regenerative, depending on the frequency of catalyst regeneration (Gary and Handwerk, 1994). In the continuous process, the catalysts can be replaced during normal operation, and regenerated in a separate reactor. In the semiregenerative reactor, the reactor needs to be stopped for regeneration of the catalysts. Depending on the severity and operating conditions, the period between regenerations is between 3 and 24 months (Gary and Handwerk, 1994). The cyclic process is an alternative in between these two processes. The advantage of the semi-regenerative process is the low capital cost. The marketed processes vary in reactor design. 
Fluid Catalytic Cracker (FCC). The fuel oil from the CDU is converted into lighter products over a hot catalyst bed in the fluid catalytic cracker (FCC). The FCC is the most widely used conversion process in refineries. The FCC produces high octane gasoline, diesel, and fuel oil. The FCC is mostly used to convert heavy fuel oils into gasoline and lighter products. The FCC has virtually replaced all thermal crackers.

In a fluidized bed reactor filled with particles carrying the hot catalyst and a preheated feed $\left(500-800^{\circ} \mathrm{F}, 260-425^{\circ} \mathrm{C}\right)$, at a temperature of $900-1000^{\circ} \mathrm{F}\left(480-540^{\circ} \mathrm{C}\right)$ the feed is 'cracked' to molecules with smaller chains. Different cracking products are generated, depending on the feed and conditions. During the process, coke is deposited on the catalysts. The used catalyst is continuously regenerated for reuse, by burning off the coke to either a mixture of carbon monoxide (CO) and carbon dioxide $\left(\mathrm{CO}_{2}\right)$ or completely to $\mathrm{CO}_{2}$. If burned off to a $\mathrm{CO} / \mathrm{CO}_{2}$-mixture, the $\mathrm{CO}$ is combusted to $\mathrm{CO}_{2}$ in a separate CO-burning waste heat recovery boiler to produce steam. The regeneration process is easier to control if the coke is burned directly to $\mathrm{CO}_{2}$, but a waste heat recovery boiler should be installed to recover the excess heat in the regenerator. The cracking reactions are endothermic, while the regeneration is exothermic, providing an opportunity for thermal integration of the two process steps.

Older FCCs used metal catalysts, while new FCC designs use zeolite catalysts that are more active. This has led to a re-design of modern FCC units with a smaller reactor, and most of the reactions taking place in the so-called riser, which leads the hot feed and regenerated catalysts to the reaction vessel. The different FCC designs on the market vary in the way that the reactor and regeneration vessels are integrated. Varying the catalyst circulation rate controls the process.

Fluid catalytic crackers are net energy users, due to the energy needed to preheat the feed stream. However, modern FCC designs also produce steam and power (if power recovery turbines are installed) as by-products. The power recovery turbines can also be used to compress the air for the cracker. The recovery turbine is installed prior to the $\mathrm{CO}$ or waste heat boiler, if the FCC works at pressures higher than 15 psig (Gary and Handwerk, 1994).

Hydrocracker (HCU). The hydrocracker has become an important process in the modern refinery to allow for flexibility in product mix. The hydrocracker provides a better balance of gasoline and distillates, improves gasoline yield, octane quality, and can supplement the FCC to upgrade heavy feedstocks (Gary and Handwerk, 1994). In the hydrocracker, light fuel oil is converted into lighter products under a high hydrogen pressure and over a hot catalyst bed. The main products are naphtha, jet fuel, and diesel oil. It may also be used to convert other heavy fuel stocks to lighter products. The hydrocracker concept was developed before World War II to produce gasoline from lignite in Germany, and was further developed in the early 1960s. Today hydrocrackers can be found in many modern large refineries around the world.

In the hydrocracker, many reactions take place. The principal reactions are similar to that of an FCC, although with hydrogenation. The reactions are carried out at a temperature of 500$750^{\circ} \mathrm{F}\left(290-400^{\circ} \mathrm{C}\right)$ and increased pressures of 8.3 to 13.8 Bar. The temperature and 
pressures used may differ with the licensed technology. The reactions are catalyzed by a combination of rare earth metals. Because the catalyst is susceptible to poisoning, the hydrocracker feed needs to be prepared by removing metallic salts, oxygen, nitrogenous compounds, and sulfur. This is done by first hydrogenating the feed, which also saturates the olefins. This is an exothermic reaction, but insufficient to provide all the heat for the hydrotreating units of the cracker. The nitrogen and sulfur-compounds are removed in a stripper column, while water is removed by a molecular sieve dryer or silica gel.

The prepared feed is mixed with recycled feed and hydrogen, and preheated before going to the reactor. The reactions are controlled by temperature, reactor pressure, and velocity. Typically the reactor is operated to have a conversion efficiency of $40-50 \%$, meaning that $40-50 \%$ of the reactor product has a boiling point below $400 \mathrm{~F}\left(205^{\circ} \mathrm{C}\right)$. The product flow (effluent) is passed through heat exchangers and a separator, where hydrogen is recovered for recycling. The liquid products of the separator are distilled to separate the $\mathrm{C}_{4}$ and lighter gases from the naphtha, jet fuel, and diesel. The bottom stream of the fractionator is mixed with hydrogen and sent to a second stage reactor to increase the conversion efficiency to 5070\% (Gary and Handwerk, 1994).

Various designs have been developed and are marketed by a number of licensors in the United States and Western Europe. The hydrocracker consumes energy in the form of fuel, steam, and electricity (for compressors and pumps). The hydrocracker also consumes energy indirectly in the form of hydrogen. The hydrogen consumption is between 150-300 scf/barrel of feed (27-54 Nm $3 / \mathrm{bbl})$ for hydrotreating and 1000 and $3000 \mathrm{scf} /$ barrel of feed (180-540 $\mathrm{Nm}^{3} / \mathrm{bbl}$ ) for the total plant (Gary and Handwerk, 1994). The hydrogen is produced as by-product of the catalytic reformer and in dedicated steam reforming plants (see below).

Coking. A new generation of coking processes has added additional flexibility to the refinery by converting the heavy bottom feed into lighter feedstocks and coke. Coking can be considered a severe thermal cracking process. Modern coking processes can also be used to prepare a feed for the hydrocracker (see above).

In the Flexi coking process, a heavy feed is preheated to $600-700^{\circ} \mathrm{F}\left(315-370^{\circ} \mathrm{C}\right)$ and sprayed on a bed of hot fluidized coke (recycled internally). The coke bed has a reaction temperature between 950 and $1000^{\circ} \mathrm{F}\left(510-540^{\circ} \mathrm{C}\right)$. At this temperature, cracking reactions take place. Cracked vapor products are separated in cyclones and are quenched. Some of the products are condensed, while the vapors are led to a fractionator column, which separates various product streams.

The coke is stripped from other products, and then processed in a second fluidized bed reactor where it is heated to $1100^{\circ} \mathrm{F}\left(590^{\circ} \mathrm{C}\right)$. The hot coke is then gasified in a third reactor in the presence of steam and air to produce synthesis gas. Sulfur (in the form of $\mathrm{H}_{2} \mathrm{~S}$ ) is removed, and the synthesis gas (mainly consisting of $\mathrm{CO}, \mathrm{H}_{2}, \mathrm{CO}_{2}$ and $\mathrm{N}_{2}$ ) can be used as fuel in (adapted) boilers or furnaces. The coking unit is a consumer of fuel (in preheating), steam, and power. 
Visbreaker. Visbreaking is a relatively mild thermal cracking operation, used to reduce the viscosity of the bottom products to produce fuel oil. This reduces the production of heavy fuel oils, while the products can be used to increase FCC feedstock and increase gasoline yields. This is accomplished by cracking the side chains of paraffin and aromatics in the feed, and cracking of resins to light hydrocarbons. Depending on the severity (i.e., time and temperature in the cracker) of the reactions, different products may be produced.

There are two main processes: coil (or furnace) cracking and soak cracking. Coil cracking uses higher reactor temperatures and shorter residence times, while soak cracking has slightly lower temperatures and longer residence times (Gary and Handwerk, 1994). The reaction products are pretty similar, but the soaker cracker uses less energy due to the lower temperature, and has longer run times (due to reduced coke deposition on the furnace tubes). A soaker furnace consumes about $15 \%$ less energy than a coil furnace. The visbreaker consumes fuel (to heat the feed), steam, and electricity.

Alkylation and Polymerization. Alkylation (the reverse of cracking) is used to produce alkylates (used in higher octane motor fuels), as well as butane liquids, LPG, and a tar-like by-product. The reactions are catalyzed by either hydrofluoric acid or sulfuric acid. Several designs are used, using either of the catalysts. The most suitable alkylation process for a given refinery is determined by economics, especially with regard to the costs of acid purchase and disposal (Gary and Handwerk, 1994).

Alkylation processes use steam and power. There are no large differences in energy intensity between both processes (Gary and Handwerk, 1994).

Hydrogen Manufacturing Unit or Steam reforming (HMU). There are a number of supporting processes that do not produce the main refinery products directly, but produce intermediates used in the various refining processes. Hydrogen is generated from natural gas and steam over a hot catalyst bed, similar to the processes used to make hydrogen for ammonia.

Hydrogen is produced by reforming the natural gas feedstock with steam over a catalyst, producing synthesis gas. Synthesis gas contains a mixture of carbon monoxide and hydrogen. The carbon monoxide is then reacted with steam in the water-gas-shift reaction to produce $\mathrm{CO}_{2}$ and hydrogen. The $\mathrm{CO}_{2}$ is removed from the main gas stream using absorption, producing hydrogen.

Energy is used in the form of fuel (to heat the reformer), steam (in the steam reforming), and power (for compression). Many different licensors supply the technology. Modern variants use a physical adsorption process to remove $\mathrm{CO}_{2}$, which uses less energy than chemical absorption processes.

Gas Processing Unit. Refinery gas processing units are used to recover $C_{3}, C_{4}, C_{5}$ and $C_{6}$ components from the different processes, and to produce a desulfurized gas which can be used as fuel or for hydrogen production in steam reforming (see above). The lighter products are used as fuel or for $\mathrm{H}_{2}$ production, while the heavier fraction is recycled in the refinery. 
The process consists of a number of distillation, absorption, and stripper columns to recover the ethane, propane, and butane. The process uses fuel (to heat the incoming gas) and power (for compressors and other uses).

Acid Gas Removal. Acid gases such as $\mathrm{H}_{2} \mathrm{~S}$ and $\mathrm{CO}_{2}$ need to be removed to reduce air pollution (before 1970, they were just burned off) and are produced as a by-product of producing higher quality refinery products. These gases are removed by an (chemical) absorption process, and then further processed. $\mathrm{H}_{2} \mathrm{~S}$ can be processed into elemental sulfur through the Claus process. The process consumes fuel and electricity, but the Claus process produces low-pressure steam (1.7 bar).

Bitumen Blower (BBU). Heavy fuel oil of some heavy crude oil is blown with hot air to produce bitumen or asphalt.

Other processes may be used in refineries to produce lubricants (lube oil), petrochemical feedstocks, and other specialty products. These processes consist mainly of blending, stripping, and separation processes. These processes are not discussed in detail here, as they are not found in a large number of refineries.

Table 2 and Figure 7 provide an overview of the processing capacities of the different processes used in U.S. refineries, based on capacity as of January $1^{\text {st }}, 2003$. The distribution of the processes will vary by state depending on the type of crudes used and products produced. For example, California has a much higher capacity (relative to CDU-capacity) of hydrocracking and hydrotreating, when compared to the U.S. average. This is due to the types of crude processed in California, the relative higher desired output of lighter products (e.g., gasoline), and the regulatory demand for lower sulfur content from gasoline to reduce air pollution from transport. 


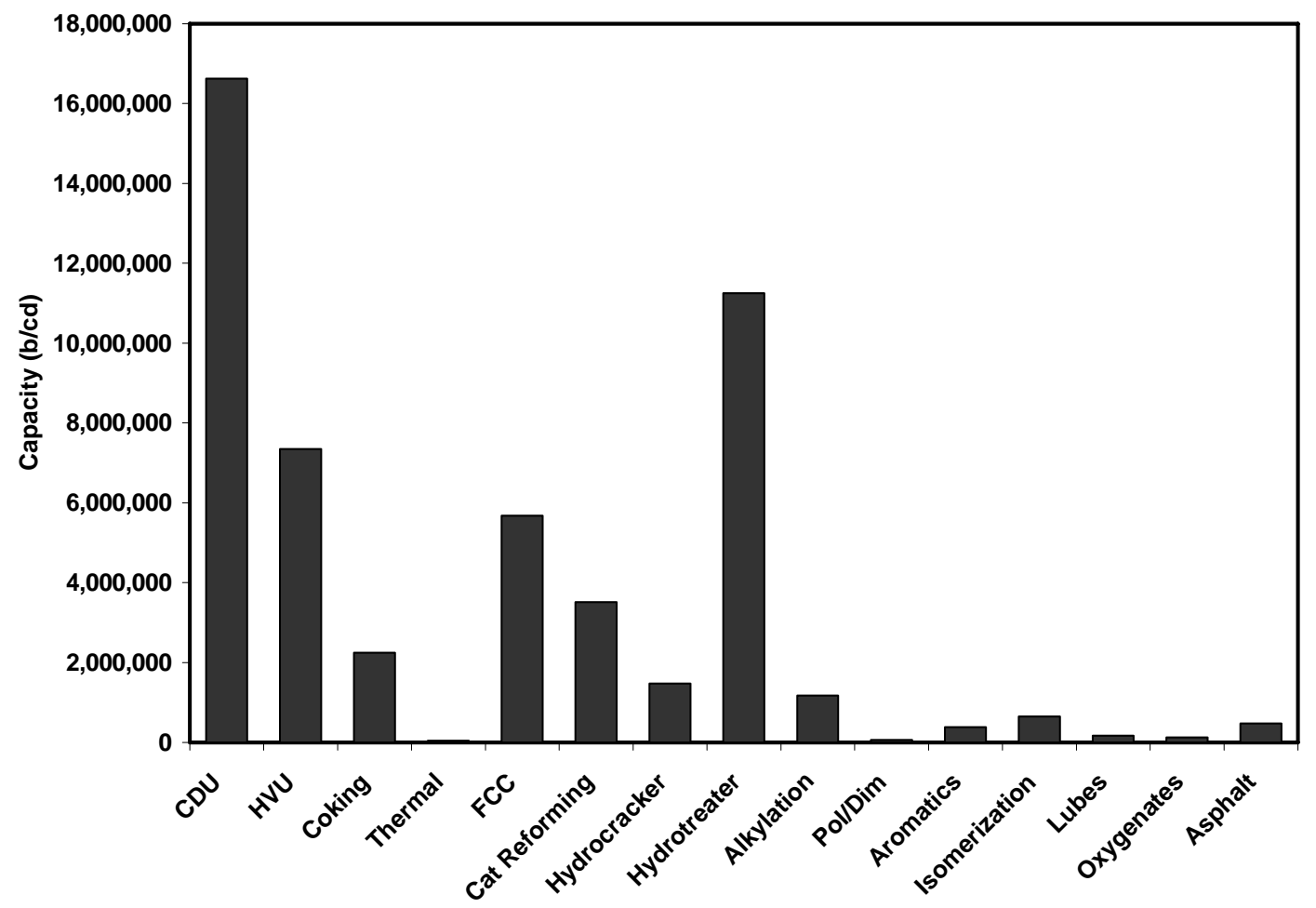

Figure 7. Capacity distribution of the major refining processes in U.S. petroleum refineries, as of January $\mathbf{1}^{\text {st }}$, 2003. Source: Oil \& Gas Journal (2002).

Table 2. Capacity distribution of the major refining processes in U.S. petroleum refineries, as of January $1^{\text {st }}$, 2003. The distribution is also given as share of CDU capacity. Source: Oil \& Gas Journal (2002).

\begin{tabular}{|c|c|c|}
\hline Process & $\begin{array}{c}\text { Capacity } \\
\text { (Barrel per calendar day) }\end{array}$ & $\begin{array}{c}\text { Distribution } \\
\text { (share of CDU capacity) }\end{array}$ \\
\hline Crude Distillation & $16,623,301$ & $100.0 \%$ \\
\hline Vacuum Distillation & $7,347,704$ & $44.2 \%$ \\
\hline Coking & $2,243,947$ & $13.5 \%$ \\
\hline Thermal Operations & 43,500 & $0.3 \%$ \\
\hline Catalytic Cracking & $5,677,355$ & $34.2 \%$ \\
\hline Catalytic Reforming & $3,512,237$ & $21.1 \%$ \\
\hline Hydrocracking & $1,474,710$ & $8.9 \%$ \\
\hline Hydrotreating & $11,247,745$ & $67.7 \%$ \\
\hline Alkylation & $1,170,019$ & $7.0 \%$ \\
\hline Polymerization/Dim. & 64,000 & $0.4 \%$ \\
\hline Aromatics & 383,255 & $2.3 \%$ \\
\hline Isomerization & 644,270 & $3.9 \%$ \\
\hline Lubes & 167,500 & $1.0 \%$ \\
\hline Oxygenates & 122,899 & $0.7 \%$ \\
\hline Asphalt & 471,850 & $2.8 \%$ \\
\hline Hydrogen & 3,631 MMcfd & \\
\hline Coke & $114,387 \mathrm{tpd}$ & \\
\hline Sulfur & $27,051 \mathrm{tpd}$ & \\
\hline
\end{tabular}




\section{Energy Consumption}

The petroleum refining industry is one of the largest energy consuming industries in the United States. Energy use in a refinery varies over time due to changes in the type of crude processed, the product mix (and complexity of refinery), as well as the sulfur content of the final products. Furthermore, operational factors like capacity utilization, maintenance practices, as well as the age of the equipment affect energy use in a refinery from year to year.

The petroleum refining industry is an energy intensive industry spending over $\$ 7$ billion on energy purchases in 2001. Figure 8 depicts the trend in energy expenditures of the U.S. petroleum refining industry. The graph shows a steady increase in total expenditures for purchased electricity and fuels, which is especially evident in the most recent years for which data is available. Value added as share of value of shipments dipped in the early 1990s and has increased since to about 20\%. Figure 8 also shows a steady increase in fuel costs. Electricity costs are more or less stable, which seems to be only partially caused by increased cogeneration.

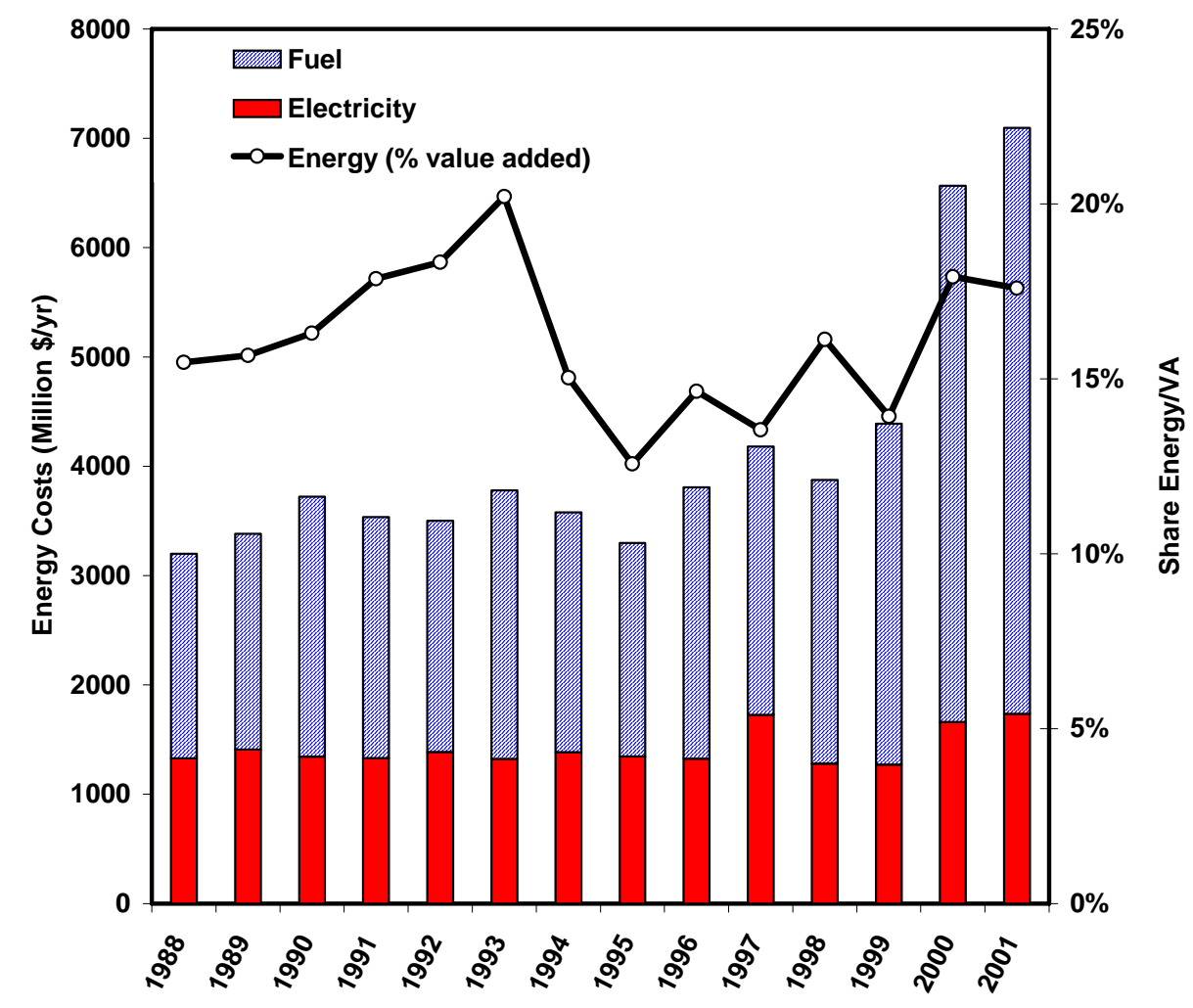

Figure 8. Annual energy costs of petroleum refineries in the United States 1988-2001 for purchased fuels. This excludes the value of fuels generated in the refinery (i.e., refinery gas and coke). Purchased fuels can be a relatively small part of the total energy costs of a refinery (see also Figure 9). The total purchased energy costs are given as share of the value added produced by petroleum refineries. Source: U.S. Census, Annual Survey of Manufacturers. 


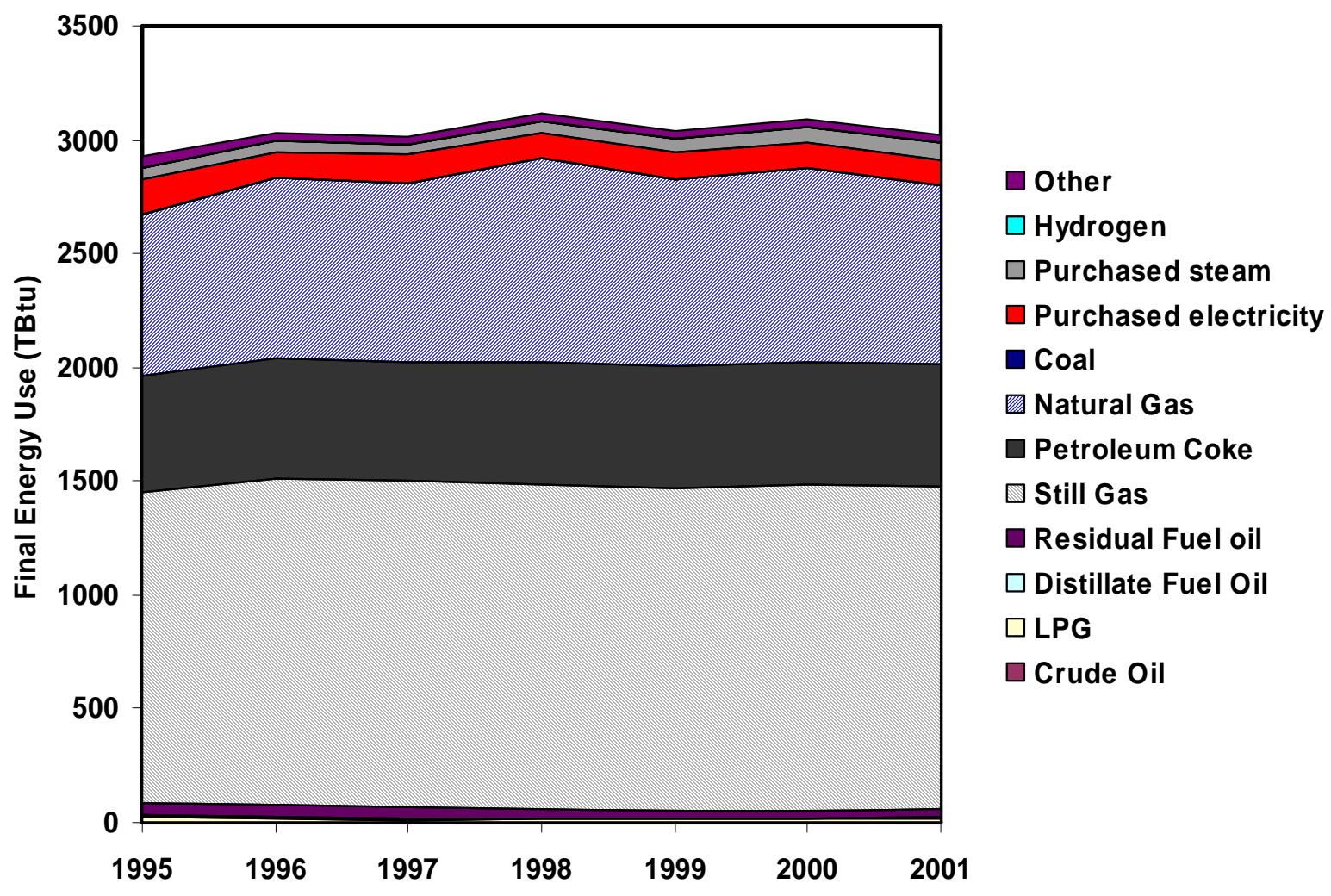

Figure 9. Annual final energy consumption of U.S. petroleum refineries for the period 1995 - 2001. Data for 1995 and 1997 contains estimated values for natural gas, coal, electricity, and steam purchases. The order in the legend corresponds with the order of fuels in the graph. Source: Petroleum Supply Annual, Energy Information Administration.

In recent years, energy consumption in refineries peaked in 1998, and has since then slightly declined. Based on data published by the Energy Information Administration, energy consumption trends are estimated by fuel since 1995. ${ }^{2}$ In 2001, the latest year for which data were available, total final energy consumption is estimated at 3,025 TBtu. Primary energy consumption $^{3}$ is estimated at 3,369 TBtu. The difference between primary and final electricity consumption is relatively low due to the small share of electricity consumption in the refinery and relatively large amount of self-produced electricity. Figure 9 depicts the annual energy consumption of petroleum refineries between 1995 and 2001. Figure 9 shows

\footnotetext{
${ }^{2}$ Data before 1995 are also available. However, for some years (including 1995 and 1997) the data reported by EIA is not complete, and interpolations were made by the authors to estimate total energy consumption. For example, for 1995 EIA did not report on consumption of natural gas, coal, purchased electricity, and purchased steam, while for 1997 it did not report on coal, purchased steam, and other fuels. Furthermore, we use electricity purchase data as reported by the EIA, although the U.S. Census reports slightly different electricity purchases for most years. The differences are generally small and do not affect overall energy use data.

${ }^{3}$ Final energy assigns only the direct energy content to secondary energy carriers like purchased electricity and steam to calculate energy consumption. Primary energy consumption includes the losses of offsite electricity and steam production. We assume an average efficiency of power generation on the public grid of $32 \%$. Steam generation efficiency is supposed to be similar to that of refinery boilers (assumed at 77\%).
} 
that energy use has basically remained flat, while production volumes and mix have changed, strongly suggesting an improvement of the energy efficiency of the industry over the same period.

Figure 9 shows that the main fuels used in the refinery are refinery gas, natural gas, and coke. The refinery gas and coke are by-products of the different processes. The coke is mainly produced in the crackers, while the refinery gas is the lightest fraction from the distillation and cracking processes. Natural gas and electricity represents the largest purchased fuels in the refineries. Natural gas is used for the production of hydrogen, fuel for co-generation of heat and power (CHP), and as supplementary fuel in furnaces.

Petroleum refineries are one of the largest cogenerators in the country, after the pulp and paper and chemical industries. In 1998, cogeneration within the refining industry represented almost 13\% of all industrial cogenerated electricity (EIA, 2001). By 1999 cogeneration increased to almost 35\% of total electricity use. In 2001, the petroleum refining industry generated about 13.2 TWh, which represented about 26\% of all power consumed onsite (EIA, 2002). Figure 10 shows the historic development of electricity generation and purchases in oil refineries (generation data for 2000 were not reported by the U.S. Census).

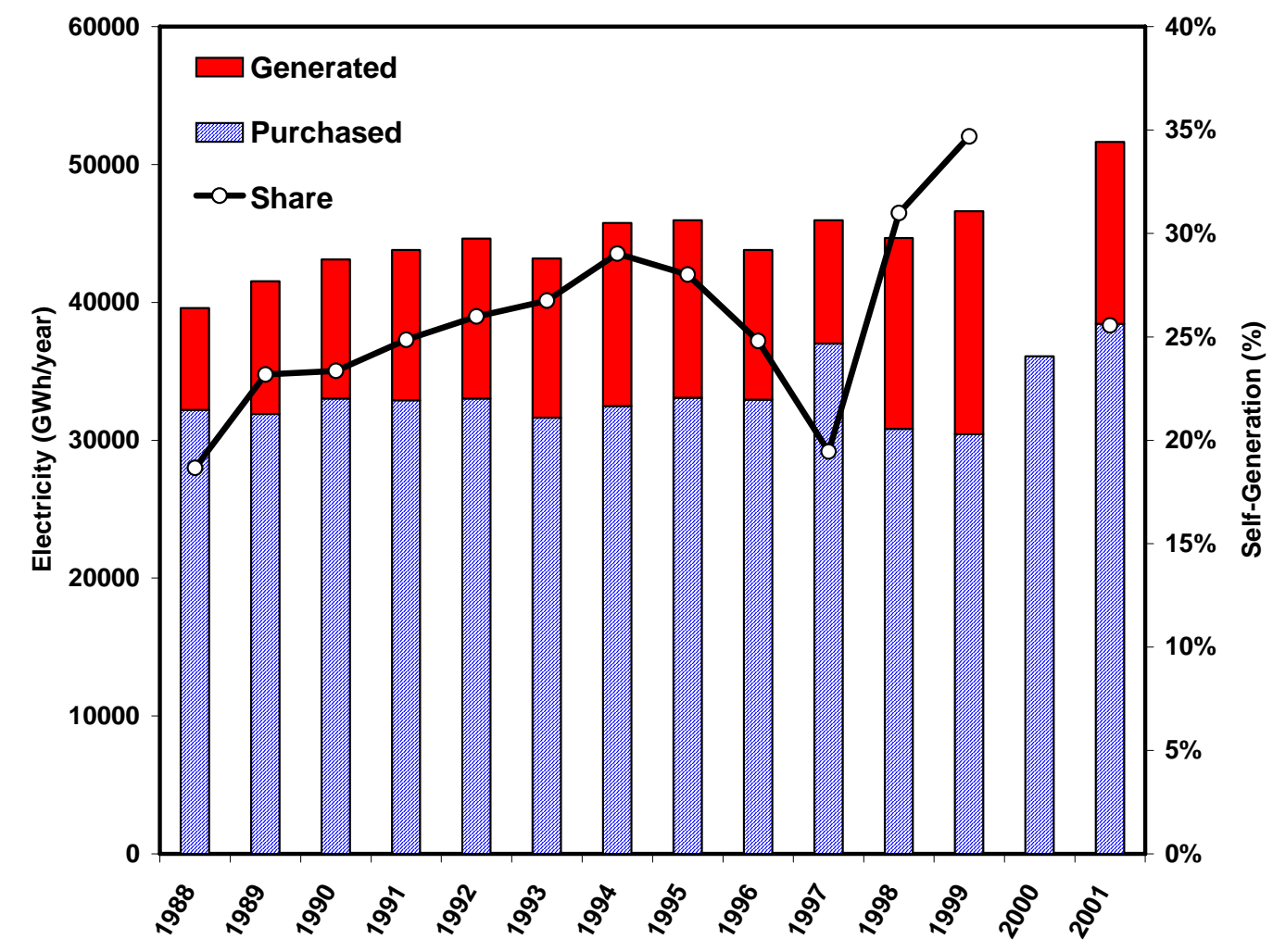

Figure 10. Electricity purchases and generation by petroleum refineries from 1988 to 2001. On the right-hand axis, the share of self-generation is expressed as a function of total power consumption. Source: U.S. Census, Annual Survey of Manufacturers. 
Table 3. Estimated 2001 energy balance for the U.S. petroleum refining industry. Estimates are based on a combination of publicly available data sources. The energy balance for an individual refinery will be different due to different process configurations. Data sources are given in the text.

\begin{tabular}{|c|c|c|c|c|c|c|}
\hline \multirow[t]{2}{*}{ Process } & Throughput & Fuel & Steam & Electricity & Final & Primary \\
\hline & Million bbl/year $^{1}$ & TBtu & TBtu & GWh & TBtu ${ }^{2}$ & TBtu ${ }^{3}$ \\
\hline Desalter & 5313.3 & 0.2 & 0.0 & 265.7 & 1.1 & 3.0 \\
\hline CDU & 5313.3 & 359.2 & 243.5 & 3613.0 & 687.8 & 714.0 \\
\hline VDU & 2416.7 & 115.5 & 126.1 & 845.8 & 282.1 & 288.3 \\
\hline Thermal & 723.4 & & & & & \\
\hline Cracking & & 84.1 & -10.5 & 4485.3 & 85.8 & 118.3 \\
\hline FCC & 1885.4 & 108.2 & 0.5 & 7013.8 & 132.8 & 183.7 \\
\hline Hydrocracker & 507.2 & 68.5 & 36.9 & 5680.7 & 135.9 & 177.1 \\
\hline Reforming & 1166.0 & 206.1 & 101.3 & 3416.3 & 349.4 & 374.1 \\
\hline Hydrotreater & 3679.8 & 253.2 & 270.1 & 15455.4 & 656.6 & 768.7 \\
\hline Deasphalting & 112.5 & 16.1 & 0.3 & 213.8 & 17.2 & 18.8 \\
\hline Alkylates & 366.8 & 13.1 & 121.1 & 2640.7 & 179.3 & 198.5 \\
\hline Aromatics & 97.2 & 11.7 & 4.1 & 291.5 & 18.0 & 20.1 \\
\hline Asphalt & 284.9 & 59.6 & 0.0 & 740.7 & 62.1 & 67.5 \\
\hline Isomers & 204.3 & 90.3 & 39.9 & 398.3 & 143.5 & 146.4 \\
\hline Lubes & 67.8 & 87.5 & 2.5 & 1247.0 & 95.0 & 104.1 \\
\hline Hydrogen & 5,959 & 268.2 & 0.0 & 893.9 & 271.2 & 277.7 \\
\hline Sulfur & 9.0 & 0.0 & -81.2 & 108.5 & -105.1 & -104.3 \\
\hline Other & & 0.0 & 10.0 & 39.0 & 13.1 & 13.4 \\
\hline & Total Process Site Use & 1741 & 865 & 47349 & 3026 & 3369 \\
\hline $\begin{array}{l}\text { Purchases } \\
\text { Site Generation }\end{array}$ & & & $\begin{array}{r}78.4 \\
786.3\end{array}$ & 34187 & & \\
\hline Cogeneration $^{4}$ & & 140.3 & 61.8 & 13162 & & \\
\hline Boiler generation & & & 724.5 & & & \\
\hline Boiler fuels & & 940.9 & & & & \\
\hline Tot & nergy Consumption & 2822 & 78 & 34187 & 3018 & 3289 \\
\hline
\end{tabular}

Notes:

1. Unit is million barrels/year, except for hydrogen (million lbs/year) and sulfur (million short tons/year).

2. Final fuel use is calculated by estimating the boiler fuel to generate steam used. Electricity is accounted as site electricity at 3,412 Btu/kWh.

3. Primary fuel use includes the boiler fuel use and primary fuels used to generate electricity. Including transmission and distribution losses the electric efficiency of the public grid is equal to $32 \%$, accounting electricity as $10,660 \mathrm{Btu} / \mathrm{kWh}$. Some refineries operate combined cycles with higher efficiencies. For comparison, Solomon accounts electricity at 9,090 Btu/kWh.

4. Cogeneration is assumed to be in large singe-cycle gas turbines with an electric efficiency of $32 \%$.

5. Boiler efficiency is estimated at $77 \%$.

A number of key processes are the major energy consumers in a typical refinery, i.e., crude distillation, hydrotreating, reforming, vacuum distillation, and catalytic cracking. Hydrocracking and hydrogen production are growing energy consumers in the refining industry. An energy balance for refineries for 2001 has been developed based on publicly available data on process throughput (EIA, 2002), specific energy consumption (Gary and Handwerk, 1994; U.S. DOE-OIT, 1998a, U.S. DOE-OIT, 2002), and energy consumption data (EIA, 2001; EIA, 2002; U.S. Census, 2003). Table 3 provides the estimated energy balance for 2001. The energy balance is an estimate based on publicly available data, and is based on many assumptions on process efficiencies and throughputs. The estimated energy 
balance matches with available energy consumption data for almost $100 \%$ on a final energy basis, and almost $98 \%$ on a primary energy basis. The process energy uses should be seen as approximate values to provide a view on important energy using processes in the refinery.

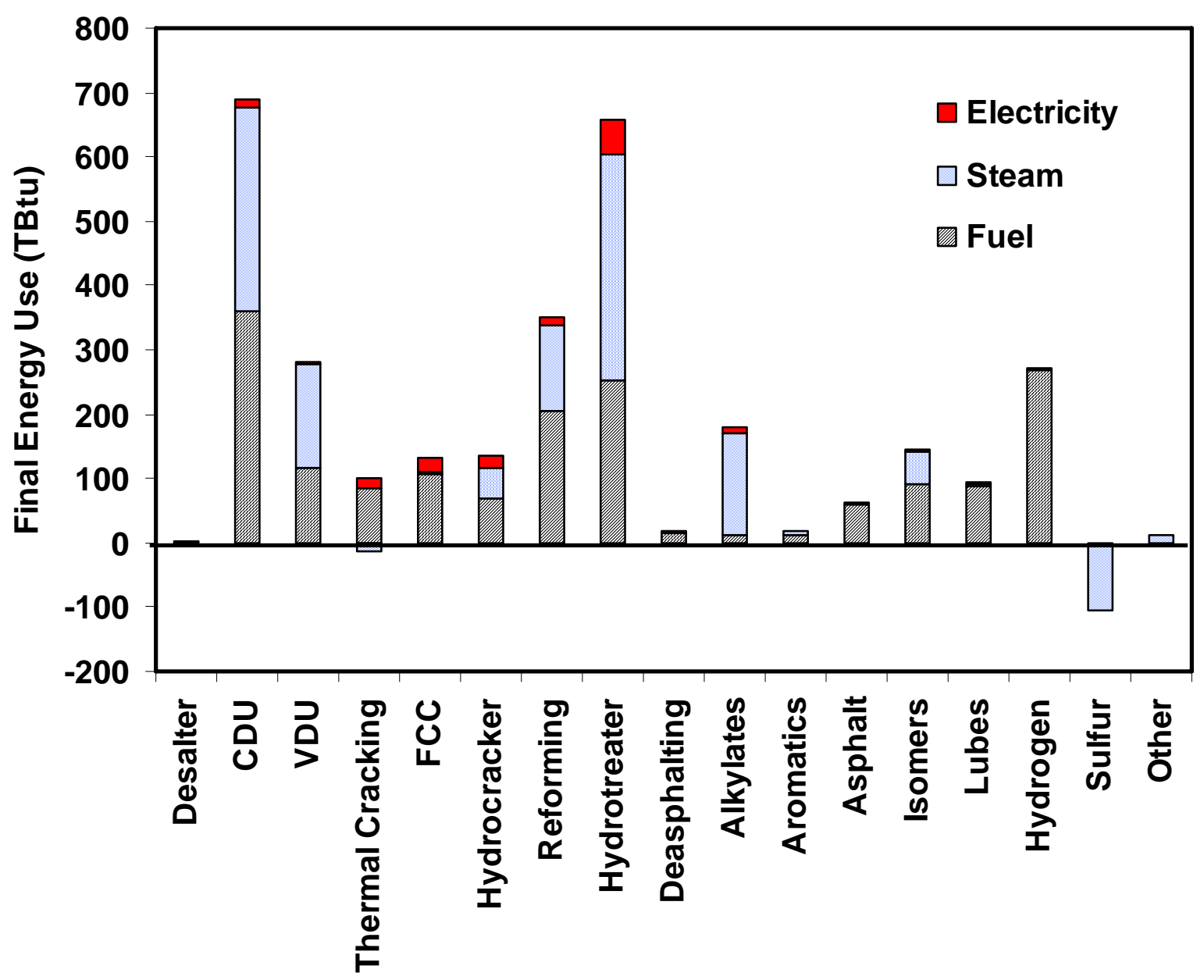

Figure 11. Estimated energy use by petroleum refining process. Energy use is expressed as primary energy consumption. Electricity is converted to fuel using 10,666 $\mathrm{Btu} / \mathbf{k W h}$ (equivalent to an efficiency of $32 \%$ including transmission and distribution losses). All steam is generated in boilers with an efficiency of $77 \%$.

The major energy consuming processes are crude distillation, followed by the hydrotreater, reforming, and vacuum distillation. This is followed by a number of processes consuming a somewhat similar amount of energy, i.e., thermal cracking, catalytic cracking, hydrocracking, alkylate and isomer production.

Note that the figures in Table 2 and Figure 11 are based on publicly available data. A similar capacity utilization is assumed for all installed processes, based on the average national capacity utilization. In reality, the load of the different processes may vary, which may lead to a somewhat different distribution. In cracking the severity and in hydrotreating the treated feed may affect energy use. An average severity is assumed for both factors. Furthermore, 
energy intensity assumptions are based on a variety of sources, and balanced on the basis of available data. The different literature sources provide varying assumptions for some processes, especially for electricity consumption.

Although the vast majority of greenhouse gas (GHG) emissions in the petroleum fuel cycle occur at the final consumer of the petroleum products, refineries are still a substantial source of GHG emissions. The high energy consumption in refineries also leads to substantial GHG emissions. This Energy Guide focuses on $\mathrm{CO}_{2}$ emissions due to the combustion of fossil fuels, although process emissions of methane and other GHGs may occur at refineries. The estimate in this Energy Guide is based on the fuel consumption as reported in the Petroleum Supply Annual of the Energy Information Administration, and emission factors determined by the Energy Information Administration and U.S. Environmental Protection Agency. The Energy Information Administration provided emission factors for electricity consumption. The $\mathrm{CO}_{2}$ emissions in 2001 are estimated at 222 million tonnes of $\mathrm{CO}_{2}$ (equivalent to 60.5 $\mathrm{MtCE}$ ). This is equivalent to $11.6 \%$ of industrial $\mathrm{CO}_{2}$ emissions in the United States. Figure 12 provides estimates of $\mathrm{CO}_{2}$ emissions (by fuel) for several recent years. Figure 12 shows that the main fuels contributing to the emissions are still gas, natural gas, and coke.

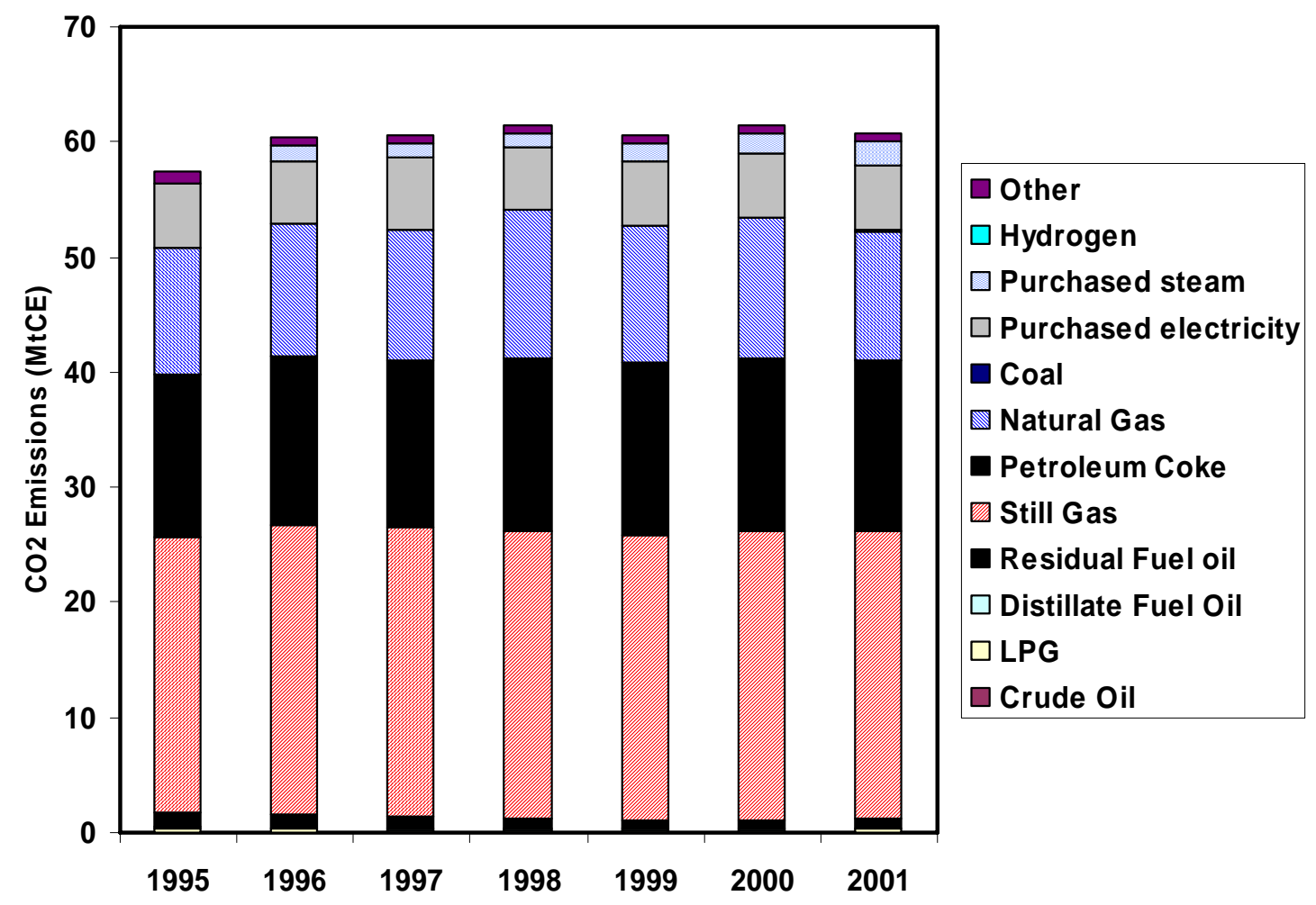

Figure 12. Estimated $\mathrm{CO}_{2}$ emissions from fuel combustion and electricity consumption at U.S. petroleum refineries. Data for 1995 and 1997 includes estimates for different fuels (i.e., coal, purchased steam, and other fuels). Sources: Energy Information Administration, U.S. Environmental Protection Agency.

The Energy Information Administration estimated $\mathrm{CO}_{2}$ emissions at 87.4 MtCE in 1998. This is substantially higher than the estimate above. The reason for the differences is 
unclear. Partially these may be due to different data sources and potentially due to emissions from flaring that are not included in the above estimate. 


\section{Energy Efficiency Opportunities}

A large variety of opportunities exist within petroleum refineries to reduce energy consumption while maintaining or enhancing the productivity of the plant. Studies by several companies in the petroleum refining and petrochemical industries have demonstrated the existence of a substantial potential for energy efficiency improvement in almost all facilities. Competitive benchmarking data indicate that most petroleum refineries can economically improve energy efficiency by 10-20\%. For example, a 2002 audit of energy use at the Equilon refinery (now Shell) at Martinez, California, found an overall efficiency improvement potential of 12\% (US DOE-OIT, 2002b). This potential for savings amounts to annual costs savings of millions to tens of millions of dollars for a refinery, depending on current efficiency and size. Improved energy efficiency may result in co-benefits that far outweigh the energy cost savings, and may lead to an absolute reduction in emissions.

Major areas for energy efficiency improvement are utilities (30\%), fired heaters (20\%), process optimization (15\%), heat exchangers (15\%), motor and motor applications (10\%), and other areas (10\%). Of these areas, optimization of utilities, heat exchangers, and fired heaters offer the most low investment opportunities, while other opportunities may require higher investments. Experiences of various oil companies have shown that most investments are relatively modest. However, all projects require operating costs as well as engineering resources to develop and implement the project. Every refinery and plant will be different. The most favorable selection of energy efficiency opportunities should be made on a plantspecific basis.

In the following chapters energy efficiency opportunities are classified based on technology area. In each technology area, technology opportunities and specific applications by process are discussed. Table 4 summarizes the energy efficiency measures described in this Energy Guide, and provides access keys by process and utility system to the descriptions of the energy efficiency opportunities. This Energy Guide is far from exhaustive. For example, the Global Energy Management System (GEMS) of ExxonMobil has developed 12 manuals containing some 1,200 pages, which describe in detail over 200 best practices and performance measures for key process units, major equipment, and utility systems. In addition to the strong focus on operation and maintenance of existing equipment, these practices also address energy efficiency in the design of new facilities. GEMS identified opportunities to improve energy efficiency by $15 \%$ at ExxonMobil refineries and chemical plants worldwide. This Energy Guide provides a general overview in am easily accessible format to help energy managers to select areas for energy efficiency improvement based on experiences around the world.

This Energy Guide includes case studies from U.S. refineries with specific energy and cost savings data when available. For other measures, the Energy Guide includes case study data from refineries around the world. For individual refineries, actual payback period and energy savings for the measures will vary, depending on plant configuration and size, plant location, and plant operating characteristics. Hence, the values presented in this Energy Guide are offered as guidelines. Wherever possible, the Energy Guide provides a range of savings and payback periods found under varying conditions. 
Although technological changes in equipment conserve energy, changes in staff behavior and attitude can have a great impact. Staff should be trained in both skills and the company's general approach to energy efficiency in their day-to-day practices. Personnel at all levels should be aware of energy use and objectives for energy efficiency improvement. Often this information is acquired by lower level managers but not passed to upper management or down to staff (Caffal, 1995). Though changes in staff behavior, such as switching off lights or improving operating guidelines, often save only very small amounts of energy at one time, taken continuously over longer periods they can have a great effect. Further details for these programs can be found in Chapter 6 .

Participation in voluntary programs like the ENERGY STAR program, or implementing an environmental management system such as ISO 14001, can help companies to track energy and implement energy efficiency measures. One ENERGY STAR partner noted that combining energy management programs with ISO 14001 has had the largest effect on saving energy at their plants.

Companies like BP have successfully implemented aggressive greenhouse gas (GHG) emission reduction programs at all their facilities worldwide (including exploration and refining). BP has reduced its global GHG emissions to $10 \%$ below 1990 levels within 5 years of the inception of its program; years ahead of its goal, while decreasing operation costs. These efforts demonstrate the potential success of a corporate strategy to reduce energy use and associated emissions. Yet, other companies used participation in voluntary programs to boost energy management programs. Petro-Canada participates in Canada's Climate Change Voluntary Challenge and Registry. Petro-Canada has developed a corporate-wide emission reduction and energy efficiency program, and reports the results annually. In Europe, various countries have voluntary agreements between industry sectors and governments to reduce energy or GHG emission intensity. For example, all refineries in the Netherlands participated in the Long-Term Agreements between 1989 and 2000. BP, ExxonMobil, Shell, and Texaco all operate refineries in the Netherlands. The refineries combined (processing about 61 million tons of crude annually) achieved a 17\% improvement of energy efficiency. Today, the refineries participate in a new agreement in which the refineries will be among most energy efficient refineries worldwide by 2010, using the Solomon's index as a gauge.

Table 4 provides an access key to the Energy Guide. For each of the main processes used in a refinery, Table 4 provides the relevant sections describing energy efficiency measures that are applicable to that process and may be relevant when assessing energy efficiency opportunities for a particular process. Utility measures are summarized in the last row of Table 4 . While boilers and lighting will be distributed around the refinery, they are only designated as utilities. 
Table 4. Matrix of energy efficiency opportunities in petroleum refineries. For each major process in the refinery (in rows) the applicable categories of energy efficiency measures are given (in columns). The numbers refer to the chapter or section describing energy efficiency.

\begin{tabular}{|c|c|c|c|c|c|c|c|c|c|c|c|c|c|c|c|c|c|c|}
\hline Process & 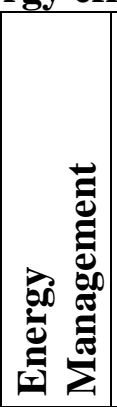 & 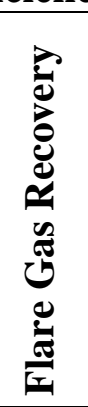 & 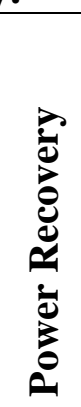 & $\frac{n}{\tilde{D}}$ & 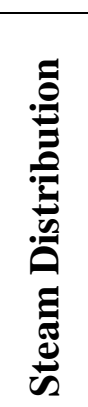 & 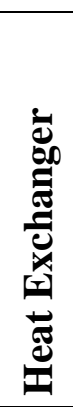 & 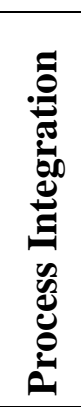 & 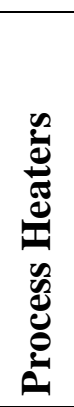 & & 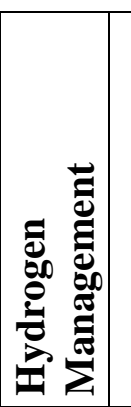 & 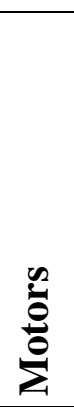 & 禀 & 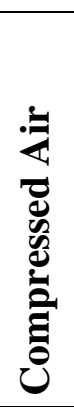 & $\underset{\tilde{J}}{\mathscr{J}}$ & & 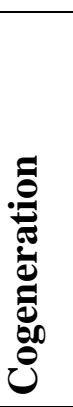 & 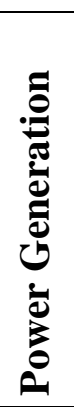 & 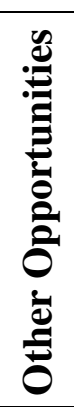 \\
\hline Desalting & 6 & & & & & & & & & & & 14 & & & & & & \\
\hline $\mathrm{CDU}$ & 6 & 7.1 & & & 8.2 & 9.1 & 9.2 & 10 & 11 & & 13 & 14 & & 16 & & & & \\
\hline VDU & 6 & & & & 8.2 & 9.1 & 9.2 & 10 & 11 & & & & & 16 & & & & \\
\hline Hydrotreater & 6 & & & & 8.2 & 9.1 & 9.2 & 10 & 11 & 12 & & & & 16 & & & & \\
\hline Cat.Reformer & 6 & 7.1 & & & 8.2 & 9.1 & 9.2 & 10 & 11 & 12 & & & & 16 & & & & \\
\hline FCC & 6 & 7.1 & 7.2 & & 8.2 & 9.1 & 9.2 & 10 & 11 & & & & & 16 & & & & \\
\hline Hydrocracker & 6 & 7.1 & 7.2 & & 8.2 & 9.1 & 9.2 & 10 & 11 & 12 & & & & 16 & & & & \\
\hline Coker & 6 & 7.1 & & & 8.2 & 9.1 & 9.2 & 10 & 11 & & & & & 16 & & & & \\
\hline Visbreaker & 6 & 7.1 & & & 8.2 & 9.1 & 9.2 & 10 & 11 & & & & & 16 & & & & \\
\hline Alkylation & 6 & & & & 8.2 & 9.1 & 9.2 & 10 & 11 & & & & & 16 & & & & \\
\hline Light End & 6 & & & & 8.2 & 9.1 & 9.2 & & 11 & & & & & & & & & \\
\hline Aromatics & 6 & & & & 8.2 & 9.1 & 9.2 & 10 & 11 & & & & & & & & & \\
\hline Hydrogen & 6 & & & & 8.2 & 9.1 & 9.2 & 10 & & 12 & & & & 16 & & & & \\
\hline Utilities & 6 & 7.1 & 7.2 & 8.1 & 8.2 & 9.1 & 9.2 & & & 12 & & & 15 & 16 & 17 & 18 & 18 & 19 \\
\hline
\end{tabular}




\section{Energy Management and Control}

Improving energy efficiency in refineries should be approached from several directions. A strong, corporate-wide energy management program is essential. Cross-cutting equipment and technologies, such as boilers, compressors, and pumps, common to most plants and manufacturing industries including petroleum refining, present well-documented opportunities for improvement. Equally important, the production process can be fine-tuned to produce additional savings.

\subsection{Energy Management Systems (EMS) and Programs}

Changing how energy is managed by implementing an organization-wide energy management program is one of the most successful and cost-effective ways to bring about energy efficiency improvements.

An energy management program creates a foundation for improvement and provides guidance for managing energy throughout an organization. In companies without a clear program in place, opportunities for improvement may be unknown or may not be promoted or implemented because of organizational barriers. These barriers may include a lack of communication among plants, a poor understanding of how to create support for an energy efficiency project, limited finances, poor accountability for measures, or perceived change from the status quo. Even when energy is a significant cost for an industry, many companies still lack a strong commitment to improve energy management.

The U.S. EPA, through ENERGY STAR, has worked with many of the leading industrial manufacturers to identify the basic aspects of an effective energy management program. ${ }^{4}$ The major elements are depicted in Figure 13.

A successful program in energy management begins with a strong commitment to continuous improvement of energy efficiency. This typically involves assigning oversight and management duties to an energy director, establishing an energy policy, and creating a cross-functional energy team. Steps and procedures are then put in place to assess performance, through regular reviews of energy data, technical assessments, and benchmarking. From this assessment, an organization is then able to develop a baseline of performance and set goals for improvement.

Performance goals help to shape the development and implementation of an action plan. An important aspect for ensuring the successes of the action plan is involving personnel throughout the organization. Personnel at all levels should be aware of energy use and goals for efficiency. Staff should be trained in both skills and general approaches to energy efficiency in day-to-day practices. In addition, performance results should be regularly evaluated and communicated to all personnel, recognizing high performers. Some examples of simple employee tasks are outlined in Appendix B.

\footnotetext{
${ }^{4}$ See the U.S. EPA’s Guidelines for Energy Management at www.energystar.gov.
} 


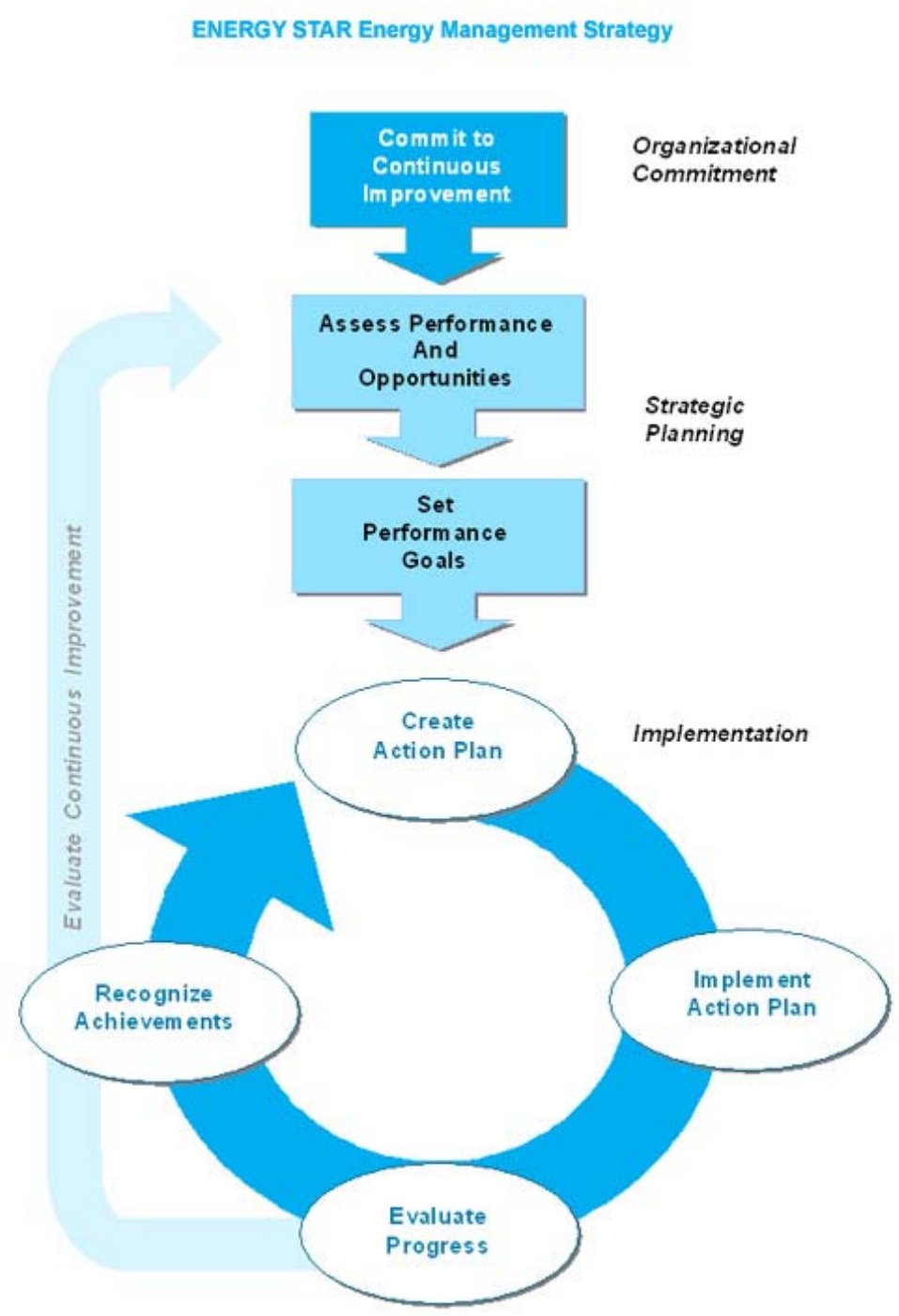

Figure 13. Main elements of a strategic energy management system.

Evaluating performance involves the regular review of both energy use data and the activities carried out as part of the action plan. Information gathered during the formal review process helps in setting new performance goals and action plans and in revealing best practices. Establishing a strong communications program and seeking recognition for accomplishments are also critical steps. Strong communication and recognition help to build support and momentum for future activities.

A quick assessment of an organization's efforts to manage energy can be made by comparing the current program against the table contained in Appendix C. Appendix D provides the ENERGY STAR energy management matrix to evaluate and score an energy management system. 


\subsection{Monitoring \& Process Control Systems}

The use of energy monitoring and process control systems can play an important role in energy management and in reducing energy use. These may include sub-metering, monitoring and control systems. They can reduce the time required to perform complex tasks, often improve product and data quality and consistency, and optimize process operations. Typically, energy and cost savings are around 5\% or more for many industrial applications of process control systems. These savings apply to plants without updated process control systems; many refineries may already have modern process control systems in place to improve energy efficiency.

Although energy management systems are already widely disseminated in various industrial sectors, the performance of the systems can still be improved, reducing costs and increasing energy savings further. For example, total site energy monitoring and management systems can increase the exchange of energy streams between plants on one site. Traditionally, only one process or a limited number of energy streams were monitored and managed. Various suppliers provide site-utility control systems (HCP, 2001).

Specific energy savings and payback periods for overall adoption of an energy monitoring system vary greatly from plant to plant and company to company.

A variety of process control systems are available for virtually any industrial process. A wide body of literature is available assessing control systems in most industrial sectors such as chemicals and petroleum refining. Table 5 provides an overview of classes of process control systems.

Table 5. Classification of control systems and typical energy efficiency improvement potentials.

\begin{tabular}{|c|c|c|}
\hline System & Characteristics & $\begin{array}{c}\text { Typical energy savings } \\
(\%)\end{array}$ \\
\hline $\begin{array}{l}\text { Monitoring and } \\
\text { Targeting }\end{array}$ & $\begin{array}{l}\text { Dedicated systems for various } \\
\text { industries, well established in } \\
\text { various countries and sectors }\end{array}$ & $\begin{array}{c}\text { Typical savings } 4-17 \% \text {, average } \\
8 \% \text {, based on experiences in the } \\
\text { UK }\end{array}$ \\
\hline $\begin{array}{l}\text { Computer } \\
\text { Integrated } \\
\text { Manufacturing } \\
\text { (CIM) }\end{array}$ & $\begin{array}{l}\text { Improvement of overall economics } \\
\text { of process, e.g., stocks, productivity } \\
\text { and energy }\end{array}$ & $>2 \%$ \\
\hline Process control & $\begin{array}{l}\text { Moisture, oxygen and temperature } \\
\text { control, air flow control } \\
\text { "Knowledge based, fuzzy logic" }\end{array}$ & Typically 2-18\% savings \\
\hline
\end{tabular}

Note: The estimated savings are valid for specific applications (e.g., lighting energy use). The energy savings cannot be added, due to overlap of the systems. Sources: (Caffal 1995, Martin et al., 2000).

Modern control systems are often not solely designed for energy efficiency, but rather for improving productivity, product quality, and the efficiency of a production line. 
Applications of advanced control and energy management systems are in varying development stages and can be found in all industrial sectors. Control systems result in reduced downtime, reduced maintenance costs, reduced processing time, and increased resource and energy efficiency, as well as improved emissions control. Many modern energy efficient technologies depend heavily on precise control of process variables, and applications of process control systems are growing rapidly. Modern process control systems exist for virtually any industrial process. Still, large potentials exist to implement control systems and more modern systems enter the market continuously. Hydrocarbon Processing produces a semi-annual overview of new advanced process control technologies for the oil refining industry (see e.g., HCP, 2001).

Process control systems depend on information from many stages of the processes. A separate but related and important area is the development of sensors that are inexpensive to install, reliable, and analyze in real-time. Current development efforts are aimed at the use of optical, ultrasonic, acoustic, and microwave systems, that should be resistant to aggressive environments (e.g., oxidizing environments in furnace or chemicals in chemical processes) and withstand high temperatures. The information of the sensors is used in control systems to adapt the process conditions, based on mathematical ("rule"-based) or neural networks and "fuzzy logic" models of the industrial process.

Neural network based control systems have successfully been used in the cement (kilns), food (baking), non-ferrous metals (alumina, zinc), pulp and paper (paper stock, lime kiln), petroleum refineries (process, site), and steel industries (electric arc furnaces, rolling mills). New energy management systems that use artificial intelligence, fuzzy logic (neural network), or rule-based systems mimic the "best" controller, using monitoring data and learning from previous experiences.

Process knowledge based systems (KBS) have been used in design and diagnostics, but are hardly used in industrial processes. Knowledge bases systems incorporate scientific and process information applying a reasoning process and rules in the management strategy. A recent demonstration project in a sugar beet mill in the UK using model based predictive control system demonstrated a 1.2 percent reduction in energy costs, while increasing product yield by almost one percent and reducing off-spec product from 11 percent to four percent. This system had a simple payback period of 1.4 years (CADDET, 2000).

Although energy management systems are already widely disseminated in various industrial sectors, the performance of the systems can still be improved, reducing costs and increasing energy savings further. Research for advanced sensors and controls is ongoing in all sectors, both funded with public funds and private research. Several projects within U.S. DOE's Industries of the Future program try to develop more advanced control technologies (U.S. DOE-OIT, 2000). Sensors and control techniques are identified as key technologies in various development areas including energy efficiency, mild processing technology, environmental performance and inspection, and containment boundary integrity. Sensors and controls are also represented in a cross-cutting OIT-program. Outside the United States, Japan and Europe also give much attention to advanced controls. Future steps include further development of new sensors and control systems, demonstration in commercial 
scale, and dissemination of the benefits of control systems in a wide variety of industrial applications.

Process control systems are available for virtually all processes in the refinery, as well as for management of refinery fuel gas, hydrogen, and total site control. An overview of commercially offered products is produced by the journal Hydrocarbon Processing. The most recent overview was published in 2001. Below examples of processes and site-wide process control systems are discussed, selected on the basis of available case studies to demonstrate the specific applications and achieved energy savings

Refinery Wide Optimization. Total site energy monitoring and management systems (Kawano, 1996) can increase the exchange of energy streams between plants on one site. Traditionally, only one plant or a limited number of energy streams were monitored and managed. Various suppliers provide site-utility control systems (HCP, 2001). Valero and AspenTech have developed a plant-wide energy optimization model to optimize the flows of intermediates, hydrogen, steam, fuel and electricity use, integrated with an energy monitoring system. The optimization system includes the cogeneration unit, FCC power recovery, and optimum load allocation of boilers, as well as selection of steam turbines or electric motors to run compressors. The system was implemented at Valero's Houston refinery in 2003 and is expected to reduce overall site-wide energy use by 2-8\%. Company wide, Valero expects to save \$7-\$27 million annually at 12 refineries (Valero, 2003).

CDU. A few companies supply control equipment for CDUs. Aspen technology has supplied over 70 control applications for CDUs and 10 optimization systems for CDUs. Typical cost savings are \$0.05 - \$0.12/bbl of feed, with paybacks less than 6 months. Key Control supplies an expert system advisor for CDUs. It has installed one system at a CDU, which resulted in reduced energy consumption and flaring and increased throughput with a payback of 1 year.

Installation of advanced control equipment at Petrogals Sines refinery (Portugal) on the CDU resulted in increased throughputs of 3-6\% with a payback period of 3 months.

FCC. Several companies offer FCC control systems, including ABB Simcon, AspenTech, Honeywell, Invensys, and Yokogawa. Cost savings may vary between $\$ 0.02$ to $\$ 0.40 / \mathrm{bbl}$ of feed with paybacks between 6 and 18 months.

Timmons et al. (2000) report on the advantages of combining an online optimizer with an existing control system to optimize the operation of a FCC unit at the CITGO refinery in Corpus Christi, Texas. The Citgo refinery installed a modern control system and an online optimizer on a 65,000 bpd FCC unit. The combination of the two systems was effective in improving the economic operation of the FCC. The installation of the optimizer led to additional cost savings of approximately $\$ 0.05 /$ barrel of feed to the FCC, which resulted in an attractive payback (Timmons et al., 2000). 
The ENI refinery in Sanassazzo (Italy) installed in 2001 an optimizer on a FCC unit from Aspen Technology. The system resulted in cost savings of $\$ 0.10 / \mathrm{bbl}$ with a payback of less than one year.

Hydrotreater. Installation of a multivariable predictive control (MPC) system was demonstrated on a hydrotreater at a SASOL refinery in South Africa. The MPC aimed to improve the product yield while minimizing the utility costs. The implementation of the system led to improved yield of gasoline and diesel, reduction of flaring, and a $12 \%$ reduction in hydrogen consumption and an $18 \%$ reduction in fuel consumption of the heater (Taylor et al., 2000). Fuel consumption for the reboiler increased to improve throughput of the unit. With a payback period of 2 months, the project resulted in improved yield and in direct and indirect (i.e., reduced hydrogen consumption) energy efficiency improvements.

Alkylation. Motiva's Convent (Louisiana) refinery implemented an advanced control system for their 100,000 bpd sulfuric acid alkylation plant. The system aims to increase product yield (by approximately $1 \%$ ), reduce electricity consumption by $4.4 \%$, reduce steam use by $2.2 \%$, reduce cooling water use by $4.9 \%$, and reduce chemicals consumption by $5-6 \%$ (caustic soda by $5.1 \%$, sulfuric acid by 6.4\%) (U.S. DOE-OIT, 2000). The software package integrates information from chemical reactor analysis, pinch analysis, information on flows, and information on energy use and emissions to optimize efficient operation of the plant. No economic performance data was provided, but the payback is expected to be rapid as only additional computer equipment and software had to be installed. The program is available through the Gulf Coast Hazardous Substance research Center and Louisiana State University. Other companies offering alkylation controls are ABB Simcon, Aspen technology, Emerson, Honeywell, Invensys, and Yokogawa. The controls typically result in cost savings of $\$ 0.10$ to $\$ 0.20 / \mathrm{bbl}$ of feed with paybacks of 6 to 18 months. 


\section{Energy Recovery}

\subsection{Flare Gas Recovery}

Flare gas recovery (or zero flaring) is a strategy evolving from the need to improve environmental performance. Conventional flaring practice has been to operate at some flow greater than the manufacturer's minimum flow rate to avoid damage to the flare (Miles, 2001). Typically, flared gas consists of background flaring (including planned intermittent and planned continuous flaring) and upset-blowdown flaring. In offshore flaring, background flaring can be as much as $50 \%$ of all flared gases (Miles, 2001). In refineries, background flaring will generally be less than $50 \%$, depending on practices in the individual refinery. Recent discussions on emissions from flaring by refineries located in the San Francisco Bay Area have highlighted the issue from an environmental perspective (Ezerksy, 2002). ${ }^{5}$ The report highlighted the higher emissions compared to previous assumptions of the Air Quality District, due to larger volumes of flared gases. The report also demonstrated the differences among various refineries, and plants within the refineries. Reduction of flaring will not only result in reduced air pollutant emissions, but also in increased energy efficiency replacing fuels, as well as less negative publicity around flaring.

Emissions can be further reduced by improved process control equipment and new flaring technology. Development of gas-recovery systems, development of new ignition systems with low-pilot-gas consumption, or elimination of pilots altogether with the use of new ballistic ignition systems can reduce the amount of flared gas considerably (see also section 19.3). Development and demonstration of new ignition systems without a pilot may result in increased energy efficiency and reduced emissions.

Reduction of flaring can be achieved by improved recovery systems, including installing recovery compressors and collection and storage tanks. This technology is commercially available. Various refineries in the United States have installed flare gas recovery systems, e.g., ChevronTexaco in Pascagoula (Mississippi) and even some small refineries like Lion Oil Co. (El Dorado, Arkansas). A plant-wide assessment of the Equilon refinery in Martinez (now fully owned by Shell) highlighted the potential for flare gas recovery. The refinery will install new recovery compressors and storage tanks to reduce flaring. No specific costs were available for the flare gas recovery project, as it is part of a large package of measures for the refinery. The overall project has projected annual savings of \$52 million and a payback period of 2 years (U.S. DOE-OIT, 2002b).

Installation of two flare gas recovery systems at the 65,000 bpd Lion Oil Refinery in El Dorado (Arkansas) in 2001 has reduced flaring to near zero levels (Fisher and Brennan, 2002). The refinery will only use the flares in emergencies where the total amount of gas will exceed the capacity of the recovery unit. The recovered gas is compressed and used in the refineries fuel system. No information on energy savings and payback were given for this particular installation. John Zink Co., the installer of the recovery system, reports that

\footnotetext{
${ }^{5}$ ChevronTexaco commented on the report by the Bay Area Air Quality Management District on refinery flaring. The comments were mainly directed towards the VOC-calculations in the report and an explanation of the flaring practices at the ChevronTexaco refinery in Richmond, CA (Hartwig, 2003).
} 
the payback period of recovery systems may be as short as one year. Furthermore, flare gas recovery systems offer increased flare tip life and emission reductions.

\subsection{Power Recovery}

Various processes run at elevated pressures, enabling the opportunity for power recovery from the pressure in the flue gas. The major application for power recovery in the petroleum refinery is the fluid catalytic cracker (FCC). However, power recovery can also be applied to hydrocrackers or other equipment operated at elevated pressures. Modern FCC designs use a power recovery turbine or turbo expander to recover energy from the pressure. The recovered energy can be used to drive the FCC compressor or to generate power. Power recovery applications for FCC are characterized by high volumes of high temperature gases at relatively low pressures, while operating continuously over long periods of time between maintenance stops (> 32,000 hours). There is wide and long-term experience with power recovery turbines for FCC applications. Various designs are marketed, and newer designs tend to be more efficient in power recovery. Recovery turbines are supplied by a small number of global suppliers, including GE Power Systems.

Many refineries in the United States and around the world have installed recovery turbines. Valero has recently upgraded the turbo expanders at its Houston and Corpus Christi (Texas) and Wilmington (California) refineries. Valero's Houston Refinery replaced an older power recovery turbine to enable increased blower capacity to allow an expansion of the FCC. At the Houston refinery, the re-rating of the FCC power recovery train led to power savings of $22 \mathrm{MW}$ (Valero, 2003), and will export additional power (up to $4 \mathrm{MW}$ ) to the grid. Petro Canada's Edmonton refinery replaced an older turbo expander by a new more efficient unit in October 1998, saving around 18 TBtu annually.

Power recovery turbines can also be applied at hydrocrackers. Power can be recovered from the pressure difference between the reactor and fractionation stages of the process. In 1993, the Total refinery in Vlissingen, the Netherlands, installed a $910 \mathrm{~kW}$ power recovery turbine to replace the throttle at its hydrocracker (get data on hydrocracker). The cracker operates at 160 bar. The power recovery turbine produces about 7.3 million $\mathrm{kWh} /$ year (assuming 8000 hours/year). The investment was equal to $\$ 1.2$ million (1993\$). This resulted in a payback period of approximately 2.5 years at the conditions in the Netherlands (Caddet, 2003). 


\section{Steam Generation and Distribution}

Steam is used throughout the refinery. An estimated 30\% of all onsite energy use in U.S. refineries is used in the form of steam. Steam can be generated through waste heat recovery from processes, cogeneration, and boilers. In most refineries, steam will be generated by all three sources, while some (smaller) refineries may not have cogeneration equipment installed. While the exact size and use of a modern steam systems varies greatly, there is an overall pattern that steam systems follow, as shown in Figure 14.

Figure 14 depicts a schematic presentation of a steam system. Treated cold feed water is fed to the boiler, where it is heated to form steam. Chemical treatment of the feed water is required to remove impurities. The impurities would otherwise collect on the boiler walls. Even though the feed water has been treated, some impurities still remain and can build up in the boiler water. As a result, water is periodically drained from the bottom of the boiler in a process known as blowdown. The generated steam travels along the pipes of the distribution system to get to the process where the heat will be used. Sometimes the steam is passed through a pressure reduction valve if the process requires lower pressure steam. As the steam is used to heat processes, and even as it travels through the distribution system to get there, the steam cools and some is condensed. This condensate is removed by a steam trap, which allows condensate to pass through, but blocks the passage of steam. The condensate can be recirculated to the boiler, thus recovering some heat and reducing the need for fresh treated feed water. The recovery of condensate and blowdown will also reduce the costs of boiler feed water treatment. For example, optimization of blowdown steam use at Valero's Houston refinery use led to cost savings of \$213,500/year (Valero, 2003).

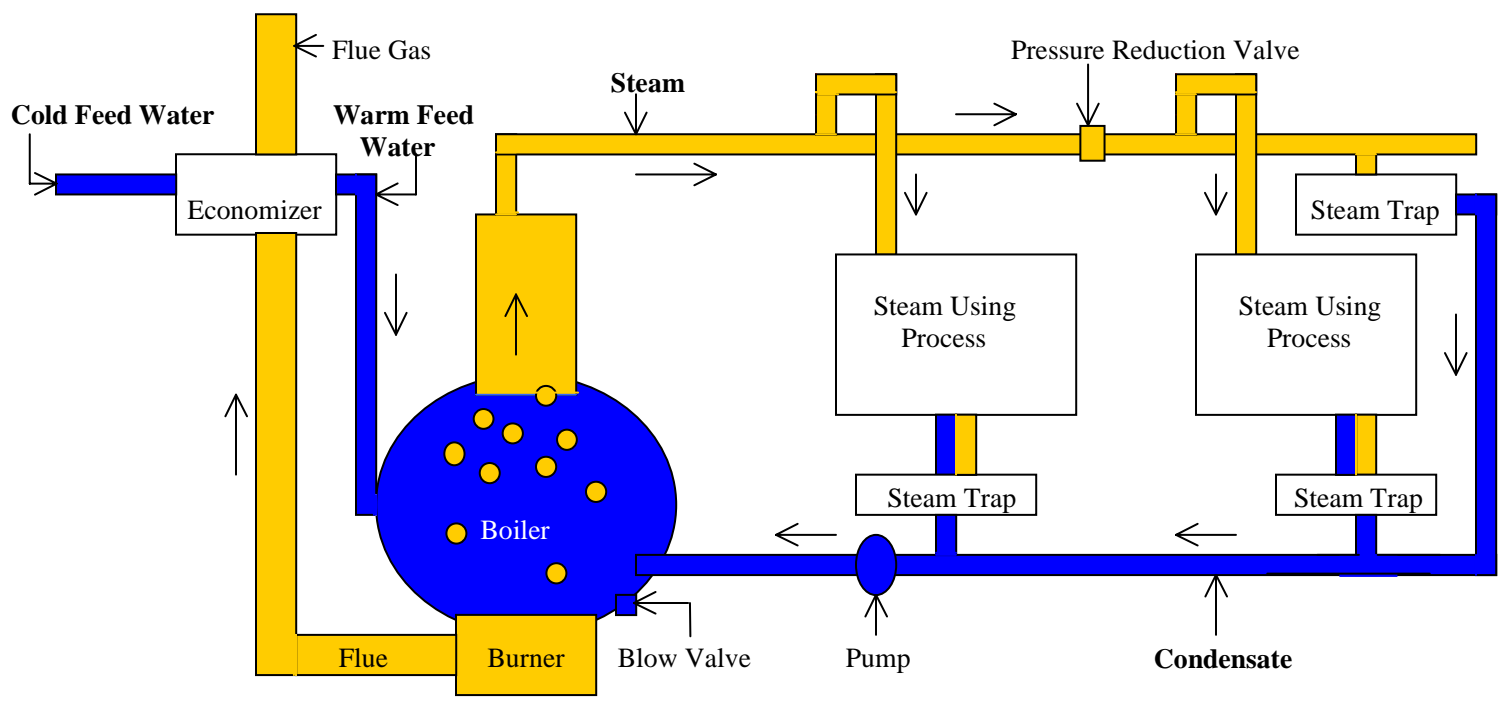

Figure 14. Schematic presentation of a steam production and distribution system.

The refining industry uses steam for a wide variety of purposes, the most important being process heating, drying or concentrating, steam cracking, and distillation. Whatever the use 
or the source of the steam, efficiency improvements in steam generation, distribution and end-use are possible. A recent study by the U.S. Department of Energy estimates the overall potential for energy savings in petroleum refineries at over 12\% (U.S. DOE, 2002). It is estimated that steam generation, distribution, and cogeneration offer the most cost-effective energy efficiency opportunities on the short term. This section focuses on the steam generation in boilers (including waste heat boilers) and distribution. Table 6 summarizes the boiler efficiency measures, while Table 7 summarizes the steam distribution system measures.

Steam, like any other secondary energy carrier, is expensive to produce and supply. The use of steam should be carefully considered and evaluated. Often steam is generated at higher pressures than needed or in larger volumes than needed at a particular time. These inefficiencies may lead steam systems to let down steam to a lower pressure or to vent steam to the atmosphere. Hence, it is strongly recommended to evaluate the steam system on the use of appropriate pressure levels and production schedules. If it is not possible to reduce the steam generation pressure, it may still be possible to recover the energy through a turbo expander or steam expansion turbine (see section 18.3). Excess steam generation can be reduced through improved process integration (see section 9.2) and improved management of steam flows in the refinery (see section 6.2 on total site management systems). Many refineries operate multiple boilers. By dispatching boilers on the basis of efficiency, it is possible to save energy. An audit of the Equilon refinery (now owned by Shell) in Martinez, California, found that scheduling of steam boilers on the basis of efficiency (and minimizing losses in the steam turbines) can result in annual energy savings equaling \$5.4 million (U.S. DOE-OIT, 2002b).

\subsection{Boilers}

Boiler Feed Water Preparation. Depending on the quality of incoming water, the boiler feed water (BFW) needs to be pre-treated to a varying degree. Various technologies may be used to clean the water. A new technology is based on the use of membranes. In reverse osmosis (RO), the pre-filtered water is pressed at increased pressure through a semipermeable membrane. Reverse osmosis and other membrane technologies are used more and more in water treatment (Martin et al., 2000). Membrane processes are very reliable, but need semi-annual cleaning and periodic replacement to maintain performance.

The Flying J refinery in North Salt Lake (Utah) installed a RO-unit to remove hardness and reduce the alkalinity from boiler feedwater, replacing a hot lime water softener. The unit started operation in 1998, resulting in reduced boiler blowdown (from 13.3\% to 1.5\% of steam produced) and reduced chemical use, maintenance, and waste disposal costs (U.S. DOE-OIT, 2001). With an investment of \$350,000 and annual benefits of approximately $\$ 200,000$, the payback period amounted to less than 2 years.

Improved Process Control. Flue gas monitors are used to maintain optimum flame temperature, and to monitor $\mathrm{CO}$, oxygen and smoke. The oxygen content of the exhaust gas is a combination of excess air (which is deliberately introduced to improve safety or reduce emissions) and air infiltration (air leaking into the boiler). By combining an oxygen monitor with an intake airflow monitor, it is possible to detect (small) leaks. Using a combination of 
$\mathrm{CO}$ and oxygen readings, it is possible to optimize the fuel/air mixture for high flame temperature (and thus the best energy efficiency) and low emissions. The payback of improved process control is approximately 0.6 years (IAC, 1999). This measure may be too expensive for small boilers.

Reduce Flue Gas Quantities. Often, excessive flue gas results from leaks in the boiler and the flue, reducing the heat transferred to the steam, and increasing pumping requirements. These leaks are often easily repaired. Savings amount to 2-5\% (OIT, 1998). This measure consists of a periodic repair based on visual inspection. The savings from this measure and from flue gas monitoring are not cumulative, as they both address the same losses.

Reduce Excess Air. The more air is used to burn the fuel, the more heat is wasted in heating air. Air slightly in excess of the ideal stoichometric fuel/air ratio is required for safety, and to reduce $\mathrm{NO}_{\mathrm{x}}$ emissions, and is dependent on the type of fuel. For gas and oil-fired boilers, approximately 15\% excess air is adequate (OIT, 1998; Ganapathy, 1994). Poorly maintained boilers can have up to $140 \%$ excess air. Reducing this back down to $15 \%$ even without continuous automatic monitoring would save $8 \%$.

Improve Insulation. New materials insulate better, and have a lower heat capacity. Savings of $6-26 \%$ can be achieved if this improved insulation is combined with improved heater circuit controls. This improved control is required to maintain the output temperature range of the old firebrick system. As a result of the ceramic fiber's lower heat capacity, the output temperature is more vulnerable to temperature fluctuations in the heating elements (Caffal, 1995). The shell losses of a well-maintained boiler should be less than $1 \%$.

Maintenance. A simple maintenance program to ensure that all components of the boiler are operating at peak performance can result in substantial savings. In the absence of a good maintenance system, the burners and condensate return systems can wear or get out of adjustment. These factors can end up costing a steam system up to $20-30 \%$ of initial efficiency over 2-3 years (DOE, 2001a). On average, the possible energy savings are estimated at 10\% (DOE, 2001a). Improved maintenance may also reduce the emission of criteria air pollutants.

Fouling of the fireside of the boiler tubes or scaling on the waterside of the boiler should also be controlled. Fouling and scaling are more of a problem with coal-fed boilers than with natural gas or oil-fed ones (i.e., boilers that burn solid fuels like coal should be checked more often as they have a higher fouling tendency than liquid fuel boilers do). Tests show that a soot layer of 0.03 inches $(0.8 \mathrm{~mm})$ reduces heat transfer by $9.5 \%$, while a 0.18 inch $(4.5 \mathrm{~mm})$ soot layer reduces heat transfer by 69\% (CIPEC, 2001). For scaling, 0.04 inches (1 $\mathrm{mm}$ ) of buildup can increase fuel consumption by 2\% (CIPEC, 2001). Moreover, scaling may result in tube failures.

Recover Heat From Flue Gas. Heat from flue gasses can be used to preheat boiler feed water in an economizer. While this measure is fairly common in large boilers, there is often still potential for more heat recovery. The limiting factor for flue gas heat recovery is the economizer wall temperature that should not drop below the dew point of acids in the flue 
gas. Traditionally this is done by keeping the flue gases at a temperature significantly above the acid dew point. However, the economizer wall temperature is more dependent on the feed water temperature than flue gas temperature because of the high heat transfer coefficient of water. As a result, it makes more sense to preheat the feed water to close to the acid dew point before it enters the economizer. This allows the economizer to be designed so that the flue gas exiting the economizer is just barely above the acid dew point. One percent of fuel use is saved for every $25^{\circ} \mathrm{C}$ reduction in exhaust gas temperature. (Ganapathy, 1994). Since exhaust gas temperatures are already quite low, limiting savings to $1 \%$ across all boilers, with a payback of 2 years (IAC, 1999).

Recover Steam From Blowdown. When the water is blown from the high-pressure boiler tank, the pressure reduction often produces substantial amounts of steam. This steam is low grade, but can be used for space heating and feed water preheating. For larger high-pressure boilers, the losses may be less than $0.5 \%$. It is estimated that this measure can save $1.3 \%$ of boiler fuel use for all boilers below $100 \mathrm{MMBtu} / \mathrm{hr}$ (approximately 5\% of all boiler capacity in refineries). The payback period of blowdown steam recovery will vary between 1 and 2.7 years (IAC, 1999).

Table 6. Summary of energy efficiency measures in boilers.

\begin{tabular}{|l|c|c|l|}
\hline Measure & Fuel Saved & $\begin{array}{l}\text { Payback } \\
\text { Period (years) }\end{array}$ & Other Benefits \\
\hline $\begin{array}{l}\text { Improved Process } \\
\text { Control }\end{array}$ & $3 \%$ & 0.6 & Reduced Emissions \\
\hline $\begin{array}{l}\text { Reduced Flue Gas } \\
\text { Quantity }\end{array}$ & $2-5 \%$ & - & Cheaper emission controls \\
\hline Reduced Excess Air & $\begin{array}{c}\text { 1\% improvement for } \\
\text { each 15\% less excess } \\
\text { air }\end{array}$ & - & \\
\hline Improved Insulation & $6-26 \%$ & $?$ & Faster warm-up \\
\hline Boiler Maintenance & $10 \%$ & 0 & Reduced emissions \\
\hline $\begin{array}{l}\text { Flue Gas Heat } \\
\text { Recovery }\end{array}$ & $1 \%$ & 2 & $\begin{array}{l}\text { Reduced damage to structures } \\
\text { (less moist air is less corrosive) }\end{array}$ \\
\hline $\begin{array}{l}\text { Blowdown Steam } \\
\text { Heat Recovery }\end{array}$ & $1.3 \%$ & $\begin{array}{l}\text { Reduces solid waste stream at } \\
\text { the cost of increased air } \\
\text { emissions }\end{array}$ \\
\hline Alternative Fuels & Variable & - & \\
\hline
\end{tabular}

Reduce Standby Losses. In refineries often one or more boilers are kept on standby in case of failure of the operating boiler. The steam production at standby can be reduced to virtually zero by modifying the burner, combustion air supply and boiler feedwater supply. By installing an automatic control system the boiler can reach full capacity within 12 minutes. Installing the control system and modifying the boiler can result in energy savings up to $85 \%$ of the standby boiler, depending on the use pattern of the boiler.

The Kemira Oy ammonia plant at Rozenburg (the Netherlands) applied this system to a small $40 \mathrm{t} / \mathrm{hr}$ steam boiler, reducing the standby steam consumption from the boiler from 6 $\mathrm{t} / \mathrm{hr}$ to $1 \mathrm{t} / \mathrm{hr}$. This resulted in energy savings of $54 \mathrm{TBtu} / \mathrm{year}$. Investments were 
approximately $\$ 270,000$ (1991\$), resulting in a payback period of 1.5 years at this particular plant (Caddet, 1997b).

\subsection{Steam Distribution}

When designing new steam distribution systems, it is very important to take into account the velocity and pressure drop (Van de Ruit, 2000). This reduces the risk of oversizing a steam pipe, which is not only a cost issue but would also lead to higher heat losses. A pipe too small may lead to erosion and increased pressure drop. Installations and steam demands change over time, which may lead to under-utilization of steam distribution capacity utilization, and extra heat losses. However, it may be too expensive to optimize the system for changed steam demands. Still, checking for excess distribution lines and shutting off those lines is a cost-effective way to reduce steam distribution losses. Other maintenance measures for steam distribution systems are described below.

Improve Insulation. This measure can be to use more insulating material, or to make a careful analysis of the proper insulation material. Crucial factors in choosing insulating material include: low thermal conductivity, dimensional stability under temperature change, resistance to water absorption, and resistance to combustion. Other characteristics of insulating material may also be important depending on the application, e.g., tolerance of large temperature variations and system vibration, and compressive strength where insulation is load bearing (Baen and Barth, 1994). Improving the insulation on the existing stock of heat distribution systems would save an average of $3-13 \%$ in all systems (OIT, 1998) with an average payback period of 1.1 years $^{6}$ (IAC, 1999). The U.S. Department of Energy has developed the software tool 3E-Plus to evaluate the optimal insulation for steam systems (see Appendix E).

Maintain Insulation. It is often found that after repairs, the insulation is not replaced. In addition, some types of insulation can become brittle, or rot. As a result, energy can be saved by a regular inspection and maintenance system (CIBO, 1998). Exact energy savings and payback periods vary with the specific situation in the plant.

Improve Steam Traps. Using modern thermostatic elements, steam traps can reduce energy use while improving reliability. The main advantages offered by these traps are that they open when the temperature is very close to that of the saturated steam (within $2^{\circ} \mathrm{C}$ ), purge non-condensable gases after each opening, and are open on startup to allow a fast steam system warm-up. These traps are also very reliable, and useable for a wide variety of steam pressures (Alesson, 1995). Energy savings will vary depending on the steam traps installed and state of maintenance.

Maintain Steam Traps. A simple program of checking steam traps to ensure that they operate properly can save significant amounts of energy. If the steam traps are not regularly monitored, $15-20 \%$ of the traps can be malfunctioning. In some plants, as many as $40 \%$ of the steam traps were malfunctioning. Energy savings for a regular system of steam trap

\footnotetext{
${ }^{6}$ The IAC database shows a series of case studies where a particular technology was used. It gives a wide variety of information, including the payback period for each case. We calculated an overall payback for a technology by averaging all the individual cases.
} 
checks and follow-up maintenance is estimated at up to 10\% (OIT, 1998; Jones 1997; Bloss, 1997 ) with a payback period of 0.5 years (IAC, 1999). This measure offers a quick payback but is often not implemented because maintenance and energy costs are separately budgeted. Some systems already use this practice.

An audit of the Flying J Refinery in North Salt Lake (Utah) identified annual savings of $\$ 147,000$ by repairing leaking steam traps (Brueske et al., 2002).

Monitor Steam Traps Automatically. Attaching automated monitors to steam traps in conjunction with a maintenance program can save even more energy, without significant added cost. This system is an improvement over steam trap maintenance alone, because it gives quicker notice of steam trap malfunctioning or failure. Using automatic monitoring is estimated to save an additional 5\% over steam trap maintenance, with a payback of 1 year ${ }^{7}$ (Johnston, 1995; Jones, 1997). Systems that are able to implement steam trap maintenance are also likely to be able to implement automatic monitoring. On average, $50 \%$ of systems can still implement automatic monitoring of steam traps.

Repair Leaks. As with steam traps, the distribution pipes themselves often have leaks that go unnoticed without a program of regular inspection and maintenance. In addition to saving up to $3 \%$ of energy costs for steam production, having such a program can reduce the likelihood of having to repair major leaks (OIT, 1998). On average, leak repair has a payback period of 0.4 years (IAC, 1999).

Recover Flash Steam. When a steam trap purges condensate from a pressurized steam distribution system to ambient pressure, flash steam is produced. This steam can be used for space heating or feed water preheating (Johnston, 1995). The potential for this measure is extremely site dependent, as it is unlikely that a producer will want to build an entirely new system of pipes to transport this low-grade steam to places where it can be used, unless it can be used close to the steam traps. Hence, the savings are strongly site dependent. Many sites will use multi-pressure steam systems. In this case, flash steam formed from highpressure condensate can be routed to reduced pressure systems.

Vulcan Chemicals in Geismar (Louisiana) implemented a flash steam recovery project at one of the processes at their chemical plant. The project recovers $100 \%$ of the flash steam and resulted in net energy savings of 2.8\% (Bronhold, 2000).

\footnotetext{
${ }^{7}$ Calculated based on a UK payback of 0.75 years. The U.S. payback is longer because energy prices in the U.S. are lower, while capital costs are similar.
} 
Table 7. Summary of energy efficiency measures in steam distribution systems.

\begin{tabular}{|l|l|l|l|}
\hline Measure & \multicolumn{1}{|c|}{ Fuel Saved } & $\begin{array}{c}\text { Payback } \\
\text { Period (years) }\end{array}$ & \multicolumn{1}{|c|}{ Other Benefits } \\
\hline Improved Insulation & $3-13 \%$ & 1.1 & Greater reliability \\
\hline Improved Steam Traps & Unknown & Unknown & \\
\hline $\begin{array}{l}\text { Steam Trap } \\
\text { Maintenance }\end{array}$ & $10-15 \%$ & 0.5 & $\begin{array}{l}\text { Reduced requirement for major } \\
\text { repairs }\end{array}$ \\
\hline $\begin{array}{l}\text { Automatic Steam Trap } \\
\text { Monitoring }\end{array}$ & $5 \%$ & 1 & Reduced water treatment costs \\
\hline $\begin{array}{l}\text { Leak Repair } \\
\text { Flash Steam Recovery/ } \\
\text { Condensate Return }\end{array}$ & $83 \%{ }^{9}$ & 0.4 & Reduced water treatment costs \\
\hline $\begin{array}{l}\text { Condensate Return } \\
\text { Alone }\end{array}$ & $10 \%$ & 1.1 & \\
\hline
\end{tabular}

Return Condensate. Reusing the hot condensate in the boiler saves energy and reduces the need for treated boiler feed water. The substantial savings in energy costs and purchased chemicals costs makes building a return piping system attractive. This measure has already been implemented in most places where it is easy to accomplish. Care has to be taken to design the recovery system to reduce efficiency losses (van de Ruit, 2000). Maximum energy savings are estimated at 10\% (OIT, 1998) with a payback of 1.1 years (IAC, 1999) for those sites without or with insufficient condensate return. An additional benefit of condensate recovery is the reduction of the blowdown flow rate because boiler feedwater quality has been increased.

\footnotetext{
${ }^{8}$ In addition to a regular maintenance program

${ }^{9}$ Includes flash steam recovery from the boiler. Although this represents actual savings achieved in a case study, it seems much to high to be a generally applicable savings number. As a result, it is not included in our total savings estimate.
} 


\section{Heat Exchangers and Process Integration}

Heating and cooling are operations found throughout the refinery. Within a single process, multiple streams are heated and cooled multiple times. Optimal use and design of heat exchangers is a key area for energy efficiency improvement.

\subsection{Heat Transfer- Fouling}

Heat exchangers are used throughout the refinery to recover heat from processes and transfer heat to the process flows. Next to efficient integration of heat flows throughout the refinery (see process integration below), the efficient operation of heat exchangers is a major area of interest. In a complex refinery, most processes occur under high temperature and pressure conditions; the management and optimization of heat transfer among processes is therefore key to increasing overall energy efficiency. Fouling, a deposit buildup in units and piping that impedes heat transfer, requires the combustion of additional fuel. For example, the processing of many heavy crude oils in the United States increases the likelihood of localized coke deposits in the heating furnaces, thereby reducing furnace efficiency and creating potential equipment failure. An estimate by the Office of Industrial Technology at the U.S. Department of Energy noted that the cost penalty for fouling could be as much as $\$ 2$ billion annually in material and energy costs. The problem of fouling is expected to increase with the trend towards processing heavier crudes.

Fouling is the effect of several process variables and heat exchanger design. Fouling may follow the combination of different mechanisms (Bott, 2001). Several methods of investigation have been underway to attempt to reduce fouling including the use of sensors to detect early fouling, physical and chemical methods to create high temperature coatings (without equipment modification), the use of ultrasound, as well as the improved long term design and operation of facilities. The U.S. Department of Energy initially funded preliminary research into this area, but funding has been discontinued (Huangfu, 2000; Bott, 2000). Worldwide, research in fouling reduction and mitigation is continuing (Polley and Pugh, 2002; Polley et al. 2002) by focusing on understanding the principles of fouling and redesign of heat exchangers and reactors. Currently, various methods to reduce fouling focus on process control, temperature control, regular maintenance and cleaning of the heat exchangers (either mechanically or chemically) and retrofit of reactor tubes (Barletta, 1998).

A study of European refineries identified overall energy savings of $0.7 \%$ by cleaning the heat exchanger tubes of the CDU and other furnaces with an estimated payback period of 0.7 years.

Fouling was identified as a major energy loss in an audit of the Equilon refinery in Martinez, California (now owned by Shell). Regular cleaning of heat exchangers and maintenance of insulation would result in estimated annual savings of over $\$ 14$ million at a total expenditure of $\$ 9.85$ million (U.S. DOE-OIT, 2002b). Hence, the simple payback period is around 8 months.

CDU. Fouling is an important factor for efficiency losses in the CDU, and within the CDU, the crude preheater is especially susceptible to fouling (Barletta, 1998). Initial analysis on 
fouling effects of a 100,000 bbl/day crude distillation unit found an additional heating load of $12.3 \mathrm{kBtu} /$ barrel (13.0 MJ/barrel) processes (Panchal and Huangfu, 2000). Reducing this additional heating load could results in significant energy savings.

\subsection{Process Integration}

Process integration or pinch technology refers to the exploitation of potential synergies that are inherent in any system that consists of multiple components working together. In plants that have multiple heating and cooling demands, the use of process integration techniques may significantly improve efficiencies.

Developed in the early 1970s, it is now an established methodology for continuous processes (Linnhoff, 1992; Caddet, 1993). The methodology involves the linking of hot and cold streams in a process in a thermodynamic optimal way (i.e., not over the so-called 'pinch'). Process integration is the art of ensuring that the components are well suited and matched in terms of size, function and capability. Pinch analysis takes a systematic approach to identifying and correcting the performance limiting constraint (or pinch) in any manufacturing process (Kumana, 2000a). It was developed originally in the late 1970s at the University of Manchester in England and other places (Linnhoff, 1993) in response to the "energy crisis" of the 1970s and the need to reduce steam and fuel consumption in oil refineries and chemical plants by optimizing the design of heat exchanger networks. Since then, the pinch approach has been extended to resource conservation in general, whether the resource is capital, time, labor, electrical power, water or a specific chemical species such as hydrogen.

The critical innovation in applying pinch analysis was the development of "composite curves" for heating and cooling, which represent the overall thermal energy demand and availability profiles for the process as a whole. When these two curves are drawn on a temperature-enthalpy graph, they reveal the location of the process pinch (the point of closest temperature approach), and the minimum thermodynamic heating and cooling requirements. These are called the energy targets. The methodology involves first identifying the targets and then following a systematic procedure for designing heat exchanger networks to achieve these targets. The optimum approach temperature at the pinch is determined by balancing the capital-energy tradeoffs to achieve the desired payback. The procedure applies equally well to new designs as well as to retrofits of existing plants.

The analytical approach to this analysis has been well documented in the literature (Kumana, 2000b; Smith, 1995; Shenoy, 1994). Energy savings potential using pinch analysis far exceeds that from well-known conventional techniques such as heat recovery from boiler flue gas, insulation and steam trap management.

Pinch analysis, and competing process integration tools, have been developed further in the past several years. The most important developments in the energy area are the inclusion of alternative heat recovery processes such as heat pumps and heat transformers, as well as the development of pinch analysis for batch processes (or in other words bringing in time as a factor in the analysis of heat integration). Furthermore, pinch analysis should be used in the 
design of new processes and plants, as process integration goes beyond optimization of heat exchanger networks (Hallale, 2001). Even in new designs additional opportunities for energy efficiency improvement can be identified. Pinch analysis has also been extended to the areas of water recovery and efficiency, and hydrogen recovery (hydrogen pinch, see also below). Water used to be seen as a low-cost resource to the refinery, and was used inefficiently. However, as the standards and costs for waste water treatment increase and the costs for feedwater makeup increase, the industry has become more aware of water costs. In addition, large amounts of energy are used to process and move water through the refinery. Hence, water savings will lead to additional energy savings. Water pinch can be used to develop targets for minimal water use by reusing water in an efficient manner. Optimization software has been developed to optimize investment and operation costs for water systems in a plant (Hallale, 2001). New tools have been developed to optimize water and energy use in an integrated manner (Wu, 2000). Water pinch has until now mainly been used in the food industry, reporting reductions in water intake of up to 50\% (Polley and Polley, 2000). Dunn and Bush (2001) report the use of water pinch for optimization of water use in chemical plants operated by Solutia, resulting in sufficient water use reductions to allow expansion of production and of the site with no net increase in water use. No water pinch analysis studies specific for the petroleum refining industry were found. Major oil companies, e.g., BP and Exxon, have applied hydrogen pinch analysis for selected refineries.

Total Site Pinch Analysis has been applied by over 40 refineries around the world to find optimum site-wide utility levels by integrating heating and cooling demands of various processes, and by allowing the integration of CHP into the analysis. Process integration analysis of existing refineries and processes should be performed regularly, as continuous changes in product mix, mass flows, and applied processes can provide new or improved opportunities for energy and resource efficiency.

Major refineries that have applied total site pinch analysis are: Amoco, Agip (Italy), BP, Chevron, Exxon (in the Netherlands and UK), and Shell (several European plants). Typical savings identified in these site-wide analyses are around $20-30 \%$, although the economic potential was found to be limited to 10-15\% (Linnhoff-March, 2000). A total-site analysis was performed of a European oil refinery in the late 1990s. The Solomon's EII of the refinery was within the top quartile. The refinery operates 16 processes including a CDU, VDU, FCC, reformer, coker and hydrotreaters. A study of the opportunities offered by individual process optimization of the CDU, VDU, FCC, coker, and two hydrotreaters found a reduction in site EII of $7.5 \%$. A total-site analysis including the cogeneration unit identified a potential reduction of 16\% (Linnhoff-March, 2000). Identified opportunities including the conversion of a back-pressure turbine to a condensing turbine, and improved integration of the medium-pressure and low-pressure steam networks. The economically attractive projects would result in savings of approximately $12-13 \%$.

Site analyses by chemical producer Solutia identified annual savings of $\$ 3.9$ million (of which 2.7 with a low payback) at their Decatur plant, 0.9M\$/year at the Anniston site and 3.6 M\$/year at the Pensacola site (Dunn and Bush, 2001). 
Process Integration - Hot Rundown - Typically process integration studies focus on the integration of steam flows within processes and between processes. Sometimes it is possible to improve the efficiency by retaining the heat in intermediate process flows from one unit to another unit. This reduces the need for cooling or quenching in one unit and reheating in the other unit. Such an integration of two processes can be achieved through automated process controls linking the process flows between both processes. An audit of the Equilon refinery in Martinez, California, identified annual savings of \$4.3 million (U.S. DOE-OIT, 2002b). However, the audit results did not include an assessment of investments and payback.

Crude Distillation Unit (CDU). The CDU process all the incoming crude and, hence, is a major energy user in all refinery layouts (except for those refineries that receive intermediates by pipeline from other refineries). In fact, in Chapter 4 it is estimated that the $\mathrm{CDU}$ is the largest energy consuming process of all refinery processes. Energy use and products of the CDU depend on the type of crude processed. New CDUs are supplied by a number of global companies such as ABB Lummus, Kellog Brown \& Root, Shell Global Solutions, Stone \& Webster, Technip/Elf, and UOP. An overview of available process designs is published as Hydrocarbon Processing's Refining Processes (HCP, 2000).

Process integration is especially important in the CDU, as it is a large energy consumer processing all incoming crude oil. Older process integration studies show reductions in fuel use between 10 and 19\% for the CDU (Clayton, 1986; Sunden, 1988; Lee, 1989) with payback periods less than 2 years. An interesting opportunity is the integration of the CDU and VDU, which can lead to fuel savings from 10-20\% (Clayton, 1986; Petrick and Pellegrino, 1999) compared to non-integrated units, at relatively short paybacks. The actual payback period will depend heavily on the layout of the refinery, needed changes in the heat exchanger network and the fuel prices.

The CDU at BP's Kwinana (Australia) refinery was already performing well with limited opportunities for further economic process integration. An analysis of the CDU identified a significant potential for reduction but with a payback of around 6 years. However, integration with the residue cracking unit offered significant opportunities to reduce the combined heating demand by $35-40 \%$ with a simple payback period of 1.6 years (Querzoli, 2002).

Fluid Catalytic Cracker (FCC). The FCC is a considerable energy consumer in a modern refiner. In this Energy Guide, the FCC energy use is estimated at 6\% of total energy use. Depending on the design and product mix of a particular refinery, FCC energy use can be higher than 6\%. There are a large number of FCC designs in use, and many were originally built in the 1970s. Today, more energy efficient designs are being marketed by a number of suppliers. The designs vary in reactor design, type of catalyst used and degree of heat integration. An overview of available process designs is published as Hydrocarbon Processing's Refining Processes (HCP, 2000). The major suppliers are ABB Lummus, Kellog Brown \& Root, Shell Global Solutions, Stone \& Webster, and UOP. The optimal design will be based on the type of feed processed and desired product mix and quality. 
When selecting a new FCC, process energy efficiency should be an integral part of the selection process.

In existing FCC units, energy efficiency can be improved by increasing heat integration and recovery, process flow scheme changes, and power recovery. A FCC has a multitude of flows that need to be heated (sink) and cooled (source). The better the integration of the heat sinks and sources, the lower the energy consumption of an FCC will be. Older FCC designs often do not have an optimized heat exchange setup, which may especially lead to wasted low-temperature heat, which could be used to preheat boiler feed water or cold feed. However, by better integrating the sources and sinks, following the principles of pinch technology (see above), through improved combinations of temperature levels and heating/cooling loads energy use is lowered. Various authors have reported on the application of pinch analysis and process optimization of FCCs (Hall et al., 1995; Golden and Fulton, 2000). The appropriate combination will depend on the feed processed and output produced. Furthermore, economics for the installation of heat exchangers may determine the need for less efficient combinations.

Al-Riyami et al. (2001) studied the opportunities for process integration of a FCC unit in a refinery in Romania. The FCC unit was originally built by UOP and is used to convert vacuum gas oil and atmospheric gas oil. Several design options were identified to reduce utility consumption. The study of the FCC identified a reduction in utilities of $27 \%$ at a payback of 19 months. However, the calculation for the payback period only includes the heat exchangers, and, depending on the design of the FCC and layout of the plant, the payback period may be longer for other plant designs.

At a refinery in the United Kingdom, a site analysis of energy efficiency opportunities was conducted. The audit identified additional opportunities for heat recovery in the FCC by installing a waste heat boiler before the electrostatic precipitator, resulting in savings of $\$ 210,000 /$ year at a payback of 2 years (Venkatesan and Iordanova, 2003).

FCC-Process Flow Changes. The product quality demands and feeds of FCCs may change over time. The process design should remain optimized for this change. Increasing or changing the number of pumparounds can improve energy efficiency of the FCC, as it allows increased heat recovery (Golden and Fulton, 2000). A change in pumparounds may affect the potential combinations of heat sinks and sources.

New design and operational tools enable the optimization of FCC operating conditions to enhance product yields. Petrick and Pellegrino (1999) cite studies that have shown that optimization of the FCC-unit with appropriate modifications of equipment and operating conditions can increase the yield of high octane gasoline and alkylate from $3 \%$ to $7 \%$ per barrel of crude oil. This would result in energy savings.

Reformer. At a refinery in the United Kingdom, a site analysis of energy efficiency opportunities was conducted. The audit identified opportunities to improve the performance of the economizer in the waste heat boilers of two reformer furnaces. The changes would 
result in annual savings of $\$ 140,000$ in each reformer at a payback period of 2 years (Venkatesan and Iordanova, 2003).

Coker. A simulation and optimization of a coker of Jinling Petrochemical Corp.'s Nanjing refinery (China) in 1999 identified a more efficient way to integrate the heat flows in the process. By changing the diesel pumparound, they achieved an energy cost reduction of $\$ 100,000 / y e a r$ (Zhang, 2001). Unfortunately, there is insufficient data to estimate the savings for U.S. refineries or to evaluate the economics of the project under U.S. conditions. 


\section{Process Heaters}

Over $60 \%$ of all fuel used in the refinery is used in furnaces and boilers. The average thermal efficiency of furnaces is estimated at $75-90 \%$ (Petrick and Pellegrino, 1999). Accounting for unavoidable heat losses and dewpoint considerations, the theoretical maximum efficiency is around 92\% (HHV) (Petrick and Pellegrino, 1999). This suggests that on average a $10 \%$ improvement in energy efficiency can be achieved in furnace and burner design.

The efficiency of heaters can be improved by improving heat transfer characteristics, enhancing flame luminosity, installing recuperators or air-preheaters, and improved controls. New burner designs aim at improved mixing of fuel and air and more efficient heat transfer. Many different concepts are developed to achieve these goals, including lean-premix burners (Seebold et al., 2001), swirl burners (Cheng, 1999), pulsating burners (Petrick and Pellegrino, 1999) and rotary burners (U.S. DOE-OIT, 2002e). At the same time, furnace and burner design has to address safety and environmental concerns. The most notable is the reduction of NOx emissions. Improved NOx control will be necessary in almost all refineries to meet air quality standards, especially as many refineries are located in nonattainment areas.

\subsection{Maintenance}

Regular maintenance of burners, draft control and heat exchangers is essential to maintain safe and energy efficient operation of a process heater.

Draft Control. Badly maintained process heaters may use excess air. This reduces the efficiency of the burners. Excess air should be limited to 2-3\% oxygen to ensure complete combustion.

Valero's Houston refinery has installed new control systems to reduce excess combustion air at the three furnaces of the CDU. The control system allows running the furnace with $1 \%$ excess oxygen instead of the regular 3-4\%. The system has not only reduced energy use by 3 to $6 \%$ but also reduced NOx emissions by $10-25 \%$, and enhanced the safety of the heater (Valero, 2003). The energy savings result in an estimated cost savings of $\$ 340,000$. Similar systems will be introduced in 94 process heaters at the 12 Valero refineries, and is expected to result in savings of $\$ 8.8$ million/year.

An audit of the Paramount Petroleum Corp.'s asphalt refinery in Paramount (California) identified excess draft air in six process heaters. Regular maintenance (twice per year) can reduce the excess draft air and would result in annual savings of over $\$ 290,000$ (or nearly 100,000 MBtu/year). The measure has a simple payback period of 2 months (U.S. DOEOIT, 2003b).

An audit co-funded by U.S. Department of Energy, of the Equilon refinery (now owned by Shell) in Martinez (California) found that reduction of excess combustion and draft air would result in annual savings of almost $\$ 12$ million (U.S. DOE-OIT, 2002b). A similar audit of the Flying J Refinery at North Salt Lake (Utah) found savings of \$100,000/year 
through oxygen control of the flue gases to control the air intake of the furnaces (Brueske et al., 2002).

\subsection{Air Preheating}

Air preheating is an efficient way of improving the efficiency and increasing the capacity of a process heater. The flue gases of the furnace are used to preheat the combustion air. Every $35^{\circ} \mathrm{F}$ drop in the exit flue gas temperature increases the thermal efficiency of the furnace by $1 \%$ (Garg, 1998). Typical fuel savings range between 8 and $18 \%$, and is typically economically attractive if the flue gas temperature is higher than $650^{\circ} \mathrm{F}$ and the heater size is $50 \mathrm{MMBtu} / \mathrm{hr}$ or more (Garg, 1998). The optimum flue gas temperature is also determined by the sulfur content of the flue gases to reduce corrosion. When adding a preheater, the burner needs to be rerated for optimum efficiency. The typical payback period for combustion air preheating in a refinery is estimated at 2.5 years. However, the costs may vary strongly depending on the layout of the refinery and furnace construction.

VDU. At a refinery in the United Kingdom, a site analysis of energy efficiency opportunities was conducted. The refinery operated 3 VDUs of which one still used natural draught and had no heat recovery installed. By installing a combustion air preheater, using the hot flue gas, and an additional FD fan, the temperature of the flue gas was reduced to $470^{\circ} \mathrm{F}$. This led to energy cost savings of $\$ 109,000 /$ year with a payback period of 2.2 years (Venkatesan and Iordanova, 2003).

\subsection{New Burners}

In many areas, new air quality regulation will demand refineries to reduce NOx and VOC emissions from furnaces and boilers. Instead of installing expensive selective catalytic reduction (SCR) flue gas treatment plants, new burner technology reduces emissions dramatically. This will result in cost savings as well as help to decrease electricity costs for the SCR.

ChevronTexaco, in collaboration with John Zink Co., developed new low-NOx burners for refinery applications based on the lean premix concept. The burners help to reduce NOx emissions from $180 \mathrm{ppm}$ to below $20 \mathrm{ppm}$. The burners have been installed in a CDU, VDU, and a reformer at ChevronTexaco's Richmond, (California) refinery, without taking the furnace out of production. The burner was also applied to retrofit a steam boiler. The installation of the burners in a reforming furnace reduced emissions by over $90 \%$, while eliminating the need for an SCR. This saved the refinery $\$ 10$ million in capital costs and $\$ 1.5$ million in annual operating costs of the SCR (Seebold et al., 2001). The operating costs include the saved electricity costs for operating compressors and fans for the SCR. The operators had to be retrained to operate the new burners as some of the operation characteristics had changed. 


\section{Distillation}

Distillation is one of the most energy intensive operations in the petroleum refinery. Distillation is used throughout the refinery to separate process products, either from the CDU/VDU or from conversion processes. The incoming flow is heated, after which the products are separated on the basis of boiling points. Heat is provided by process heaters (see Chapter 10) and/or by steam (see Chapter 9). Energy efficiency opportunities exist in the heating side and by optimizing the distillation column.

Operation Procedures. The optimization of the reflux ratio of the distillation column can produce significant energy savings. The efficiency of a distillation column is determined by the characteristics of the feed. If the characteristics of the feed have changed over time or compared to the design conditions, operational efficiency can be improved. If operational conditions have changed, calculations to derive new optimal operational procedures should be done. The design reflux should be compared with the actual ratios controlled by each shift operator. Steam and/or fuel intensity can be compared to the reflux ratio, product purity, etc. and compared with calculated and design performance on a daily basis to improve the efficiency.

Check Product Purity. Many companies tend to excessively purify products and sometimes with good reason. However, purifying to $98 \%$ when $95 \%$ is acceptable is not necessary. In this case, the reflux rate should be decreased in small increments until the desired purity is obtained. This will decrease the reboiler duties. This change will require no or very low investments (Saxena, 1997).

Seasonal Operating Pressure Adjustments. For plants that are in locations that experience winter climates, the operating pressure can be reduced according to a decrease in cooling water temperatures (Saxena, 1997). However, this may not apply to the VDU or other separation processes operating under vacuum. These operational changes will generally not require any investment.

Reducing Reboiler Duty. Reboilers consume a large part of total refinery energy use as part of the distillation process. By using chilled water, the reboiler duty can in principal be lowered by reducing the overhead condenser temperature. A study of using chilled water in a 100,000 bbl/day CDU has led to an estimated fuel saving of $12.2 \mathrm{MBtu} / \mathrm{hr}$ for a 5\% increase in cooling duty (2.5 MBtu/hr) (Petrick and Pellegrino, 1999), assuming the use of chilled water with a temperature of $50^{\circ} \mathrm{F}$. The payback period was estimated at 1 to 2 years, however, excluding the investments to change the tray design in the distillation tower. This technology is not yet proven in a commercial application. This technology can also be applied in other distillation processes.

Upgrading Column Internals. Damaged or worn internals can result in increased operation costs. As the internals become damaged, efficiency decreases and pressure drops rise. This causes the column to run at a higher reflux rate over time. With an increased reflux rate, energy costs will increase accordingly. Replacing the trays with new ones or adding a high performance packing can have the column operating like the day it was brought online. If 
operating conditions have seriously deviated from designed operating conditions, the investment may have a relative short payback.

New tray designs are marketed and developed for many different applications. When replacing the trays, it will often be worthwhile to consider new efficient tray designs. New tray designs can result in enhanced separation efficiency and decrease pressure drop. This will result in reduced energy consumption. When considering new tray designs, the number of trays should be optimized

Stripper Optimization. Steam is injected into the process stream in strippers. Steam strippers are used in various processes, and especially the CDU is a large user. The strip steam temperature can be too high, and the strip steam use may be too high. Optimization of these parameters can reduce energy use considerably. This optimization can be part of a process integration (or pinch) analysis for the particular unit (see section 9.2).

Progressive Crude Distillation. Technip and Elf (France) developed an energy efficient design for a crude distillation unit, by redesigning the crude preheater and the distillation column. The crude preheat train was separated in several steps to recover fractions at different temperatures. The distillation tower was re-designed to work at low pressure and the outputs were changed to link to the other processes in the refinery and product mix of the refinery. The design resulted in reduced fuel consumption and better heat integration (reducing the net steam production of the CDU). Technip claims up to a 35\% reduction in fuel use when compared to a conventional CDU (Technip, 2000). This technology has been applied in the new refinery constructed at Leuna (Germany) in 1997 and is being used for another new refinery under construction in Europe. Because of the changes in CDU-output and needed changes in intermediate flows, progressive crude distillation is especially suited for new construction or large crude distillation expansion projects. 


\section{Hydrogen Management and Recovery}

Hydrogen is used in the refinery in processes such as hydrocrackers and desulfurization using hydrotreaters. The production of hydrogen is an energy intensive process using naphtha reformers and natural gas-fueled reformers. These processes and other processes also generate gas streams that may contain a certain amount of hydrogen not used in the processes, or generated as by-product of distillation of conversion processes. In addition, different processes have varying quality (purity) demands for the hydrogen feed. Reducing the need for hydrogen make-up will reduce energy use in the reformer and reduce the need for purchased natural gas. Natural gas is an expensive energy input in the refinery process, and lately associated with large fluctuations in prices (especially in California). The major technology developments in hydrogen management within the refinery are hydrogen process integration (or hydrogen cascading) and hydrogen recovery technology (Zagoria and Huycke, 2003). Revamping and retrofitting existing hydrogen networks can increase hydrogen capacity between 3\% and 30\% (Ratan and Vales, 2002).

\subsection{Hydrogen Integration}

Hydrogen network integration and optimization at refineries is a new and important application of pinch analysis (see above). Most hydrogen systems in refineries feature limited integration and pure hydrogen flows are sent from the reformers to the different processes in the refinery. But as the use of hydrogen is increasing, especially in California refineries, the value hydrogen is more and more appreciated. Using the approach of composition curves used in pinch analysis, the production and uses of hydrogen of a refinery can be made visible. This allows identification of the best matches between different hydrogen sources and uses based on quality of the hydrogen streams. It allows the user to select the appropriate and most cost-effective technology for hydrogen purification. A recent improvement of the analysis technology also accounts for gas pressure, to reduce compression energy needs (Hallale, 2001). The analysis method accounts also for costs of piping, besides the costs for generation, fuel use, and compression power needs. It can be used for new and retrofit studies.

The BP refinery at Carson (California), in a project with the California Energy Commission, has executed a hydrogen pinch analysis of the large refinery. Total potential savings of $\$ 4.5$ million on operating costs were identified, but the refinery decided to realize a more costeffective package saving \$3.9 million per year. As part of the plant-wide assessment of the Equilon (Shell) refinery at Martinez, an analysis of the hydrogen network has been included (U.S. DOE-OIT, 2002b). This has resulted in the identification of large energy savings. Further development and application of the analysis method at California refineries, especially as the need for hydrogen is increasing due to reduced future sulfur-content of diesel and other fuels, may result in reduced energy needs at all refineries with hydrogen needs (Khorram and Swaty, 2002). One refinery identified savings of \$6 million/year in hydrogen savings without capital projects (Zagoria and Huycke, 2003).

\subsection{Hydrogen Recovery}

Hydrogen recovery is an important technology development area to improve the efficiency of hydrogen recovery, reduce the costs of hydrogen recovery, and increase the purity of the 
resulting hydrogen flow. Hydrogen can be recovered indirectly by routing low-purity hydrogen streams to the hydrogen plant (Zagoria and Huycke, 2003). Hydrogen can also be recovered from offgases by routing it to the existing purifier of the hydrogen plant, or by installing additional purifiers to treat the offgases and ventgases. Suitable gas streams for hydrogen recovery are the offgases from the hydrocracker, hydrotreater, coker, or FCC. Not only the hydrogen content determines the suitability, but also the pressure, contaminants (i.e., low on sulfur, chlorine and olefins) and tail end components $\left(\mathrm{C}_{5}+\right)$ (Ratan and Vales, 2002). The characteristics of the source stream will also impact the choice of recovery technology. The cost savings of recovered hydrogen are around $50 \%$ of the costs of hydrogen production (Zagoria and Huycke, 2003).

Hydrogen can be recovered using various technologies, of which the most common are pressure swing and thermal swing absorption, cryogenic distillation, and membranes. The choice of separation technology is driven by desired purity, degree of recovery, pressure, and temperature. Various manufacturers supply different types of hydrogen recovery technologies, including Air Products, Air Liquide, and UOP. Membrane technology generally represents the lowest cost option for low product rates, but not necessarily for high flow rates (Zagoria and Hucyke, 2003). For high-flow rates, PSA technology is often the conventional technology of choice. PSA is the common technology to separate hydrogen from the reformer product gas. Hundreds of PSA units are used around the world to recover hydrogen from various gas streams. Cryogenic units are favored if other gases, such as LPG, can be recovered from the gas stream as well. Cryogenic units produce a medium purity hydrogen gas steam (up to $96 \%$ ).

Membranes are an attractive technology for hydrogen recovery in the refinery. If the content of recoverable products is higher than $2-5 \%$ (or preferably $10 \%$ ), recovery may make economic sense (Baker et al., 2000). New membrane applications for the refinery and chemical industries are under development. Membranes for hydrogen recovery from ammonia plants have first been demonstrated about 20 years ago (Baker et al., 2000), and are used in various state-of-the-art plant designs. Refinery offgas flows have a different composition, making different membranes necessary for optimal recovery. Membrane plants have been demonstrated for recovery of hydrogen from hydrocracker offgases. Various suppliers offer membrane technologies for hydrogen recovery in the refining industry, including Air Liquide, Air Products and UOP. Air Liquide and UOP have sold over 100 membrane hydrogen recovery units around the world. Development of low-cost and efficient membranes is an area of research interest to improve cost-effectiveness of hydrogen recovery, and enable the recovery of hydrogen from gas streams with lower concentrations.

At the refinery at Ponca City (Oklahoma, currently owned by ConocoPhilips), a membrane system was installed to recover hydrogen from the waste stream of the hydrotreater, although the energy savings were not quantified (Shaver et al., 1991). Another early study quotes a 6\% reduction in hydrogen makeup after installing a membrane hydrogen recovery unit at a hydrocracker (Glazer et al., 1988). 


\subsection{Hydrogen Production}

Reformer - Adiabatic Pre-Reformer. If there is excess steam available at a plant, a prereformer can be installed at the reformer. Adiabatic steam reforming uses a highly active nickel catalyst to reform a hydrocarbon feed, using waste heat $\left(900^{\circ} \mathrm{F}\right)$ from the convection section of the reformer. This may result in a production increase of as much as $10 \%$ (Abrardo and Khurana, 1995). The Kemira Oy ammonia plant in Rozenburg, the Netherlands, implemented an adiabatic pre-reformer. Energy savings equaled about 4\% of the energy consumption at a payback period between 1 and 3 years (Worrell and Blok, 1994). ChevronTexaco included a pre-reformer in the design of the new hydrogen plant for the El Segundo refinery (California). The technology can also be used to increase the production capacity at no additional energy cost, or to increase the feed flexibility of the reformer. This is especially attractive if a refinery faces increased hydrogen demand to achieve increased desulfurization needs or switches to heavier crudes. Various suppliers provide pre-reformers including Haldor-Topsoe, Süd-Chemie, and Technip-KTI. 


\section{Motors}

Electric motors are used throughout the refinery, and represent over $80 \%$ of all electricity use in the refinery. The major applications are pumps (60\% of all motor use), air compressors (15\% of all motor use), fans (9\%), and other applications (16\%). The following sections discuss opportunities for motors in general (section 13.1), pumps (Chapter 14), compressors (Chapter 15), and fans (Chapter 16). When available, specific examples are listed detailing the refining process to which the measure has been applied and to what success.

Using a "systems approach" that looks at the entire motor system (pumps, compressors, motors, and fans) to optimize supply and demand of energy services often yields the most savings. For example, in pumping, a systems approach analyzes both the supply and demand sides and how they interact, shifting the focus of the analysis from individual components to total system performance. The measures identified below reflect aspects of this system approach including matching speed and load (adjustable speed drives), sizing the system correctly, as well as upgrading system components. However, for optimal savings and performance, the systems approach is recommended. Pumps and compressors are both discussed in more detail in Chapters 14 and 15.

\subsection{Motor Optimization}

Sizing of Motors. Motors and pumps that are sized inappropriately result in unnecessary energy losses. Where peak loads can be reduced, motor size can also be reduced. Correcting for motor oversizing saves $1.2 \%$ of their electricity consumption (on average for the U.S. industry), and even larger percentages for smaller motors (Xenergy, 1998).

Higher Efficiency Motors. High efficiency motors reduce energy losses through improved design, better materials, tighter tolerances, and improved manufacturing techniques. With proper installation, energy efficient motors run cooler and consequently have higher service factors, longer bearing and insulation life and less vibration. Yet, despite these advantages, less than $8 \%$ of U.S. industrial facilities address motor efficiency in specifications when purchasing a motor (Tutterow, 1999).

Typically, high efficiency motors are economically justified when exchanging a motor that needs replacement, but are not economically feasible when replacing a motor that is still working (CADDET, 1994). Typically, motors have an annual failure rate varying between 3 and $12 \%$ (House et al., 2002). Sometimes though, according to a case study by the Copper Development Association (CDA, 2000), even working motor replacements may be beneficial. The payback for individual motors varies based on size, load factor, and running time. The best savings are achieved on motors running for long hours at high loads. When replacing retiring motors, paybacks are typically less than one year from energy savings alone (LBNL et al., 1998).

To be considered energy efficient in the United States, a motor must meet performance criteria published by the National Electrical Manufacturers Association (NEMA). However, most manufacturers offer lines of motors that significantly exceed the NEMA-defined 
criteria (U.S. DOE-OIT, 2001d). NEMA and other organizations have created the "Motor Decisions Matter" campaign to market NEMA approved premium efficient motors to industry (NEMA, 2001). Even these premium efficiency motors may have low a payback period. According to data from the CDA, the upgrade to high efficiency motors, as compared to motors that achieve the minimum efficiency as specified by the Energy Policy Act, have paybacks of less than 15 months for 50 hp motors (CDA, 2001). Because of the fast payback, it usually makes sense not only to buy an energy efficient motor but also to buy the most efficient motor available (LBNL, 1998).

Replacing a motor with a high efficiency motor is often a better choice than rewinding a motor. The practice of rewinding motors currently has no quality or efficiency standards. To avoid uncertainties in performance of the motor, a new high efficiency motor can be purchased instead of rewinding one.

Power Factor. Inductive loads like transformers, electric motors and HID lighting may cause a low power factor. A low power factor may result in increased power consumption, and hence increased electricity costs. The power factor can be corrected by minimizing idling of electric motors, avoiding operation of equipment over its rated voltage, replacing motors by energy efficient motors (see above) and installing capacitors in the AC circuit to reduce the magnitude of reactive power in the system.

Voltage Unbalance. Voltage unbalance degrades the performance and shortens the life of three-phase motors. A voltage unbalance causes a current unbalance, which will result torque pulsations, increased vibration and mechanical stress, increased losses, motor overheating reducing the life of a motor. Voltage unbalances may be caused by faulty operation of power correction equipment, unbalanced transformer bank or open circuit. It is recommended that voltage unbalance at the motor terminals does not exceed 1\%. Even a 1\% unbalance will reduce motor efficiency at part load operation. If the unbalance would increase to $2.5 \%$, motor efficiency will also decrease at full load operation. For a $100 \mathrm{hp}$ motor operating 8000 hours per year, a correction of the voltage unbalance from $2.5 \%$ to $1 \%$ will result in electricity savings of $9,500 \mathrm{kWh}$ or almost $\$ 500$ at an electricity rate of 5 $\mathrm{cts} / \mathrm{kWh}$ (U.S. DOE-OIT, 2000b). By regularly monitoring the voltages at the motor terminal and using annual thermographic inspections of motors, voltage unbalances may be identified. Furthermore, make sure that single-phase loads are evenly distributed and install ground fault indicators. Another indicator for a voltage unbalance is a $120 \mathrm{~Hz}$ vibration (U.S. DOE-OIT, 2000b).

Adjustable Speed Drives (ASDS)/ Variable Speed Drives (VSDs). ASDs better match speed to load requirements for motor operations. Energy use on many centrifugal systems like pumps, fans and compressors is approximately proportional to the cube of the flow rate. Hence, small reductions in flow that are proportional to motor speed can sometimes yield large energy savings. Although they are unlikely to be retrofitted economically, paybacks for installing new ASD motors in new systems or plants can be as low as 1.1 years (Martin et al., 2000). The installation of ASDs improves overall productivity, control and product quality, and reduces wear on equipment, thereby reducing future maintenance costs. 
Variable Voltage Controls (VVCs). In contrast to ASDs, which have variable flow requirements, VVCs are applicable to variable loads requiring constant speed. The principle of matching supply with demand, however, is the same as for ASDs. 


\section{Pumps}

In the petroleum refining industry, about $59 \%$ of all electricity use in motors is for pumps (Xenergy, 1998). This equals $48 \%$ of the total electrical energy in refineries, making pumps the single largest electricity user in a refinery. Pumps are used throughout the entire plant to generate a pressure and move liquids. Studies have shown that over $20 \%$ of the energy consumed by these systems could be saved through equipment or control system changes (Xenergy, 1998).

It is important to note that initial costs are only a fraction of the life cycle costs of a pump system. Energy costs, and sometimes operations and maintenance costs, are much more important in the lifetime costs of a pump system. In general, for a pump system with a lifetime of 20 years, the initial capital costs of the pump and motor make up merely $2.5 \%$ of the total costs (Best Practice Programme, 1998). Depending on the pump application, energy costs may make up about $95 \%$ of the lifetime costs of the pump. Hence, the initial choice of a pump system should be highly dependent on energy cost considerations rather than on initial costs. Optimization of the design of a new pumping system should focus on optimizing the lifecycle costs. Hodgson and Walters (2002) discuss software developed for this purpose (OPSOP) and discuss several case studies in which they show large reductions in energy use and lifetime costs of a complete pumping system. Typically, such an approach will lead to energy savings of $10-17 \%$.

Pumping systems consist of a pump, a driver, pipe installation, and controls (such as adjustable speed drives or throttles) and are a part of the overall motor system, discussed in Section 13.1. Using a "systems approach" on the entire motor system (pumps, compressors, motors and fans) was also discussed in section 13.1. In this section, the pumping systems are addressed; for optimal savings and performance, it is recommended that the systems approach incorporating pumps, compressors, motors and fans be used.

There are two main ways to increase pump system efficiency, aside from reducing use. These are reducing the friction in dynamic pump systems (not applicable to static or "lifting" systems) or adjusting the system so that it draws closer to the best efficiency point (BEP) on the pump curve (Hovstadius, 2002). Correct sizing of pipes, surface coating or polishing and adjustable speed drives, for example, may reduce the friction loss, increasing energy efficiency. Correctly sizing the pump and choosing the most efficient pump for the applicable system will push the system closer to the best efficiency point on the pump curve.

Operations and Maintenance. Inadequate maintenance at times lowers pump system efficiency, causes pumps to wear out more quickly and increases costs. Better maintenance will reduce these problems and save energy. Proper maintenance includes the following (Hydraulic Institute, 1994; LBNL et al., 1999):

- Replacement of worn impellers, especially in caustic or semi-solid applications.

- Bearing inspection and repair.

- Bearing lubrication replacement, once annually or semiannually.

- Inspection and replacement of packing seals. Allowable leakage from packing seals is usually between two and sixty drops per minute. 
- Inspection and replacement of mechanical seals. Allowable leakage is typically one to four drops per minute.

- Wear ring and impeller replacement. Pump efficiency degrades from 1 to 6 points for impellers less than the maximum diameter and with increased wear ring clearances (Hydraulic Institute, 1994).

- Pump/motor alignment check.

Typical energy savings for operations and maintenance are estimated to be between 2 and $7 \%$ of pumping electricity use for the U.S. industry. The payback is usually immediate to one year (Xenergy, 1998; U.S. DOE-OIT, 2002c).

Monitoring. Monitoring in conjunction with operations and maintenance can be used to detect problems and determine solutions to create a more efficient system. Monitoring can determine clearances that need be adjusted, indicate blockage, impeller damage, inadequate suction, operation outside preferences, clogged or gas-filled pumps or pipes, or worn out pumps. Monitoring should include:

- Wear monitoring

- Vibration analyses

- Pressure and flow monitoring

- Current or power monitoring

- Differential head and temperature rise across the pump (also known as thermodynamic monitoring)

- Distribution system inspection for scaling or contaminant build-up

Reduce Need. Holding tanks can be used to equalize the flow over the production cycle, enhancing energy efficiency and potentially reducing the need to add pump capacity. In addition, bypass loops and other unnecessary flows should be eliminated. Energy savings may be as high as $5-10 \%$ for each of these steps (Easton Consultants, 1995). Total head requirements can also be reduced by lowering process static pressure, minimizing elevation rise from suction tank to discharge tank, reducing static elevation change by use of siphons, and lowering spray nozzle velocities.

More Efficient Pumps. According to inventory data, 16\% of pumps are more than 20 years old. Pump efficiency may degrade 10 to $25 \%$ in its lifetime (Easton Consultants, 1995). Newer pumps are 2 to 5\% more efficient. However, industry experts claim the problem is not necessarily the age of the pump but that the process has changed and the pump does not match the operation. Replacing a pump with a new efficient one saves between 2 to $10 \%$ of its energy consumption (Elliott, 1994). Higher efficiency motors have also been shown to increase the efficiency of the pump system 2 to $5 \%$ (Tutterow, 1999).

A number of pumps are available for specific pressure head and flow rate capacity requirements. Choosing the right pump often saves both in operating costs and in capital costs (of purchasing another pump). For a given duty, selecting a pump that runs at the highest speed suitable for the application will generally result in a more efficient selection as well as the lowest initial cost (Hydraulic Institute and Europump, 2001). Exceptions to this 
include slurry handling pumps, high specific speed pumps, or where the pump would need a very low minimum net positive suction head at the pump inlet.

Correct Sizing Of Pump(s) (Matching Pump To Intended Duty). Pumps that are sized inappropriately result in unnecessary losses. Where peak loads can be reduced, pump size can also be reduced. Correcting for pump oversizing can save 15 to 25\% of electricity consumption for pumping (on average for the U.S. industry) (Easton Consultants, 1995). In addition, pump load may be reduced with alternative pump configurations and improved O\&M practices.

Where pumps are dramatically oversized, speed can be reduced with gear or belt drives or a slower speed motor. This practice, however, is not common. Paybacks for implementing these solutions are less than one year (OIT, 2002a).

The Chevron Refinery in Richmond, California, identified two large horsepower secondary pumps at the blending and shipping plant that were inappropriately sized for the intended use and needed throttling when in use. The $400 \mathrm{hp}$ and $700 \mathrm{hp}$ pump were replaced by two 200 hp pumps, and also equipped with adjustable speed drives. The energy consumption was reduced by 4.3 million $\mathrm{kWh}$ per year, and resulted in annual savings of \$215,000 (CEC, 2001). With investments of $\$ 300,000$ the payback period was 1.4 years.

The Welches Point Pump Station, a medium sized waste water treatment plant located in Milford (CT), as a participant in the Department of Energy's Motor Challenge Program, decided to replace one of their system's three identical pumps with one smaller model (Flygt, 2002). They found that the smaller pump could more efficiently handle typical system flows and the remaining two larger pumps could be reserved for peak flows. While the smaller pump needed to run longer to handle the same total volume, its slower pace and reduced pressure resulted in less friction-related losses and less wear and tear. Substituting the smaller pump has a projected savings of $36,096 \mathrm{~kW}$, more than $20 \%$ of the pump system's annual electrical energy consumption. Using this system at each of the city's 36 stations would result in energy savings of over $\$ 100,000$. In addition to the energy savings projected, less wear on the system results in less maintenance, less downtime and longer life of the equipment. The station noise is significantly reduced with the smaller pump.

Use Multiple Pumps. Often using multiple pumps is the most cost-effective and most energy efficient solution for varying loads, particularly in a static head-dominated system. Installing parallel systems for highly variable loads saves 10 to $50 \%$ of the electricity consumption for pumping (on average for the U.S. industry) (Easton Consultants, 1995). Variable speed controls should also be considered for dynamic systems (see below). Parallel pumps also offer redundancy and increased reliability. One case study of a Finnish pulp and paper plant indicated that installing an additional small pump (a "pony pump"), running in parallel to the existing pump used to circulate water from the paper machine into two tanks, reduced the load in the larger pump in all cases except for startup. The energy savings were estimated at \$36,500 (or $486 \mathrm{MWh}, 58 \%$ ) per year giving a payback of 0.5 years (Hydraulic Institute and Europump, 2001). 
Trimming Impeller (or Shaving Sheaves). If a large differential pressure exists at the operating rate of flow (indicating excessive flow), the impeller (diameter) can be trimmed so that the pump does not develop as much head. In the food processing, paper and petrochemical industries, trimming impellers or lowering gear ratios is estimated to save as much as $75 \%$ of the electricity consumption for specific pump applications (Xenergy, 1998).

In one case study in the chemical processing industry, the impeller was reduced from 320 $\mathrm{mm}$ to $280 \mathrm{~mm}$, which reduced the power demand by more than 25\% (Hydraulic Institute and Europump, 2001). Annual energy demand was reduced by 83 MWh (26\%). With an investment cost of $\$ 390$ (US), the payback on energy savings alone was 23 days. In addition to energy savings, maintenance costs were reduced, system stability was improved, cavitation was reduced, and excessive vibration and noise were eliminated.

In another case study, Salt Union Ltd., the largest salt producer in the UK, trimmed the diameter of a pump impeller at its plant from $320 \mathrm{~mm}$ to $280 \mathrm{~mm}$ (13 to 11 inches) (Best Practice Programme, 1996b). After trimming the impeller, they found significant power reductions of $30 \%$, or $197,000 \mathrm{kWh}$ per year $(710 \mathrm{GJ} /$ year), totaling 8,900 GBP $(\$ 14,000$ 1994 US). With an investment cost of 260 GBP (\$400 1993 US), and maintenance savings of an additional 3,000 GBP (\$4,600 1994 US), this resulted in a payback of 8 days (11 days from energy savings alone). In addition to energy and maintenance savings, like the chemical processing plant, cavitation was reduced and excessive vibration and noise were eliminated. With the large decrease in power consumption, the $110 \mathrm{~kW}$ motor could be replaced with a 75kW motor, with additional energy savings of about 16,000 kWh per year.

Controls. The objective of any control strategy is to shut off unneeded pumps or reduce the load of individual pumps until needed. Remote controls enable pumping systems to be started and stopped more quickly and accurately when needed, and reduce the required labor. In 2000, Cisco Systems (CA) upgraded the controls on its fountain pumps to turn off the pumps during peak hours (CEC and OIT, 2002). The wireless control system was able to control all pumps simultaneously from one location. The project saved $\$ 32,000$ and 400,000 $\mathrm{kWh}$ annually, representing a savings of $61.5 \%$ of the fountain pumps' total energy consumption. With a total cost of $\$ 29,000$, the simple payback was 11 months. In addition to energy savings, the project reduced maintenance costs and increased the pumping system's equipment life.

Adjustable Speed Drives (ASDs). ASDs better match speed to load requirements for pumps where, as for motors, energy use is approximately proportional to the cube of the flow rate ${ }^{10}$. Hence, small reductions in flow that are proportional to pump speed may yield large energy savings. New installations may result in short payback periods. In addition, the installation of ASDs improves overall productivity, control, and product quality, and reduces wear on equipment, thereby reducing future maintenance costs.

\footnotetext{
${ }^{10}$ This equation applies to dynamic systems only. Systems that solely consist of lifting (static head systems) will accrue no benefits from (but will often actually become more inefficient) ASDs because they are independent of flow rate. Similarly, systems with more static head will accrue fewer benefits than systems that are largely dynamic (friction) systems. More careful calculations must be performed to determine actual benefits, if any, for these systems.
} 
According to inventory data collected by Xenergy (1998), 82\% of pumps in U.S. industry have no load modulation feature (or ASD). Similar to being able to adjust load in motor systems, including modulation features with pumps is estimated to save between 20 and $50 \%$ of pump energy consumption, at relatively short payback periods, depending on application, pump size, load and load variation (Xenergy, 1998; Best Practice Programme, 1996a). As a general rule of thumb, unless the pump curves are exceptionally flat, a $10 \%$ regulation in flow should produce pump savings of $20 \%$ and $20 \%$ regulation should produce savings of 40\% (Best Practice Programme, 1996a).

The ChevronTexaco refinery in Richmond (California) upgraded the feed pumps of the diesel hydrotreater by installing an ASD on a 2,250 hp primary feed pump, as well as changing the operation procedures for a backup pump system. The cost savings amount to $\$ 700,000 / y e a r$ reducing electricity consumption by $12 \mathrm{GWh} /$ year. The pump system retrofit was implemented as part of a demand side management program by the local utility. The refinery did not have to put up any investment capital as it participated in this program (U.S. DOE-OIT, 1999).

Hodgson and Walters (2002) discuss the application of an ASD to replace a throttle of a new to build pumping system. Optimization of the design using a dedicated software package led to the recommendation to install an ASD. This would result in 71\% lower energy costs over the lifetime of the system, a 54\% reduction in total lifetime costs of the system.

Avoid Throttling Valves. Throttling valves should always be avoided. Extensive use of throttling valves or bypass loops may be an indication of an oversized pump (Tutterow et al., 2000). Variable speed drives or on off regulated systems always save energy compared to throttling valves (Hovstadius, 2002).

An audit of the 25,000 bpd Flying J Refinery in Salt Lake City (Utah) identified throttle losses at two $200 \mathrm{hp}$ charge pumps. Minimizing the throttle losses would result in potential energy cost savings of $\$ 39,000$ (Brueske et al., 2002). The shutdown of a 250 hp pump when not needed and the minimization of throttle losses would result in additional savings of $\$ 28,000$ per year.

Correct Sizing Of Pipes. Similar to pumps, undersized pipes also result in unnecessary losses. The pipe work diameter is selected based on the economy of the whole installation, the required lowest flow velocity, and the minimum internal diameter for the application, the maximum flow velocity to minimize erosion in piping and fittings, and plant standard pipe diameters. Increasing the pipe diameter may save energy but must be balanced with costs for pump system components. Easton Consultants (1995) and others in the pulp and paper industry (Xenergy, 1998) estimate retrofitting pipe diameters saves 5 to 20\% of their energy consumption, on average for the U.S. industry. Correct sizing of pipes should be done at the design or system retrofit stages where costs may not be restrictive.

Replace Belt Drives. Inventory data suggests $4 \%$ of pumps have V-belt drives, many of which can be replaced with direct couplings to save energy (Xenergy, 1998). Savings are estimated at 1\% (on average for the U.S. industry) (Xenergy, 1998). 
Precision Castings, Surface Coatings, Or Polishing. The use of castings, coatings, or polishing reduces surface roughness that in turn, increases energy efficiency. It may also help maintain efficiency over time. This measure is more effective on smaller pumps. One case study in the steel industry analyzed the investment in surface coating on the mill supply pumps (350 kW pumps). They determined that the additional cost of coating, $\$ 1,200$, would be paid back in 5 months by energy savings of $\$ 2,700$ (or $36 \mathrm{MWh}, 2 \%$ ) per year (Hydraulic Institute and Europump, 2001). Energy savings for coating pump surfaces are estimated to be 2 to 3\% over uncoated pumps (Best Practice Programme, 1998).

Sealings. Seal failure accounts for up to $70 \%$ of pump failures in many applications (Hydraulic Institute and Europump, 2001). The sealing arrangements on pumps will contribute to the power absorbed. Often the use of gas barrier seals, balanced seals, and nocontacting labyrinth seals optimize pump efficiency.

Curtailing Leakage Through Clearance Reduction. Internal leakage losses are a result of differential pressure across the clearance between the impeller and the pump casing. The larger the clearance, the greater is the internal leakage causing inefficiencies. The normal clearance in new pumps ranges from 0.35 to $1.0 \mathrm{~mm}$ (0.014 to $0.04 \mathrm{in}$.) (Hydraulic Institute and Europump, 2001). With wider clearances, the leakage increases almost linearly with the clearance. For example, a clearance of $5 \mathrm{~mm}$ (0.2 in.) decreases the efficiency by 7 to $15 \%$ in closed impellers and by 10 to $22 \%$ in semi-open impellers. Abrasive liquids and slurries, even rainwater, can affect the pump efficiency. Using very hard construction materials (such as stainless steel) can reduce the wear rate.

Dry Vacuum Pumps. Dry vacuum pumps were introduced in the semiconductor industry in Japan in the mid-1980s, and were introduced in the U.S. chemical industry in the late 1980s. The advantages of a dry vacuum pump are high energy efficiency, increased reliability, and reduced air and water pollution. It is expected that dry vacuum pumps will displace oilsealed pumps (Ryans and Bays, 2001). Dry pumps have major advantages in applications where contamination is a concern. Due to the higher investment costs of a dry pump, it is not expected to make inroads in the petroleum refining industry in a significant way, except for special applications where contamination and pollution control are an important driver. 


\section{Compressors and Compressed Air}

Compressors consume about $12 \%$ of total electricity use in refineries, or an estimated 5,800 GWh. The major energy users are compressors for furnace combustion air and gas streams in the refinery. Large compressors can be driven by electric motors, steam turbines, or gas turbines. A relatively small part of energy consumption of compressors in refineries is used to generate compressed air. Compressed air is probably the most expensive form of energy available in an industrial plant because of its poor efficiency. Typically, efficiency from start to end-use is around $10 \%$ for compressed air systems (LBNL et al., 1998). In addition, the annual energy cost required to operate compressed air systems is greater than their initial cost. Because of this inefficiency and the sizeable operating costs, if compressed air is used, it should be of minimum quantity for the shortest possible time, constantly monitored and reweighed against alternatives. Because of its limited use in a refinery (but still an inefficient source of energy), the main compressed air measures found in other industries are highlighted. Many opportunities to reduce energy in compressed air systems are not prohibitively expensive; payback periods for some options are extremely short - less than one year.

Compressed Air - Maintenance. Inadequate maintenance can lower compression efficiency, increase air leakage or pressure variability and lead to increased operating temperatures, poor moisture control and excessive contamination. Better maintenance will reduce these problems and save energy. Proper maintenance includes the following (LBNL et al., 1998, unless otherwise noted):

- Blocked pipeline filters increase pressure drop. Keep the compressor and intercooling surfaces clean and foul-free by inspecting and periodically cleaning filters. Seek filters with just a 1 psi pressure drop. Payback for filter cleaning is usually under 2 years (Ingersoll-Rand, 2001). Fixing improperly operating filters will also prevent contaminants from entering into equipment and causing them to wear out prematurely. Generally, when pressure drop exceeds 2 to 3 psig replace the particulate and lubricant removal elements. Inspect all elements at least annually. Also, consider adding filters in parallel to decrease air velocity and, therefore, decrease pressure drop. A $2 \%$ reduction of annual energy consumption in compressed air systems is projected for more frequent filter changing (Radgen and Blaustein, 2001). However, one must be careful when using coalescing filters; efficiency drops below $30 \%$ of design flow (Scales, 2002).

- Poor motor cooling can increase motor temperature and winding resistance, shortening motor life, in addition to increasing energy consumption. Keep motors and compressors properly lubricated and cleaned. Compressor lubricant should be sampled and analyzed every 1000 hours and checked to make sure it is at the proper level. In addition to energy savings, this can help avoid corrosion and degradation of the system.

- Inspect fans and water pumps for peak performance.

- Inspect drain traps periodically to ensure they are not stuck in either the open or closed position and are clean. Some users leave automatic condensate traps partially open at all times to allow for constant draining. This practice wastes substantial 
amounts of energy and should never be undertaken. Instead, install simple pressure driven valves. Malfunctioning traps should be cleaned and repaired instead of left open. Some automatic drains do not waste air, such as those that open when condensate is present. According to vendors, inspecting and maintaining drains typically has a payback of less than 2 years (Ingersoll-Rand, 2001).

- Maintain the coolers on the compressor to ensure that the dryer gets the lowest possible inlet temperature (Ingersoll-Rand, 2001).

- Check belts for wear and adjust them. A good rule of thumb is to adjust them every 400 hours of operation.

- Check water-cooling systems for water quality (pH and total dissolved solids), flow and temperature. Clean and replace filters and heat exchangers per manufacturer's specifications.

- Minimize leaks (see also Reduce leaks section, below).

- Specify regulators that close when failed.

- Applications requiring compressed air should be checked for excessive pressure, duration or volume. They should be regulated, either by production line sectioning or by pressure regulators on the equipment itself. Equipment not required to operate at maximum system pressure should use a quality pressure regulator. Poor quality regulators tend to drift and lose more air. Otherwise, the unregulated equipment operates at maximum system pressure at all times and wastes the excess energy. System pressures operating too high also result in shorter equipment life and higher maintenance costs.

Monitoring. Proper monitoring (and maintenance) can save a lot of energy and money in compressed air systems. Proper monitoring includes the following (CADDET, 1997):

- Pressure gauges on each receiver or main branch line and differential gauges across dryers, filters, etc.

- Temperature gauges across the compressor and its cooling system to detect fouling and blockages

- Flow meters to measure the quantity of air used

- Dew point temperature gauges to monitor the effectiveness of air dryers

- $\mathrm{kWh}$ meters and hours run meters on the compressor drive

- Compressed air distribution systems should be checked when equipment has been reconfigured to be sure no air is flowing to unused equipment or obsolete parts of the compressed air distribution system.

- Check for flow restrictions of any type in a system, such as an obstruction or roughness. These require higher operating pressures than are needed. Pressure rise resulting from resistance to flow increases the drive energy on the compressor by $1 \%$ of connected power for every 2 psi of differential (LBNL et al., 1998; IngersollRand, 2001). Highest pressure drops are usually found at the points of use, including undersized or leaking hoses, tubes, disconnects, filters, regulators, valves, nozzles and lubricators (demand side), as well as air/lubricant separators, aftercoolers, moisture separators, dryers and filters.

Reduce leaks (in pipes and equipment). Leaks can be a significant source of wasted energy. A typical plant that has not been well maintained could have a leak rate between 20 
to $50 \%$ of total compressed air production capacity (Ingersoll Rand, 2001). Leak repair and maintenance can sometimes reduce this number to less than 10\%. Overall, a 20\% reduction of annual energy consumption in compressed air systems is projected for fixing leaks (Radgen and Blaustein, 2001).

The magnitude of a leak varies with the size of the hole in the pipes or equipment. A compressor operating 2,500 hours per year at 6 bar (87 psi) with a leak diameter of 0.02 inches $(1 / 2 \mathrm{~mm})$ is estimated to lose $250 \mathrm{kWh} /$ year; $0.04 \mathrm{in}$. (1 mm) to lose 1,100 kWh/year; $0.08 \mathrm{in}$. $(2 \mathrm{~mm})$ to lose $4,500 \mathrm{kWh} /$ year; and $0.16 \mathrm{in}$. (4 mm) to lose $11,250 \mathrm{kWh} /$ year (CADDET, 1997).

In addition to increased energy consumption, leaks can make pneumatic systems/equipment less efficient and adversely affect production, shorten the life of equipment, and lead to additional maintenance requirements and increased unscheduled downtime. Leaks cause an increase in compressor energy and maintenance costs. The most common areas for leaks are couplings, hoses, tubes, fittings, pressure regulators, open condensate traps and shut-off valves, pipe joints, disconnects, and thread sealants. Quick connect fittings always leak and should be avoided. A simple way to detect large leaks is to apply soapy water to suspect areas. The best way to detect leaks is to use an ultrasonic acoustic detector, which can recognize the high frequency hissing sounds associated with air leaks. After identification, leaks should be tracked, repaired, and verified. Leak detection and correction programs should be ongoing efforts.

A retrofit of the compressed air system of a Mobil distribution facility in Vernon (CA) led to the replacement of a compressor by a new $50 \mathrm{hp}$ compressor and the repair of air leaks in the system. The annual energy savings amounted to $\$ 20,700$, and investments were equal to $\$ 23,000$, leading to a payback period of just over 1 year (U.S. DOE-OIT, 2003b).

Reducing the Inlet Air Temperature. Reducing the inlet air temperature reduces energy used by the compressor. In many plants, it is possible to reduce inlet air temperature to the compressor by taking suction from outside the building. Importing fresh air has paybacks of up to 5 years, depending on the location of the compressor air inlet (CADDET, 1997). As a rule of thumb, each $5^{\circ} \mathrm{F}\left(3^{\circ} \mathrm{C}\right)$ will save $1 \%$ compressor energy use (CADDET, 1997; Parekh, 2000).

Maximize Allowable Pressure Dew Point at Air Intake. Choose the dryer that has the maximum allowable pressure dew point, and best efficiency. A rule of thumb is that desiccant dryers consume 7 to $14 \%$ of the total energy of the compressor, whereas refrigerated dryers consume 1 to $2 \%$ as much energy as the compressor (Ingersoll Rand, 2001). Consider using a dryer with a floating dew point. Note that where pneumatic lines are exposed to freezing conditions, refrigerated dryers are not an option.

Controls. Remembering that the total air requirement is the sum of the average air consumption for pneumatic equipment, not the maximum for each, the objective of any control strategy is to shut off unneeded compressors or delay bringing on additional compressors until needed. All compressors that are on should be running at full load, except 
for one, which should handle trim duty. Positioning of the control loop is also important; reducing and controlling the system pressure downstream of the primary receiver results in reduced energy consumption of up to $10 \%$ or more (LBNL et al., 1998). Radgen and Blaustein (2001) report energy savings for sophisticated controls to be $12 \%$ annually. Start/stop, load/unload, throttling, multi-step, variable speed, and network controls are options for compressor controls and described below.

Start/stop (on/off) is the simplest control available and can be applied to small reciprocating or rotary screw compressors. For start/stop controls, the motor driving the compressor is turned on or off in response to the discharge pressure of the machine. They are used for applications with very low duty cycles. Applications with frequent cycling will cause the motor to overheat. Typical payback for start/stop controls is 1 to 2 years (CADDET, 1997).

Load/unload control, or constant speed control, allows the motor to run continuously but unloads the compressor when the discharge pressure is adequate. In most cases, unloaded rotary screw compressors still consume 15 to $35 \%$ of full-load power when fully unloaded, while delivering no useful work (LBNL et al., 1998). Hence, load/unload controls may be inefficient and require ample receiver volume.

Modulating or throttling controls allows the output of a compressor to be varied to meet flow requirements by closing down the inlet valve and restricting inlet air to the compressor. Throttling controls are applied to centrifugal and rotary screw compressors. Changing the compressor control to a variable speed control has saved up to $8 \%$ per year (CADDET, 1997). Multi-step or part-load controls can operate in two or more partially loaded conditions. Output pressures can be closely controlled without requiring the compressor to start/stop or load/unload.

Properly Sized Regulators. Regulators sometimes contribute to the biggest savings in compressed air systems. By properly sizing regulators, compressed air will be saved that is otherwise wasted as excess air. Also, it is advisable to specify pressure regulators that close when failing.

Sizing Pipe Diameter Correctly. Inadequate pipe sizing can cause pressure losses, increase leaks, and increase generating costs. Pipes must be sized correctly for optimal performance or resized to fit the current compressor system. Increasing pipe diameter typically reduces annual energy consumption by 3\% (Radgen and Blaustein, 2001).

Heat Recovery For Water Preheating. As much as 80 to 93\% of the electrical energy used by an industrial air compressor is converted into heat. In many cases, a heat recovery unit can recover 50 to $90 \%$ of the available thermal energy for space heating, industrial process heating, water heating, makeup air heating, boiler makeup water preheating, industrial drying, industrial cleaning processes, heat pumps, laundries or preheating aspirated air for oil burners (Parekh, 2000). Paybacks are typically less than one year. With large watercooled compressors, recovery efficiencies of 50 to $60 \%$ are typical (LBNL et al., 1998). Implementing this measure recovers up to $20 \%$ of the energy used in compressed air systems annually for space heating (Radgen and Blaustein, 2001). 
Adjustable Speed Drives (ASDs). Implementing adjustable speed drives in rotary compressor systems has saved 15\% of the annual compressed air energy consumption (Radgen and Blaustein, 2001). The profitability of installing an ASD on a compressor depends strongly on the load variation of the particular compressor. When there are strong variations in load and/or ambient temperatures there will be large swings in compressor load and efficiency. In those cases, or where electricity prices are relatively high ( $>4 \mathrm{cts} / \mathrm{kWh}$ ) installing an ASD may result in attractive payback periods (Heijkers et al., 2000).

High Efficiency Motors. Installing high efficiency motors in compressor systems reduces annual energy consumption by $2 \%$, and has a payback of less than 3 years (Radgen and Blaustein, 2001). For compressor systems, the largest savings in motor performance are typically found in small machines operating less than 10kW (Radgen and Blaustein, 2001). 


\section{Fans}

Fans are used in boilers, furnaces, cooling towers, and many other applications. As in other motor applications, considerable opportunities exist to upgrade the performance and improve the energy efficiency of fan systems. Efficiencies of fan systems vary considerably across impeller types (Xenergy, 1998). However, the cost-effectiveness of energy efficiency opportunities depends strongly on the characteristics of the individual system.

Fan Oversizing. Most of the fans are oversized for the particular application, which can result in efficiency losses of 1-5\% (Xenergy, 1998). However, it may often be more costeffective to control the speed (see below with adjustable speed drives) than to replace the fan system.

Adjustable Speed Drive (ASD). Significant energy savings can be achieved by installing adjustable speed drives on fans. Savings may vary between 14 and $49 \%$ when retrofitting fans with ASDs (Xnergy, 1998).

An audit of the Paramount Petroleum Corp.'s asphalt refinery in Paramount (California) identified the opportunity to install ASDs on six motors in the cooling tower (ranging from $40 \mathrm{hp}$ to $125 \mathrm{hp}$ ). The motors are currently operated manually, and are oversized for operation in the winter. If ASDs were installed at all six motors to maintain the cold-water temperature set point electricity savings of 1.2 million $\mathrm{kWh} /$ year could be achieved (U.S. DOE-OIT, 2003b). The payback would vary be relatively high due to the size of the motors and was to be around 5.8 years, resulting in annual savings of $\$ 46,000$.

High Efficiency Belts (Cog Belts). Belts make up a variable, but significant portion of the fan system in many plants. It is estimated that about half of the fan systems use standard Vbelts, and about two-thirds of these could be replaced by more efficient cog belts (Xenergy, 1998). Standard V-belts tend to stretch, slip, bend and compress, which lead to a loss of efficiency. Replacing standard V-belts with cog belts can save energy and money, even as a retrofit. Cog belts run cooler, last longer, require less maintenance and have an efficiency that is about $2 \%$ higher than standard V-belts. Typical payback periods will vary from less than one year to three years. 


\section{Lighting}

Lighting and other utilities represent less than 3\% of electricity use in refineries. Still, potential energy efficiency improvement measures exist, and may contribute to an overall energy management strategy. Because of the relative minor importance of lighting and other utilities, this Energy Guide focuses on the most important measures that can be undertaken. Additional information on lighting guidelines and efficient practices is available from the Illuminating Engineering Society of North America (www.iesna.org) and the California Energy Commission (CEC, 2003).

Lighting Controls. Lights can be shut off during non-working hours by automatic controls, such as occupancy sensors, which turn off lights when a space becomes unoccupied. Manual controls can also be used in addition to automatic controls to save additional energy in small areas.

Replace T-12 Tubes by T-8 Tubes or Metal Halides. T-12 refers to the diameter in $1 / 8$ inch increments (T-12 means 12/8 inch or $3.8 \mathrm{~cm}$ diameter tubes). The initial output for T12 lights is high, but energy consumption is also high. T-12 tubes have poor efficacy, lamp life, lumen depreciation and color rendering index. Because of this, maintenance and energy costs are high. Replacing T-12 lamps with T-8 lamps approximately doubles the efficacy of the former. It is important to remember, however, to work both with the suppliers and manufacturers on the system through each step of the retrofit process. There are a number of T-8 lights and ballasts on the market and the correct combination should be chosen for each system.

Ford North America paint shops retrofitted eleven of their twenty-one paint shops and saw lighting costs reduced by more than 50\% (DEQ, 2001). Initial light levels were lower, but because depreciation is less, the maintained light level is equal and the new lamps last two to three times longer. Energy savings totaled 17.5 million kWh annually; operation savings were \$500,000 per year. The Gillette Company manufacturing facility in Santa Monica, California replaced $4300 \mathrm{~T}-12$ lamps with 496 metal halide lamps in addition to replacing 10 manual switches with 10 daylight switches (EPA, 2001). They reduced electricity use by $58 \%$ and saved $\$ 128,608$ annually. The total project cost was $\$ 176,534$, producing a payback of less than 1.5 years.

Replace Mercury Lights by Metal Halide or High-Pressure Sodium Lights. In industries where color rendition is critical, metal halide lamps save 50\% compared to mercury or fluorescent lamps (Price and Ross, 1989). Where color rendition is not critical, high-pressure sodium lamps offer energy savings of 50 to $60 \%$ compared to mercury lamps (Price and Ross, 1989). High-pressure sodium and metal halide lamps also produce less heat, reducing HVAC loads. In addition to energy reductions, the metal halide lights provide better lighting, provide better distribution of light across work surfaces, improve color rendition, and reduce operating costs (GM, 2001).

Replace Standard Metal Halide HID With High-Intensity Fluorescent Lights. Traditional HID lighting can be replaced with high-intensity fluorescent lighting. These new 
systems incorporate high efficiency fluorescent lamps, electronic ballasts, and high-efficacy fixtures that maximize output to the workspace. Advantages of the new system are many: lower energy consumption, lower lumen depreciation over the lifetime of the lamp, better dimming options, faster start-up and restrike capability, better color rendition, higher pupil lumens ratings, and less glare (Martin et al., 2000). High-intensity fluorescent systems yield $50 \%$ electricity savings over standard metal halide HID. Dimming controls that are impractical in the metal halide HIDs save significant energy in the new system. Retrofitted systems cost about $\$ 185$ per fixture, including installation costs (Martin et al., 2000). In addition to energy savings and better lighting qualities, high-intensity fluorescents may help improve productivity and have reduced maintenance costs.

Replace Magnetic Ballasts With Electronic Ballasts. A ballast is a mechanism that regulates the amount of electricity required to start a lighting fixture and maintain a steady output of light. Electronic ballasts save 12 to $25 \%$ power over their magnetic predecessors (EPA, 2001). Electronic ballasts have dimming capabilities as well (Eley et al., 1993). If automatic daylight sensing, occupancy sensing and manual dimming are included with the ballasts, savings can be greater than 65\% (Turiel et al., 1995).

Reflectors. A reflector is a highly polished "mirror-like" component that directs light downward, reducing light loss within a fixture. Reflectors can minimize required wattage effectively.

Light Emitting Diodes (LEDs) or Radium Lights. One way to reduce energy costs is simply switching from incandescent lamps to LEDs or radium strips in exit sign lighting. LEDs use about 90\% less energy than conventional exit signs (Anaheim Public Utilities, 2001). A 1998 Lighting Research Center survey found that about 80 percent of exit signs being sold use LEDs (LRC, 2001). In addition to exit signs, LEDs are increasingly being used for path marking and emergency way finding systems. Their long life and cool operation allows them to be embedded in plastic materials, which makes them perfect for these applications. Radium strips use no energy at all and can be used similarly.

The Flying J Refinery in North Salt Lake (Utah) replaced exit signs by new LED signs saving about $\$ 1,200 /$ year.

System Improvements. By combining several of the lighting measures above, light system improvements can be the most effective and comprehensive way to reduce lighting energy. High frequency ballasts and specular reflectors can be combined with $50 \%$ fewer efficient high-frequency fluorescent tubes and produce $90 \%$ as much light while saving 50 to $60 \%$ of the energy formerly used (Price and Ross, 1989). An office building in Michigan reworked their lighting system using high-efficiency fluorescent ballasts and reduced lighting load by $50 \%$ and total building electrical load by nearly $10 \%$ (Price and Ross, 1989). Similar results were obtained in a manufacturing facility when replacing fluorescent fixtures with metal halide lamps. Often these system improvements improve lighting as well as decrease energy consumption. 
Reducing system voltage may also save energy. One U.S. automobile manufacturer put in reduced voltage HID lights and found a 30\% reduction in lighting. Electric City is one of the suppliers of EnergySaver, a unit that attaches to a central panel switch (controllable by computer) and constricts the flow of electricity to fixtures, thereby reducing voltage and saving energy, with an imperceptible loss of light. Bristol Park Industries has patented another lighting voltage controller called the Wattman ${ }^{\odot}$ Lighting Voltage Controller that works with high intensity discharge (HID) and fluorescent lighting systems with similar energy saving results (Bristol Park Industries, 2002). 


\section{Power Generation}

Most refineries have some form of onsite power generation. In fact, refineries offer an excellent opportunity for energy efficient power generation in the form of combined heat and power production (CHP). CHP provides the opportunity to use internally generated fuels for power production, allowing greater independence of grip operation and even export to the grid. This increases reliability of supply as well as the cost-effectiveness. The cost benefits of power export to the grid will depend on the regulation in the state where the refinery is located. Not all states allow wheeling of power (i.e., sales of power directly to another customer using the grid for transport) while the regulation may also differ with respect to the tariff structure for power sales to the grid operator.

\subsection{Combined Heat and Power Generation (CHP)}

The petroleum refining industry is one of the largest users of cogeneration or CHP in the country. Current installed capacity is estimated to be over 6,000 MWe, making it the largest CHP user after the chemical and pulp \& paper industries. Still, only about $10 \%$ of all steam used in refineries is generated in cogeneration units. Hence, the petroleum refining industry is also identified as one of the industries with the largest potential for increased application of CHP. In fact, an efficient refinery can be a net exporter of electricity. The potential for exporting electricity is even enlarged with new innovative technologies currently used commercially at selected petroleum refineries (discussed below). The potential for conventional cogeneration (CHP) installations is estimated at an additional 6,700 MWe (Onsite, 2000), of which most in medium to large-scale gas turbine based installations.

Where process heat, steam, or cooling and electricity are used, cogeneration plants are significantly more efficient than standard power plants because they take advantage of what are losses in conventional power plants by utilizing waste heat. In addition, transportation losses are minimized when CHP systems are located at or near the refinery. Third parties have developed CHP for use by refineries. In this scenario, the third party company owns and operates the system for the refinery, which avoids the capital expenditures associated with CHP projects, but gains (part of) the benefits of a more energy efficient system of heat and electricity supply. In fact, about $60 \%$ of the cogeneration facilities operated within the refinery industry are operated by third party companies (Onsite, 2000). For example, in 2001 BP's Whiting refinery (Indiana) installed a new 525 MW cogeneration unit with a total investment of \$250 million carried by Primary Energy Inc. Many new cogeneration projects can be financed in this way. Other opportunities consist of joint-ventures between the refinery and an energy generation or operator to construct a cogeneration facility.

Optimization of the operation strategy of CHP units and boilers is an area in which additional savings can be achieved. The development of a dispatch optimization program at the Hellenic Aspropyrgos Refinery (Greece) to meet steam and electricity demand demonstrates the potential energy and cost-savings (Frangopoluos et al., 1996).

For systems requiring cooling, absorption cooling can be combined with CHP to use waste heat to produce cooling power. In refineries, refrigeration and cooling consumes about 5-6\% of all electricity. Cogeneration in combination with absorption cooling has been 
demonstrated for building sites and sites with refrigeration leads. The authors do not know of applications in the petroleum refinery industry.

Innovative gas turbine technologies can make CHP more attractive for sites with large variations in heat demand. Steam injected gas turbines (STIG or Cheng cycle) can absorb excess steam, e.g., due to seasonal reduced heating needs, to boost power production by injecting the steam in the turbine. The size of typical STIGs starts around $5 \mathrm{MW}_{\mathrm{e}}$, and is currently scaled up to sizes of 125 MW. STIGs have been installed at over 50 sites worldwide, and are found in various industries and applications, especially in Japan and Europe, as well as in the United States. Energy savings and payback period will depend on the local circumstances (e.g., energy patterns, power sales, conditions). In the United States, the Cheng Cycle is marketed by International Power Systems (San Jose, California). The Austrian oil company OMV has considered the use of a STIG to upgrade an existing cogeneration system. The authors do not know of any current commercial applications of STIG in an oil refinery.

Steam turbines are often used as part of the CHP system in a refinery or as stand-alone systems for power generation. The efficiency of the steam turbine is determined by the inlet steam pressure and temperature as well as the outlet pressure. Each turbine is designed for a certain steam inlet pressure and temperature, and operators should make sure that the steam inlet temperature and pressure are optimal. An $18^{\circ} \mathrm{F}$ decrease in steam inlet temperature will reduce the efficiency of the steam turbine by $1.1 \%$ (Patel and Nath, 2000). Similarly, maintaining exhaust vacuum of a condensing turbine or the outlet pressure of a backpressure turbine too high will result in efficiency losses.

Valero's Houston refinery constructed a 34 MW cogeneration unit in 1990, using two gas turbines and two heat recovery steam generators (boilers). The system supplies all electricity for the refinery and occasionally allows export to the grid. The CHP system has resulted in savings of about $\$ 55,000 /$ day (Valero, 2003).

Even for small refineries, CHP is an attractive option. An audit of the Paramount Petroleum Corp.'s asphalt refinery in Paramount (CA) identified the opportunity to install CHP at this refinery. The audit identified a CHP unit as the largest energy saving measure in this small refinery. A 6.5 MWe gas turbine CHP unit would result in annual energy savings of \$3.8 million and has a payback period 2.5 years (U.S. DOE-OIT, 2003b). In addition, the CHP unit would reduce the risk of power outages for the refinery. The investment costs assume best available control technology for emission reduction. The installation was installed in 2002.

\subsection{Gas Expansion Turbines}

Natural gas is often delivered to a refinery at very high pressures. Gas is transmitted at high pressures, from 200 to 1500 psi. Expansion turbines use the pressure drop when natural gas from high-pressure pipelines is decompressed to generate power or to use in a process heater. An expansion turbine includes both an expansion mechanism and a generator. In an expansion turbine, high-pressure gas is expanded to produce work. Energy is extracted from pressurized gas, which lowers gas pressure and temperature. These turbines have been used 
for air liquefaction in the chemical industry for several decades. The application of expansion turbines as energy recovery devices started in the early 1980s (SDI, 1982b). The technology has much improved since the 1980s and is highly reliable today. A simple expansion turbine consists of an impeller (expander wheel) and a shaft and rotor assembly attached to a generator. Expansion turbines are generally installed in parallel with the regulators that traditionally reduce pressure in gas lines. If flow is too low for efficient generation, or the expansion turbine fails, pressure is reduced in the traditional manner. The drop in pressure in the expansion cycle causes a drop in temperature. While turbines can be built to withstand cold temperatures, most valve and pipeline specifications do not allow temperatures below $-15^{\circ} \mathrm{C}$. In addition, gas can become wet at low temperatures, as heavy hydrocarbons in the gas condense. This necessitates heating the gas just before or after expansion. The heating is generally performed with either a combined heat and power (CHP) unit, or a nearby source of waste heat. Petroleum refineries often have excess lowtemperature waste heat, making a refinery an ideal location for a power recovery turbine. Industrial companies and utilities in Europe and Japan have installed expansion turbine projects. However, it is unknown if any petroleum refineries have installed this technology.

In 1994, the Corus integrated steel mill at IJmuiden (the Netherlands) installed a 2 MW power recovery turbine. The mill receives gas at $930 \mathrm{psi}$, preheats the gas, and expands with the turbine to $120 \mathrm{psi}$. The maximum turbine flow is 1.4 million $\mathrm{ft}^{3} / \mathrm{hr}\left(40,000 \mathrm{~m}^{3} / \mathrm{hr}\right)$ while the average capacity is $65 \%$, resulting in an average flow of 0.9 million $\mathrm{ft}^{3} / \mathrm{hr}$. The turbine uses cooling water from the hot strip mill of approximately $160^{\circ} \mathrm{F}\left(70^{\circ} \mathrm{C}\right)$, to preheat the gas (Lehman and Worrell, 2001). The 2 MW turbine generated roughly 11,000 MWh of electricity in 1994, while the strip mill delivered a maximum of 12,500 MWh of waste heat to the gas flow. Thus, roughly $88 \%$ of the maximum heat input to the high-pressure gas emerged as electricity. The cost of the installation was \$2.6 million, and the operation and maintenance costs total $\$ 110,000$ per year. With total costs of $\$ 110,000$ per year and income of $\$ 710,000$ per year from electricity generation (at the 1994 Dutch electricity cost of 6.5 cents per $\mathrm{kWh}$ ), the payback period for the project is 4.4 years.

\subsection{Steam Expansion Turbines.}

Steam is generated at high pressures, but often the pressure is reduced to allow the steam to be used by different processes. For example, steam is generated at 120 to 150 psig. This steam then flows through the distribution system within the plant. The pressure is reduced to as low as 10-15 psig for use in different process. Once the heat has been extracted, the condensate is often returned to the steam generating plant. Typically, the pressure reduction is accomplished through a pressure reduction valve (PRV). These valves do not recover the energy embodied in the pressure drop. This energy could be recovered by using a micro scale backpressure steam turbine. Several manufactures produce these turbine sets, such as Turbosteam (previously owned by Trigen) and Dresser-Rand.

The potential for application will depend on the particular refinery and steam system used. Applications of this technology have been commercially demonstrated for campus facilities, pulp and paper, food, and lumber industries, but not yet in the petroleum industry. The investments of a typical expansion turbine are estimated at $600 \$ / \mathrm{kWe}$, and operation and maintenance costs at $0.011 \$ / \mathrm{kWh}$. 


\subsection{High-temperature CHP}

Turbines can be pre-coupled to a crude distillation unit (or other continuously operated processes with an applicable temperature range). The offgases of the gas turbine can be used to supply the heat for the distillation furnace, if the outlet temperature of the turbine is high enough. One option is the so-called 'repowering' option. In this option, the furnace is not modified, but the combustion air fans in the furnace are replaced by a gas turbine. The exhaust gases still contain a considerable amount of oxygen, and can thus be used as combustion air for the furnaces. The gas turbine can deliver up to $20 \%$ of the furnace heat. Two of these installations are installed in the Netherlands, with a total capacity of $35 \mathrm{MW}_{\mathrm{e}}$ at refineries (Worrell et al., 1997). A refinery on the West Coast has installed a $16 \mathrm{MW}_{\mathrm{e}}$ gas turbine at a reformer (Terrible et al., 1999). The flue gases of the turbine feed to the convection section of the reformer increasing steam generation. The steam is used to power a $20 \mathrm{MW}_{\mathrm{e}}$ steam turbine.

Another option, with a larger CHP potential and associated energy savings, is "hightemperature CHP”. In this case, the flue gases of a CHP plant are used to heat the input of a furnace or to preheat the combustion air. The potential at U.S. refineries is estimated at 34 GW (Zollar, 2002). This option requires replacing the existing furnaces. This is due to the fact that the radiative heat transfer from gas turbine exhaust gases is much smaller than from combustion gases, due to their lower temperature (Worrell et al., 1997). A distinction is made between two different types. In the first type, the exhaust heat of a gas turbine is led to a waste heat recovery furnace, in which the process feed is heated. In the second type, the exhaust heat is led to a "waste heat oil heater" in which thermal oil is heated. By means of a heat exchanger, the heat content is transferred to the process feed. In both systems, the remaining heat in the exhaust gases after heating the process feed should be used for lower temperature purposes to achieve a high overall efficiency. The second type is more reliable, due to the fact that a thermal oil buffer can be included. The main difference is that in the first type the process feed is directly heated by exhaust gases, where the second uses thermal oil as an intermediate, leading to larger flexibility. An installation of the first type is installed in Fredericia, Denmark at a Shell refinery. The low temperature remaining heat is used for district heating. R\&D has to be aimed at making detailed design studies for specific refineries and the optimization of furnace design, and more demonstration projects have to be carried out.

\subsection{Gasification}

Gasification provides the opportunity for cogeneration using the heavy bottom fraction and refinery residues (Marano, 2003). Because of the increased demand for lighter products and increased use of conversion processes, refineries will have to manage an increasing stream of heavy bottoms and residues. Gasification of the heavy fractions and coke to produce synthesis gas can help to efficiently remove these by-products. The state-of-the-art gasification processes combine the heavy by-products with oxygen at high temperature in an entrained bed gasifier. Due to the limited oxygen supply, the heavy fractions are gasified to a mixture of carbon monoxide and hydrogen. Sulfur can easily be removed in the form of $\mathrm{H}_{2} \mathrm{~S}$ to produce elemental sulfur. The synthesis gas can be used as feedstock for chemical processes. However, the most attractive application seems to be generation of power in an Integrated Gasifier Combined Cycle (IGCC). In this installation the synthesis gas is 
combusted in a gas turbine (with an adapted combustion chamber to handle the low to medium-BTU gas) generating electricity. The hot fluegases are used to generate steam. The steam can be used onsite or used in a steam turbine to produce additional electricity (i.e., the combined cycle). Cogeneration efficiencies can be up to $75 \%$ (LHV) and for power production alone the efficiency is estimated at 38-39\% (Marano, 2003).

Entrained bed IGCC technology is originally developed for refinery applications, but is also used for the gasification of coal. Hence, the major gasification technology developers were oil companies like Shell and Texaco. IGCC provides a low-cost opportunity to reduce emissions (SOx, NOx) when compared to combustion of the residue, and to process the heavy bottoms and residues while producing power and/or feedstocks for the refinery. Potentially about 40 refineries in the United States have a sufficiently large capacity to make the technology attractive (Marano, 2003).

IGCC is used by the Shell refinery in Pernis (the Netherlands) to treat residues from the hydrocracker and other residues to generate 110 MWe of power and 285 tonnes of hydrogen for the refinery. The IPA Falconara refinery (Italy) uses IGCC to treat visbreaker residue to produce 241 MWe of power (Cabooter, 2001). New installations have been announced or are under construction for the refineries at Baytown (ExxonMobil, Texas), Deer Park (Shell, Texas), Sannazzaro (Agip, Italy), Lake Charles, (Citgo, Louisiana) and Bulwer Island (BP, Australia).

The investment costs will vary by capacity and products of the installation. The capital costs of a gasification unit consuming 2,000 tons per day of heavy residue would cost about $\$ 229$ million of the production of hydrogen and \$347 million for an IGCC unit. The operating cost savings will depend on the costs of power, natural gas, and the costs of heavy residue disposal or processing. 


\section{Other Opportunities}

\subsection{Process Changes and Design}

Desalter. Alternative designs for desalting include multi-stage desalters and combination of AC and DC fields. These alternative designs may lead to increased efficiency and lower energy consumption (IPPC, 2002).

Catalytic Reformer - Increased Product Recovery. Product recovery from a reformer may be limited by the temperature of the distillation to separate the various products. An analysis of a reformer at the Colorado Refinery in Commerce City, Colorado (now operated by Valero) showed increased LPG losses at increased summer temperatures. The LPG would either be flared or used as fuel gas. By installing a waste heat driven ammonia absorption refrigeration plant, the recovery temperature was lowered, debottlenecking the compressors and the unsaturated light-cycle oil streams (Petrick and Pellegrino, 1999). The heat pump uses a $290^{\circ} \mathrm{F}$ waste heat stream of the reformer to drive the compressor. The system was installed in 1997 and was supported by the U.S. Department of Energy as a demonstration project. The project resulted in annual savings of 65,000 barrels of LPG. The recovery rate varies with ambient temperature. The liquid product fraction contained a higher percentage of heavier carbon chain $\left(\mathrm{C}_{5}, \mathrm{C}_{6}+\right)$ products. The payback period is estimated at 1.5 years (Brant et al., 1998).

Hydrotreater. Desulfurization is becoming more and more important as probable future regulations will demand a lower sulfur content of fuels. Desulfurization is currently mainly done by hydrotreaters. Hydrotreaters use a considerable amount of energy directly (fuel, steam, electricity) and indirectly (hydrogen). Various alternatives are being developed, but of which many are not yet commercially available (Babich and Moulijn, 2003). New catalysts increase the efficiency of sulfur removal, while new reactor designs are proposed to integrate some of the process steps (e.g., catalytic distillation as used in the CDTech process implemented at Motiva's Port Arthur (TX) refinery. In the future, designs building on process intensification that integrate chemical reactions and separation are proposed. Use of any alternative desulfurization technology to produce low sulfur should be evaluated on the basis of the sulfur content of the naphtha and diesel streams, and on the applicability of the process to the specific conditions of the refinery.

Various alternatives are demonstrated at refineries around the world, including the oxidative desulfurization process (Valero's Krotz Springs, Louisiana) and the S Zorb process at Philip's Borger (TX). The S Zorb process is a sorbent operated in a fluidized bed reactor. Philips Petroleum Co. claims a significant reduction in hydrogen consumption to produce low-sulfur gasoline and diesel (Gislason, 2001). A cursory comparison of the characteristics of the $\mathrm{S}$ Zorb process and that of selected hydrotreaters suggests a lower fuel and electricity consumption, but increased water consumption.

\subsection{Alternative Production Flows}

FCC - Process Flow Changes. The product quality demands and feeds of FCCs may change over time. The process design should remain optimized for this change. Increasing or changing the number of pumparounds can improve energy efficiency of the FCC, as it 
allows increased heat recovery (Golden and Fulton, 2000). A change in pumparounds may affect the potential combinations of heat sinks and sources.

New design and operational tools enable the optimization of FCC operating conditions to enhance product yields. Petrick and Pellegrino (1999) cite studies that have shown that optimization of the FCC unit with appropriate modifications of equipment and operating conditions can increase the yield of high octane gasoline and alkylate from 3\% to $7 \%$ per barrel of crude oil. This would result in energy savings.

\subsection{Other Opportunities}

Flare Optimization. Flares are used to safely dispose of combustible gases and to avoid release to the environment of these gases through combustion/oxidation. All refineries operate flares. Which, in the majority of refineries are used to burn gases in the case of a system upset. Older flare systems have a pilot flame that is burning continuously. This results in losses of natural gas. Also, this may lead to methane (a powerful greenhouse gas) losses to the environment if the pilot flame is extinguished.

Modern flare pilot designs are more efficient using electronic ignition when the flare is needed, have sensors for flame detection and shut off the fuel gas, reducing methane emissions. These systems can reduce average natural gas use to below $45 \mathrm{scf} / \mathrm{hour}$. The spark ignition systems use low electrical power, which can be supplied by photovoltaic (solar cell) system, making the whole system independent of an external power supply. Various systems are marketed by a number of suppliers, e.g., John Zink.

Chevron replaced a continuous burning flare by an electronic ignition system at a refinery, which resulted in savings of 1.68 million scf/year (or $168 \mathrm{MBtu} /$ year), with a payback off less than 3 years.

Heated Storage Tanks. Some storage tanks at the refinery are kept at elevated temperatures to control viscosity of the product stored. Insulation of the tank can reduce the energy losses.

An audit of the Fling J Refinery at North Salt Lake (Utah) found that insulating the top of a 80,000 bbl storage tank that is heated to a temperature of $225^{\circ} \mathrm{F}$ would result in annual savings of \$148,000 (Brueske et al., 2002). 


\section{Summary and Conclusions}

Petroleum refining in the United States is the largest refining industry in the world, providing inputs to virtually any economic sector, including the transport sector and the chemical industry. The industry operates 146 refineries (as of 2004) around the country, employing over 65,000 employees. The refining industry produces a mix of products with a total value exceeding $\$ 151$ billion. Energy costs represents one the largest production cost factors in the petroleum refining industry, making energy efficiency improvement an important way to reduce costs and increase predictable earnings, especially in times of high energy-price volatility.

Voluntary government programs aim to assist industry to improve competitiveness through increased energy efficiency and reduced environmental impact. ENERGY STAR, a voluntary program managed by the U.S. Environmental Protection Agency, stresses the need for strong and strategic corporate energy management programs. ENERGY STAR provides energy management tools and strategies for successful corporate energy management programs. This Energy Guide describes research conducted to support ENERGY STAR and its work with the petroleum refining industry. This research provides information on potential energy efficiency opportunities for petroleum refineries.

Competitive benchmarking data indicates that most petroleum refineries can economically improve energy efficiency by $10-20 \%$. This potential for savings amounts to annual costs savings of millions to tens of millions of dollars for a refinery, depending on current efficiency and size. Improved energy efficiency may result in co-benefits that far outweigh the energy cost savings, and may lead to an absolute reduction in emissions.

This Energy Guide introduced energy efficiency opportunities available for petroleum refineries. It started with descriptions of the production trends, structure and production of the refining industry and the energy used in the refining and conversion processes. Specific energy savings for each energy efficiency measure based on case studies of plants and references to technical literature were provided. The Energy Guide draws upon the experiences with energy efficiency measures of petroleum refineries worldwide. If available, typical payback periods were also listed.

The findings suggest that given available resources and technology, there are opportunities to reduce energy consumption cost-effectively in the petroleum refining industry while maintaining the quality of the products manufactured, underling the results of benchmarking studies. Further research on the economics of the measures, as well as the applicability of these to different refineries, is needed to assess the feasibility of implementation of selected technologies at individual plants. Table 8 summarizes the energy efficiency opportunities. 
Table 8. Summary of energy efficiency opportunities for utilities and cross-cutting energy uses.

\begin{tabular}{|c|c|}
\hline $\begin{array}{l}\text { Management \& Control } \\
\text { Energy monitoring } \\
\text { Site energy control systems }\end{array}$ & $\begin{array}{l}\text { Process Integration } \\
\text { Total site pinch analysis } \\
\text { Water pinch analysis }\end{array}$ \\
\hline $\begin{array}{l}\text { Power Generation } \\
\text { CHP (cogeneration) } \\
\text { Gas expansion turbines } \\
\text { High-Temperature CHP } \\
\text { Gasification (Combined Cycle) }\end{array}$ & $\begin{array}{l}\text { Energy Recovery } \\
\text { Flare gas recovery } \\
\text { Power recovery } \\
\text { Hydrogen recovery } \\
\text { Hydrogen pinch analysis }\end{array}$ \\
\hline $\begin{array}{l}\text { Boilers } \\
\text { Boiler feedwater preparation } \\
\text { Improved boiler controls } \\
\text { Reduced flue gas volume } \\
\text { Reduced excess air } \\
\text { Improve insulation } \\
\text { Maintenance } \\
\text { Flue gas heat recovery } \\
\text { Blowdown heat recovery } \\
\text { Reduced standby losses }\end{array}$ & $\begin{array}{l}\text { Steam Distribution } \\
\text { Improved insulation } \\
\text { Maintain insulation } \\
\text { Improved steam traps } \\
\text { Maintain steam traps } \\
\text { Automatic monitoring steam traps } \\
\text { Leak repair } \\
\text { Recover flash steam } \\
\text { Return condensate }\end{array}$ \\
\hline $\begin{array}{l}\text { Heaters and Furnaces } \\
\text { Maintenance } \\
\text { Draft control } \\
\text { Air preheating } \\
\text { Fouling control } \\
\text { New burner designs }\end{array}$ & $\begin{array}{l}\text { Distillation } \\
\text { Optimized operation procedures } \\
\text { Optimized product purity } \\
\text { Seasonal pressure adjustments } \\
\text { Reduced reboiler duty } \\
\text { Upgraded column internals }\end{array}$ \\
\hline $\begin{array}{l}\text { Compressed Air } \\
\text { Maintenance } \\
\text { Monitoring } \\
\text { Reduce leaks } \\
\text { Reduce inlet air temperature } \\
\text { Maximize allowable pressure dewpoint } \\
\text { Controls } \\
\text { Properly sized regulators } \\
\text { Size pipes correctly } \\
\text { Adjustable speed drives } \\
\text { Heat recovery for water preheating }\end{array}$ & $\begin{array}{l}\text { Pumps } \\
\text { Operations \& maintenance } \\
\text { Monitoring } \\
\text { More efficient pump designs } \\
\text { Correct sizing of pumps } \\
\text { Multiple pump use } \\
\text { Trimming impeller } \\
\text { Controls } \\
\text { Adjustable speed drives } \\
\text { Avoid throttling valves } \\
\text { Correct sizing of pipes } \\
\text { Reduce leaks } \\
\text { Sealings } \\
\text { Dry vacuum pumps }\end{array}$ \\
\hline $\begin{array}{l}\text { Motors } \\
\text { Proper sizing of motors } \\
\text { High efficiency motors } \\
\text { Power factor control } \\
\text { Voltage unbalance } \\
\text { Adjustable speed drives } \\
\text { Variable voltage controls } \\
\text { Replace belt drives }\end{array}$ & $\begin{array}{l}\text { Fans } \\
\text { Properly sizing } \\
\text { Adjustable speed drives } \\
\text { High-efficiency belts }\end{array}$ \\
\hline $\begin{array}{l}\text { Lighting } \\
\text { Lighting controls } \\
\text { T8 Tubes } \\
\text { Metal halides/High-pressure sodium }\end{array}$ & $\begin{array}{l}\text { High-intensity fluorescent (T5) } \\
\text { Electronic ballasts } \\
\text { Reflectors } \\
\text { LED exit signs }\end{array}$ \\
\hline
\end{tabular}


Table 9. Summary of process-specific energy efficiency opportunities.

\begin{tabular}{|c|c|}
\hline $\begin{array}{l}\text { Desalter } \\
\text { Multi-stage desalters } \\
\text { Combined AC/DC fields }\end{array}$ & $\begin{array}{l}\text { Hydrocracker } \\
\text { Power recovery } \\
\text { Process integration (pinch) } \\
\text { Furnace controls } \\
\text { Air preheating } \\
\text { Optimization distillation } \\
\end{array}$ \\
\hline $\begin{array}{l}\text { CDU } \\
\text { Process controls } \\
\text { High-temperature CHP } \\
\text { Process integration (pinch) } \\
\text { Furnace controls } \\
\text { Air preheating } \\
\text { Progressive crude distillation } \\
\text { Optimization distillation } \\
\end{array}$ & $\begin{array}{l}\text { Coking } \\
\text { Process integration (pinch) } \\
\text { Furnace controls } \\
\text { Air preheating }\end{array}$ \\
\hline $\begin{array}{l}\text { VDU } \\
\text { Process controls } \\
\text { Process integration (pinch) } \\
\text { Furnace controls } \\
\text { Air preheating } \\
\text { Optimization distillation }\end{array}$ & $\begin{array}{l}\text { Visbreaker } \\
\text { Process integration (pinch) } \\
\text { Optimization distillation }\end{array}$ \\
\hline $\begin{array}{l}\text { Hydrotreater } \\
\text { Process controls } \\
\text { Process integration (pinch) } \\
\text { Optimization distillation } \\
\text { New hydrotreater designs }\end{array}$ & $\begin{array}{l}\text { Alkylation } \\
\text { Process controls } \\
\text { Process integration (pinch) } \\
\text { Optimization distillation }\end{array}$ \\
\hline $\begin{array}{l}\text { Catalytic Reformer } \\
\text { Process integration (pinch) } \\
\text { Furnace controls } \\
\text { Air preheating } \\
\text { Optimization distillation } \\
\end{array}$ & $\begin{array}{l}\text { Hydrogen Production } \\
\text { Process integration (pinch) } \\
\text { Furnace controls } \\
\text { Air preheating } \\
\text { Adiabatic pre-reformer } \\
\end{array}$ \\
\hline $\begin{array}{l}\text { FCC } \\
\text { Process controls } \\
\text { Power recovery } \\
\text { Process integration (pinch) } \\
\text { Furnace controls } \\
\text { Air preheating } \\
\text { Optimization distillation } \\
\text { Process flow changes }\end{array}$ & $\begin{array}{l}\text { Other } \\
\text { Optimize heating storage tanks } \\
\text { Optimize flares }\end{array}$ \\
\hline
\end{tabular}




\section{Acknowledgements}

This work was supported by the Climate Protection Partnerships Division of the U.S. Environmental Protection Agency as part of its ENERGY STAR program through the U.S. Department of Energy under Contract No. DE-AC03-76SF00098.

Many people inside and outside the industry provided helpful insights in the preparation of this Energy Guide. We would like to thank Brian Eidt and staff at ExxonMobil, F.L. Oaks (Marathon Ashland), and Marc Taylor (Shell) for the review of the draft report. We would like to thank Susan Gustofson (Valero) and Chaz Lemmon (ConocoPhillips) for providing insights into the petroleum refining industry in California. We also like to thank Gunnar Hovstadius (ITT Fluid Technology) for his review and help, as well as Elizabeth Dutrow (U.S. Environmental Protection Agency), Don Hertkorn and Fred Schoeneborn for their review of earlier drafts of the report. Despite all their efforts, any remaining errors are the responsibility of the authors. The views expressed in this paper do not necessarily reflect those of the U.S. Environmental Protection Agency, the U.S. Department of Energy or the U.S. Government. 


\section{References}

Abrardo, J.M. and V. Khuruna. 1995. Hydrogen Technologies to meet Refiners' Future Needs. Hydrocarbon Processing 274 pp.43-49 (February 1995).

Al-Riyami, B.A., J. Klemes and S. Perry. 2001. Heat Integration Retrofit Analysis of a Heat Exchanger Network of a Fluid Catalytic Cracking Plant. Applied Thermal Engineering 21 pp.1449-1487.

Alesson, T. 1995. "All Steam Traps Are Not Equal." Hydrocarbon Processing 74.

Babich, I.V. and J.A. Moulijn. 2003. Science and Technology of Novel Processes for Deep Desulfurization of Oil Refinery Streams: A Review. Fuel 82 pp.607-631.

Baen, P.R. and R.E. Barth. 1994. "Insulate Heat Tracing Systems Correctly." Chemical Engineering Progress, September, pp.41-46.

Baker, R.W., K.A. Lokhandwala, M.L. Jacobs, and D.E. Gottschlich. 2000. Recover Feedstock and Product from Reactor Vent Streams. Chemical Engineering Progress 1296 pp.51-57 (December 2000).

Barletta, A.F. 1998. Revamping Crude Units. Hydrocarbon Processing 277 pp.51-57 (February 1998).

Best Practice Programme. 1996. Good Practice Case Study 300: Energy Savings by Reducing the Size of a Pump Impeller. Available for download at http://www.energy-efficiency.gov.uk/index.cfm.

Best Practice Programme.1998. Good Practice Guide 249: Energy Savings in Industrial Water Pumping Systems. Available for download at http://www.energyefficiency.gov.uk/index.cfm

Bloss, D., R. Bockwinkel, and N. Rivers, 1997. "Capturing Energy Savings with Steam Traps.” Proc. 1997 ACEEE Summer Study on Energy Efficiency in Industry, ACEEE, Washington DC.

Bott, T.R. 2000. Biofouling Control with Ultrasound. Heat Transfer Engineering 321

Bott, T.R. 2001. To Foul or not to Foul, That is the Question. Chemical Engineering Progress 1197 pp.30-36 (November 2001).

Brant, B., et al. 1998. New Waste Heat Refrigeration Unit Cuts Flaring, Reduces Pollution. Oil \& Gas Journal, May 18 ${ }^{\text {th }}, 1998$.

Bronhold, C.J. 2000. Flash Steam Recovery Project. Proc. $22^{\text {nd }}$ Industrial Energy Technology Conference, Houston, TX, April 5-6, 2000.

Brueske, S.M., S. Smith and R. Brasier. 2002. DOE-sponsored Energy Program Yields Big Savings for Flying J Refinery. Oil \& Gas Journal, December $2^{\text {nd }}$, 2002, pp.6267.

Cabooter, A.A.A., D. Brkic, D.C. Cooperberg and K. Sep. 2001. IGCC is Environmentally Friendly Choice in Polish Refinery. Oil \& Gas Journal, February $26^{\text {th }}, 2001$, pp.58-63. 
California Energy Commission (CEC) and the Office of Industrial Technologies (OIT), U.S. Department of Energy. 2002. Case Study: Pump System Retrofit Results in Energy Savings for a Refinery, August 2001.

California Energy Commission (CEC) and the Office of Industrial Technologies (OIT), Energy Efficiency and Renewable Energy, U. S. Department of Energy. 2002. Case Study: Pump System Controls Upgrade Saves Energy at a Network Equipment Manufacturing Company’s Corporate Campus. January 2002.

California Energy Commission. 2003. Lighting Efficiency Information. Information and reports can be accessed through: http://www.energy.ca.gov/efficiency/lighting/

Canadian Industry Program for Energy Conservation (CIPEC). 2001. Boilers and Heaters, Improving Energy Efficiency. Natural Resources Canada, Office of Energy Efficiency, Ottawa, Ontario, Canada.

Centre for the Analysis and Dissemination of Demonstrated Energy Technologies (CADDET). 1993. Proceedings IEA Workshop on Process Integration, International Experiences and Future Opportunities, Sittard, The Netherlands.

Centre for the Analysis and Dissemination of Demonstrated Energy Technologies (CADDET). 1994. High Efficiency Motors for Fans and Pumps. Case study UK94.502/2B.FO5.

Centre for the Analysis and Dissemination of Demonstrated Energy Technologies (CADDET). 1997. Saving Energy with Efficient Compressed Air Systems (Maxi Brochure 06), Sittard, The Netherlands.

Centre for the Analysis and Dissemination of Demonstrated Energy Technologies (CADDET). 1997b. Keeping a Steam Boiler on Hot Standby (Project NL-1990-044). Project description can be downloaded from www.caddet.org.

Centre for the Analysis and Dissemination of Demonstrated Energy Technologies (CADDET). 2002. Gas Expansion Turbine in Eems Power Plant. Project can be downloaded from www.caddet.org

Centre for the Analysis and Dissemination of Demonstrated Energy Technologies (CADDET). 2003. Power Recovery Turbine (Project NL-1993-530). Project can be downloaded from www.caddet.org.

Caffal, C. 1995. "Energy Management in Industry." CADDET, Sittard, The Netherlands.

Cheng, R., 1999. Low Emissions Burners. EETD Newsletter, Summer 1999, Lawrence Berkeley National Laboratory, Berkeley, CA.

Clayton, R.W., 1986. Cost Reduction on an Oil Refinery Identified by a Process Integration Study at Gulf Oil Refining Ltd., Energy technology Support Unit, Harwell, United Kingdom.

Copper Development Association (CDA). 2000. Cummins engine company saves \$200,000 per Year with Energy-Efficient Motors. Case Study A6046. 
Copper Development Association (CDA). 2001. High-Efficiency Copper-Wound Motors Mean Energy and Dollar Savings. http://energy.copper.org/motorad.html.

Council of Industrial Boiler Owners (CIBO). 1998. Personal Communication

Dunn, R.F. and G.E Bush. 2001. Using Process Integration Technology for CLEANER production. Journal of Cleaner Production 19 pp.1-23.

Easton Consultants, Inc. 1995. Strategies to Promote Energy-Efficient Motor Systems in North America’s OEM Markets. Stamford, CT.

Elliot, N. R. 1994. Electricity Consumption and the Potential for Electric Energy Savings in the Manufacturing Sector. ACEEE, Washington, D.C.

Energy Information Administration (EIA), 1997. The Impact of Environmental Compliance Costs on U.S. Refining Profitability. Energy Information Administration, U.S. Department of Energy, Washington, DC, October 1997.

Energy Information Administration (EIA), 2000, Natural Gas Annual 1999, Energy Information Administration, U.S. Department of Energy, Washington, D.C.

Energy Information Administration (EIA), 2001. 1998 Manufacturing Energy Consumption Survey, Energy Information Administration, U.S. Department of Energy, Washington, DC. Data can be accessed on the web: http://www.eia.doe.gov/industrial.html

Energy Information Administration (EIA), 2002. Petroleum Supply Annual 2001, Energy Information Administration, U.S. Department of Energy, Washington, DC, June 2002.

Ezersky, A., 2002. Technical Assessment Document: Further Study Measure 8 Flares (draft). Bay Area Air Quality Management District, San Francisco, CA.

Fisher, P.W. and D. Brennan. 2002. Minimize Flaring with Flare Gas Recovery. Hydrocarbon Processing 681 pp.83-85 (June 2002).

Flygt, ITT Industries. 2002. Case Study: Flygt Helps City of Milford Meet the Challenge. Available at www.flygt.com.

Frangopoulos, C.A., A. Lygeors, C.T. Markou and P, Kaloritis. 1996. Thermoeconomic Operation Optimization of the Hellenic Aspropyrgos Refinery Combined Cycle Cogeneration System. Applied Thermal Engineering 1216 pp.949-958.

Ganapathy, V. 1994. "Understand Steam Generator Performance." Chemical Engineering Progress

Ganapathy, V. 1995. "Recover Heat from Waste Incineration." Hydrocarbon Processing 74

Garcia-Borras, T. 1998. "Improving Boilers and Furnaces." Chemical Engineering, January, pp.127-131.

Garg, A. 1998. Revamp Fired Heaters to Increase Capacity. Hydrocarbon Processing 6 77 pp.67-80 (June 1998). 
Gary, J.H. and G.E. Handwerk. 1994. Petroleum Refining: Technology and Economics, $3^{\text {rd }}$ edition, Marcel Dekker, Inc., New York, NY.

Gas Research Institute (GRI). 1996. “Analysis of the Industrial Boiler Population” Prepared by Environmental Energy Analysis, Inc.

Gislason, J. 2001. Philips Sulfur-Removal Process nears Commercialization. Oil \& Gas Journal 99, November $19^{\text {th }}, 2001$, pp.72-76.

Glazer, J.L., M.E. Schott and L.A. Stapf, 1988. Hydrocracking? Upgrade Recycle. Hydrocarbon Processing 1067 pp.61-61 (October 1988).

Golden, S.W. and S. Fulton. 2000. Low-Cost Methods to Improve FCCU Energy Efficiency. Petroleum Technical Quarterly, Summer 2000, pp.95-103.

Hall, S.G., T.P. Ognisty and A.H. Northrup. 1995. Use Process Integration to Improve FCC/VRU Design (Part 1). Hydrocarbon Processing 374 pp.63-74 (March 1995).

Hallale, N., 2001. Burning Bright: Trends in Process Integration. Chemical Engineering Progress 797 pp.30-41 (July 2001).

Hedden, K. and A. Jess, 1992. Raffinerien and Ölveredelung, Teilprojekt 4 of IKARUS, Bundesministerium für Forschung und Technologie, Bonn, Germany (in German).

Heijkers, C., E. Zeemering and W. Altena. Consider Variable-Speed, Motor-Driven Compressors in Refrigeration Units. Hydrocarbon Processing 879 pp.61-64 (August 2000).

Hodgson, J. and T. Walters. 2002. Optimizing Pumping Systems to Minimize First or Life-Cycle Costs. Proc. 19th International Pump Users Symposium, Houston, TX, February $25^{\text {th }}-28^{\text {th }}, 2002$.

House, M.B., S.B. Lee, H. Weinstein and G. Flickinger. 2002. Consider Online Predictive Technology to reduce Electric Motor Maintenance Costs. Hydrocarbon Processing 781 pp.49-50 (July 2002).

Hovstadius, G. of ITT Fluid Technology Corporation. 2002. Personal communication.

Huangfu, E. (U.S. Department of Energy). 2000. Personal communication. August.

Hydraulic Institute and Europump. 2001. Pump Life Cycle Costs: A Guide to LCC Analysis for Pumping Systems. Parsippany, NJ.

Hydraulic Institute. 1994. Efficiency Prediction Method for Centrifugal Pumps. Parsippany, NJ.

Hydraulic Institute. 2002. Website, http://www.pumps.org/.

Hydrocarbon Processing (HCP). 2000. Refining Processes 2000. Hydrocarbon Processing 1179 pp.87-142 (November 2000).

Hydrocarbon Processing (HCP). 2001. Advanced Control and Information Systems 2001. Hydrocarbon Processing 980 pp.73-159 (September 2001).

Industrial Assessment Center. 1999. “Industrial Assessment Center Database.” http://oipea-www.rutgers.edu/site_docs/dbase.html 
Ingersoll Rand. 2001. Air Solutions Group-Compressed Air Systems Energy Reduction Basics. http://www.air.ingersoll-rand.com/NEW/pedwards.htm. June 2001.

Integrated Pollution and Prevention Control. 2002. Reference Document on Best Available Techniques for Mineral Oil and Gas Refineries. Joint Research Centre, European Commission, Seville, Spain.

Johnston, B., 1995. "5 Ways to Greener Steam." The Chemical Engineer 594 (August) pp.24-27.

Jones, T. 1997. "Steam Partnership: Improving Steam Efficiency Through Marketplace Partnerships.” Proc. 1997 ACEEE Summer Study on Energy Efficiency in Industry, ACEEE, Washington DC.

Khorram, M. and T. Swaty. 2002. U.S. Refiners need more Hydrogen to Satisfy Future Gasoline and Diesel Specifications. Oil \& Gas Journal, November 25 ${ }^{\text {th }}$, 2002, pp.4247.

Killen, P.J., K.G. Spletter, N.K. Earnest and B.L. Stults, 2001. Refinery-Profitability Statistics Begin in this Issue. Oil \& Gas Journal 99 pp.46-50 (January 15 ${ }^{\text {th }}$, 2001).

Kumana, J. 2000a. Personal communication, 2000.

Kumana, J. 2000b. Pinch Analysis - What, When, Why, How. Additional publications available by contacting jkumana@aol.com

Lawrence Berkeley National Laboratory (LBNL) and Resource Dynamics Corporation. (1998). Improving Compressed Air System Performance, a Sourcebook for Industry. Prepared for the U.S. Department of Energy, Motor Challenge Program.

Lawrence Berkeley National Laboratory (LBNL), Resource Dynamics Corporation and the Hydraulic Institute. 1999. Improving Pumping System Performance: A Sourcebook for Industry. Prepared for the U.S. Department of Energy Motor Challenge Program.

Lee, K.L., M. Morabito and R.M. Wood. 1989. Refinery Heat Integration using Pinch Technology. Hydrocarbon Processing 468 pp.49-53 (April 1989).

Lehman, Bryan and Ernst Worrell. 2001. Electricity Production from Natural Gas Pressure Recovery Using Expansion Turbines, Proc. 2001 ACEEE Summer Study on Energy Efficiency in Industry - Volume 2, Tarrytown, NY, July 24-27 ${ }^{\text {th }}, 2001$, pp. 43-54.

Linnhoff, B., D.W. Townsend, D. Boland, G.F. Hewitt, B.E.A. Thomas, A.R. Guy, R.H. Marsland. 1992. A User Guide on Process Integration for the Efficient Use of Energy (1992 edition), Institution of Chemical Engineers, Rugby, UK.

Linnhoff, B. 1993. Pinch Analysis: A State-of-the-Art Overview. Chemical Engineering 71 (AS): pp.503-522.

Linnhoff March. 2000. The Methodology and Benefits of Total Site Pinch Analysis. Linnhoff March Energy Services. Paper can be downloaded from: http://www.linnhoffmarch.com/resources/technical.html 
Mafi-Trench Corporation (MTC). 1997. Origins of the Cryoexpander. Mafi-Trench Corporation News, Vol. 20, No. 2. Santa Maria, California: MTC.

Marano, J.J., 2003. Refinery Technology Profiles: Gasification and Supporting Technologies, National Energy Technologies Laboratory, U.S. Department of Energy/Energy Information Administration, Washington, DC, June 2003.

Martin, N., E. Worrell, M. Ruth, and L. Price, R. N. Elliott, A. M. Shipley, and J. Thorne. 2000. Emerging Energy-Efficient Industrial Technologies. LBNL/ACEEE, Berkeley, CA/Washington, DC.

Molden Brueske, S., S. Smith, R. Brasier, 2003. DOE and Flying J Refinery Cooperate to Determine Energy Savings. Energy matters, Winter 2003. (Newsletter published by Office of Industrial technologies, U.S. department of Energy).

Onsite Sycom Energy Corp., 2000. The Market and Technical Potential for Combined Heat and Power in the Industrial Sector. Energy Information Administration, U.S. Department of Energy, Washington, DC.

Panchal, C.B. and E-P. Huangfu, 2000. Effects of Mitigating Fouling on the Energy Efficiency of Crude Oil Distillation. Heat Transfer Engineering 21 pp.3-9.

Parekh, P. (2000). Investment Grade Compressed Air System Audit, Analysis and Upgrade. In: Twenty-second National Industrial Energy Technology Conference Proceedings. Houston, Texas. April 5-6: 270-279.

Patel, M.R. and N. Nath. 2000. Improve Steam Turbine Efficiency. Hydrocarbon Processing 679 pp.85-90 (June 2000).

Petrick, M and J Pellegrino, 1999. The Potential for Reducing Energy Utilization in the Refining Industry, Report nr. ANL/ESD/TM-158, Argonne National Laboratory, Argonne, IL.

Polley, G.T. and H.L. Polley. 2000. Design Better Water Networks. Chemical Engineering Progress 296 pp.47-52 (February 2000).

Polley, G.T. and S.J. Pugh. 2002. Identification of R\&D Needs Relating to the Mitigation of Fouling in Crude Oil Pre-Heat Trains. Proc. $24^{\text {th }}$ Industrial Energy Technology Conference, Houston, TX, April 16-19, 2002.

Polley, G.T., S.J. Pugh and D.C King. 2002. Emerging Heat Exchanger Technologies for the Mitigation of Fouling in Crude Oil Preheat Trains. Proc. $24^{\text {th }}$ Industrial Energy Technology Conference, Houston, TX, April 16-19, 2002.

Querzoli, A.L., A.F.A. Hoadley and T.E.S. Dyron. 2002. Identification of Heat Integration Retrofit Opportunities for Crude Distillation and Residue Cracking Units. Proceedings of the 9th APCChE Congress and CHEMECA 2002, 29 September-3 October 2002, Christchurch, NZ

Radgen, P. and E. Blaustein (eds.). 2001. Compressed Air Systems in the European Union, Energy, Emissions, Savings Potential and Policy Actions. Fraunhofer Institute, Karlsruhe, Germany. 
Ratan, S. and C.F. Vales, 2002. Improve your Hydrogen Potential. Hydrocarbon Processing 381 pp.57-64 (March 2002).

Ryans, J. and J. Bays. 2001. Run Clean with Dry Vacuum Pumps. Chemical Engineering Progress 1096 pp.32-41 (October 2001).

Seebold, J.G., R.T. Waibel and T.L. Webster. 2001. Control NOx Emissions CostEffectively. Hydrocarbon Processing 1180 pp.55-59 (November 2001).

Saxena, S.K. 1997. Conserve Energy in Distillation. Chemical Engineering World, September 1997.

Shaver, K.G., G.L. Poffenbarger and D.R. Groteworld. 1991. Membranes recover Hydrogen. Hydrocarbon Processing 670 pp.77-80 (June 1991).

Shenoy, U. 1994. Heat Exchanger Network Synthesis. Houston, TX: Gulf Publishing Company.

Smith, R. 1995. Chemical Process Design. New York, NY: McGraw-Hill Inc.

Strategic Directions International, Inc., 1982, Energy Recovery Opportunities in Europe: European Survey Summary, Airco Cryogenics Division, Irvine, California

Sunden, B. 1988. Analysis of the Heat recovery in Two Crude Distillation Units. Heat Recovery \& CHP Systems 58 pp.483-488.

Swain, E.J., 2002. Crudes Processed in U.S. Refineries Continue to Decline in Quality. Oil \& Gas Journal 100, pp.40-45 (November $18^{\text {th }}$, 2002).

Taylor, A.J., T.G. la Grange and G.Z. Gous, 2000. Modern Advanced Control Pays Back Rapidly. Hydrocarbon Processing 979 pp.47-50 (September 2000).

Technip, 2000. Progressive Crude Distillation. Leaflet, Technip, Paris, France.

Terrible, J., G. Shahani, C. Gagliardi, W. Baade, R. Bredehoft and M. Ralston. 1999. Consider Using Hydrogen Plants to Cogenerate Power Needs. Hydrocarbon Processing 1278 pp.43-53 (December 1999).

Timmons, C., J. Jackson and D.C. White, 2000. Distinguishing Online Optimization Benefits from Those of Advanced Controls. Hydrocarbon Processing 679 pp.69-77 (June 2000).

Tutterow, V. 1999. Energy Efficiency in Pumping Systems: Experience and Trends in the Pulp and Paper Industry. American Council for an Energy Efficient Economy (ACEEE).

Tutterow, V., D. Casada and A. McKane. 2000. "Profiting from your Pumping System,” In Proceedings of the Pump Users Expo 2000. September. Louisville, KY: Pumps \& Systems Magazine, Randall Publishing Company.

U.S. DOE-OIT. 1998a. Energy and Environmental Profile of the U.S. Petroleum Refining Industry, Office of Industrial Technologies, U.S. Department of Energy, Washington, DC.

U.S. DOE-OIT. 1998. Steam Challenge. http://www.oit.doe.gov/steam/ 
U.S. DOE-OIT, 1999. Motor Systems Upgrades Smooth the Way to Savings of $\$ 700,000$ at Chevron Refinery. Office of Industrial Technologies, U.S. Department of Energy, Washington, DC.

U.S. DOE-OIT, 2000.Advanced Process Analysis for Petroleum Refining. Office of Industrial Technologies, U.S. Department of Energy, Washington, DC.

U.S. DOE-OIT, 2000b. Energy Tips: Estimate Voltage Unbalance. Information Sheet. Office of Industrial Technologies, U.S. Department of Energy, Washington, DC.

U.S. DOE-OIT, 2001. Installation of Reverse Osmosis Unit Reduces Refinery Energy Consumption. Office of Industrial Technologies, U.S. Department of Energy, Washington, DC.

U.S. DOE-OIT, 2002. Steam System Opportunity Assessment for the Pulp \& Paper, Chemical Manufacturing and Petroleum Refining Industries. Office of Industrial Technologies, U.S. Department of Energy, Washington, DC.

U.S. DOE-OIT, 2002b. Martinez Refinery completes Plant-Wide Energy Assessment. Office of Industrial Technologies, U.S. Department of Energy, Washington, DC.

U.S. DOE-OIT, 2002c. Pumps: Cost Reduction Strategies. U.S. Department of Energy, Available at the website www.oit.doe.gov/bestpractices.

U.S. DOE-OIT, 2002d. Pump System Optimization Saves Energy and Improves Productivity at Daishowa America Paper Mill. U.S. Department of Energy, available at www.oit.doe.gov/bestpractices.

U.S. DOE-OIT, 2002e. Rotary Burner (Project Factsheet). Office of Industrial Technologies, U.S. Department of Energy, Washington, DC.

U.S. DOE-OIT, 2003. Retrofit Helps Mobil refinery Avoid a Major capital Investment. Energy Matters, Winter 2003 (Newsletter published by Office of Industrial Technologies, U.S. Department of Energy).

U.S. DOE-OIT, 2003b. Paramount Petroleum: Plant-Wide Energy-Efficiency Assessment Identifies Three Projects. Office of Industrial Technologies, U.S. Department of Energy, Washington, DC.

Valero, 2003. Valero Energy Corporation Tour Guide Book Houston Refinery. Distributed at the Texas Technology Showcase 2003, Houston, March 17-19, 2003.

Van de Ruit, H. 2000. Improve Condensate Recovery Systems. Hydrocarbon Processing 1279 pp.47-53 (December 2000).

Venkatesan, V.V. and N. Iordanova. 2003. A Case Study of Steam Evaluation in a Petroleum Refinery. Proc. $25^{\text {th }}$ Industrial Energy Technology Conference, Houston, TX, May 13-16, 2003.

Worrell, E. and K. Blok. 1994. Energy Savings in the Nitrogen Fertilizer Industry in the Netherlands. Energy, the International Journal 219 pp.195-209 (1994).

Worrell, E., J-W.Bode, and J. de Beer. 1997. Energy Efficient Technologies in Industry (ATLAS project for the European Commission). Utrecht University, Utrecht, The Netherlands. 
Wu, G., 2000. Design and Retrofit of Integrated Refrigeration Systems. Ph.D. Thesis, UMIST, Manchester, UK.

Xenergy, Inc. 1998. United States Industrial Electric Motor Systems Market Opportunities Assessment. U.S. Department of Energy's Office of Industrial Technology and Oak Ridge National Laboratory.

Zagoria, A. and R. Huycke. 2003. Refinery Hydrogen Management - The Big Picture. Hydrocarbon Processing 282 pp.41-46 (February 2003).

Zeitz, R.A. (ed.) 1997. CIBO Energy Efficiency Handbook. Council of Industrial Boiler Owners, Burke, VA.

Zhang, Y. 2001. Heat-Balance Design in Coker Reduces Energy Consumption. Oil \& Gas Journal 99 January $1^{\text {st }}$, 2001, pp.42-44.

Zollar, J., 2002. CHP Integration with Fluid Heating Processes in the Chemical and Refining Sectors, Oak Ridge National Laboratory, Oak Ridge, TN, Presentation given on January $30^{\text {th }}$, 2002. 


\section{Appendix A: Active refineries in the United States as of January 2003}

\begin{tabular}{|c|c|c|c|c|c|c|}
\hline Company & Site & State & $\begin{array}{l}\text { Capacity } \\
\text { (b/cd) }\end{array}$ & Share & $\begin{array}{l}\text { Company } \\
\text { - Total } \\
\text { (b/cd) }\end{array}$ & $\begin{array}{l}\text { Share } \\
\text { company }\end{array}$ \\
\hline \multirow{2}{*}{\begin{tabular}{|l|}
$\begin{array}{l}\text { Age Refining \& } \\
\text { Marketing }\end{array}$ \\
\end{tabular}} & Big Spring & Texas & 58,500 & $0.3 \%$ & 67,500 & $0.4 \%$ \\
\hline & San Antonio & Texas & 9,000 & $0.1 \%$ & & \\
\hline \begin{tabular}{|l|} 
American \\
I nternational Rfy \\
Inc
\end{tabular} & Lake Charles & Louisiana & 30,000 & $0.2 \%$ & 30,000 & $0.2 \%$ \\
\hline $\begin{array}{l}\text { American Refining } \\
\text { Group I nc. }\end{array}$ & Bradford & Pennsylvania & 10,000 & $0.1 \%$ & 10,000 & $0.1 \%$ \\
\hline $\begin{array}{l}\text { Atofina } \\
\text { Petrochemicals I nc. }\end{array}$ & Port Arthur & Texas & 175,068 & $1.0 \%$ & $\begin{array}{ll}175,068 \\
\end{array}$ & $1.0 \%$ \\
\hline \multirow[t]{7}{*}{ BP } & $\begin{array}{l}\text { Ferndale } \\
\text { (Cherry Point) }\end{array}$ & Washington & 225,000 & $1.3 \%$ & \multirow[t]{7}{*}{$1,519,200$} & \multirow[t]{7}{*}{$9.0 \%$} \\
\hline & Kuparuk & Alaska & 16,000 & $0.1 \%$ & & \\
\hline & Prudhoe Bay & Alaska & 14,200 & $0.1 \%$ & & \\
\hline & Toledo & Ohio & 157,000 & $0.9 \%$ & & \\
\hline & Whiting & Indiana & 410,000 & $2.4 \%$ & & \\
\hline & Texas City & Texas & 437,000 & $2.6 \%$ & & \\
\hline & Los Angeles & California & 260,000 & $1.5 \%$ & & \\
\hline $\begin{array}{l}\text { Calcasieu Refining } \\
\text { Co. }\end{array}$ & Lake Charles & Louisiana & 29,400 & $0.2 \%$ & 29,400 & $0.2 \%$ \\
\hline \multirow{3}{*}{$\begin{array}{l}\text { Calumet Lubricants } \\
\text { Co. LP }\end{array}$} & Cotton Valley & Louisiana & 13,020 & $0.1 \%$ & \multirow[t]{3}{*}{67,520} & \multirow[t]{3}{*}{$0.4 \%$} \\
\hline & Princeton & Louisiana & 8,300 & $0.0 \%$ & & \\
\hline & Shreveport & Louisiana & 46,200 & $0.3 \%$ & & \\
\hline $\begin{array}{l}\text { Cenex Harvest } \\
\text { States Coop }\end{array}$ & Laurel & Montana & 55,000 & $0.3 \%$ & 55,000 & $0.3 \%$ \\
\hline $\begin{array}{l}\text { Chalmette Refining } \\
\text { LLC }\end{array}$ & Chalmette & Louisiana & 182,500 & $1.1 \%$ & 182,500 & $1.1 \%$ \\
\hline \begin{tabular}{|l|} 
ChevronTexaco \\
\end{tabular} & \begin{tabular}{|l|} 
El Paso \\
El Segundo \\
Honolulu \\
Pascagoula \\
Perth Amboy \\
Richmond \\
Salt Lake City \\
\end{tabular} & \begin{tabular}{|l} 
Texas \\
California \\
Hawaii \\
Mississippi \\
New Jersey \\
California \\
Utah \\
\end{tabular} & $\begin{array}{r}90,000 \\
260,000 \\
54,000 \\
325,000 \\
80,000 \\
225,000 \\
45,000 \\
\end{array}$ & \begin{tabular}{l|}
$0.5 \%$ \\
$1.5 \%$ \\
$0.3 \%$ \\
$1.9 \%$ \\
$0.5 \%$ \\
$1.3 \%$ \\
$0.3 \%$ \\
\end{tabular} & $1,079,000$ & $6.4 \%$ \\
\hline Citgo & $\begin{array}{l}\text { Corpus Christi } \\
\text { Lake Charles } \\
\text { Savannah }\end{array}$ & \begin{tabular}{|l} 
Texas \\
Louisiana \\
Georgia \\
\end{tabular} & $\begin{array}{r}156,000 \\
326,000 \\
28,000 \\
\end{array}$ & \begin{tabular}{l|}
$0.9 \%$ \\
$1.9 \%$ \\
$0.2 \%$ \\
\end{tabular} & 510,000 & $3.0 \%$ \\
\hline
\end{tabular}




\begin{tabular}{|c|c|c|c|c|c|c|}
\hline Company & Site & State & $\begin{array}{r}\text { Capacity } \\
(\mathrm{b} / \mathrm{cd})\end{array}$ & Share & $\begin{array}{r}\text { Company } \\
- \text { Total } \\
\text { (b/cd) } \\
\end{array}$ & $\begin{array}{r}\text { Share } \\
\text { company }\end{array}$ \\
\hline $\begin{array}{l}\text { Coastal Eagle Point } \\
\text { Oil Co. }\end{array}$ & Westville & New Jersey & 142,287 & $0.8 \%$ & 142,287 & $0.8 \%$ \\
\hline \multirow[t]{15}{*}{ ConocoPhilips } & Arroyo Grande & California & 41,800 & $0.2 \%$ & \multirow[t]{14}{*}{$2,263,200$} & \multirow[t]{14}{*}{$13.4 \%$} \\
\hline & Belle Chasse & Louisiana & 253,500 & $1.5 \%$ & & \\
\hline & Billings & Montana & 60,000 & $0.4 \%$ & & \\
\hline & Borger & Texas & 143,800 & $0.9 \%$ & & \\
\hline & $\begin{array}{l}\text { Commerce } \\
\text { City }\end{array}$ & Colorado & 60,000 & $0.4 \%$ & & \\
\hline & $\begin{array}{l}\text { Ferndale } \\
\text { (Cherry Point) }\end{array}$ & Washington & 92,000 & $0.5 \%$ & & \\
\hline & Linden & New J ersey & 250,000 & $1.5 \%$ & & \\
\hline & Ponca City & Oklahoma & 194,000 & $1.2 \%$ & & \\
\hline & Rodeo & California & 73,200 & $0.4 \%$ & & \\
\hline & Sweeny & Texas & 213,000 & $1.3 \%$ & & \\
\hline & \begin{tabular}{|l|} 
Trainer \\
\end{tabular} & Pennsylvania & 180,000 & $1.1 \%$ & & \\
\hline & Westlake & Louisiana & 252,000 & $1.5 \%$ & & \\
\hline & Wilmington & California & 136,600 & $0.8 \%$ & & \\
\hline & Wood River & Illinois & 288,300 & $1.7 \%$ & & \\
\hline & Woods Cross & Utah & 25,000 & $0.1 \%$ & & \\
\hline $\begin{array}{l}\text { Countrymark } \\
\text { Cooperative I nc. }\end{array}$ & Mount Vernon & Indiana & 23,000 & $0.1 \%$ & 23,000 & $0.1 \%$ \\
\hline $\begin{array}{l}\text { Cross Oil Refining } \\
\text { and Mktg, I nc. }\end{array}$ & Smackover & Arkansas & 6,800 & $0.0 \%$ & 6,800 & $0.0 \%$ \\
\hline $\begin{array}{l}\text { Crown Central } \\
\text { Petroleum Corp. }\end{array}$ & Pasadena & Texas & 100,000 & $0.6 \%$ & 100,000 & $0.6 \%$ \\
\hline Edgington Oil Co. & Long Beach & California & 14,000 & $0.1 \%$ & 14,000 & $0.1 \%$ \\
\hline \multirow[t]{2}{*}{ Ergon Refining I nc. } & Vicksburg & Mississippi & 23,000 & $0.1 \%$ & \multirow[t]{2}{*}{42,400} & \multirow[t]{2}{*}{$0.3 \%$} \\
\hline & \begin{tabular}{|l|} 
Newell \\
(Congo)
\end{tabular} & West Virginia & 19,400 & $0.1 \%$ & & \\
\hline \multirow[t]{7}{*}{ ExxonMobil } & Baton Rouge & Louisiana & 491,000 & $2.9 \%$ & \multirow[t]{7}{*}{$1,823,000$} & \multirow[t]{7}{*}{$10.8 \%$} \\
\hline & Baytown & Texas & 516,500 & $3.1 \%$ & & \\
\hline & Beaumont & Texas & 348,500 & $2.1 \%$ & & \\
\hline & Billings & Montana & 58,000 & $0.3 \%$ & & \\
\hline & Joliet & Illinois & 238,000 & $1.4 \%$ & & \\
\hline & Mobile Bay & Alabama & 22,000 & $0.1 \%$ & & \\
\hline & Torrance & California & 149,000 & $0.9 \%$ & & \\
\hline $\begin{array}{l}\text { Farmland I ndustries } \\
\text { I nc. }\end{array}$ & Coffeyville & Kansas & 112,000 & $0.7 \%$ & 112,000 & $0.7 \%$ \\
\hline \multirow{2}{*}{$\begin{array}{l}\text { Flint Hills Resources } \\
\text { LP }\end{array}$} & Corpus Christi & Texas & 259,980 & $1.5 \%$ & \multirow[t]{2}{*}{524,980} & \multirow[t]{2}{*}{$3.1 \%$} \\
\hline & Saint Paul & Minnesota & 265,000 & $1.6 \%$ & & \\
\hline Flying J Inc. & $\begin{array}{l}\text { North Salt } \\
\text { Lake }\end{array}$ & Utah & 25,000 & $0.1 \%$ & 25,000 & $0.1 \%$ \\
\hline $\begin{array}{l}\text { Foreland Refining } \\
\text { Corp. }\end{array}$ & Eagle Springs & Nevada & 5,000 & $0.0 \%$ & 5,000 & $0.0 \%$ \\
\hline \multirow[t]{2}{*}{ Frontier Refg I nc. } & Cheyenne & Wyoming & 46,000 & $0.3 \%$ & \multirow[t]{2}{*}{149,000} & \multirow[t]{2}{*}{$0.9 \%$} \\
\hline & El Dorado & Kansas & 103,000 & $0.6 \%$ & & \\
\hline
\end{tabular}




\begin{tabular}{|c|c|c|c|c|c|c|}
\hline Company & Site & State & $\begin{array}{r}\text { Capacity } \\
(\mathrm{b} / \mathrm{cd})\end{array}$ & Share & $\begin{array}{r}\text { Company } \\
- \text { Total } \\
(\mathrm{b} / \mathrm{cd}) \\
\end{array}$ & $\begin{array}{r}\text { Share } \\
\text { company }\end{array}$ \\
\hline \multirow[t]{3}{*}{ Giant Refining Co. } & Bloomfield & New Mexico & 16,800 & $0.1 \%$ & \multirow[t]{3}{*}{96,200} & \multirow[t]{3}{*}{$0.6 \%$} \\
\hline & Gallup & New Mexico & 20,800 & $0.1 \%$ & & \\
\hline & Yorktown & Virginia & 58,600 & $0.3 \%$ & & \\
\hline \begin{tabular}{|l|} 
Haltermann \\
Products
\end{tabular} & Channelview & Texas & 880 & $0.0 \%$ & 880 & $0.0 \%$ \\
\hline Hunt Refining Co. & Tuscaloosa & Alabama & 35,000 & $0.2 \%$ & 35,000 & $0.2 \%$ \\
\hline $\begin{array}{l}\text { Kern Oil \& Refining } \\
\text { Co. }\end{array}$ & Bakersfield & California & 25,000 & $0.1 \%$ & 25,000 & $0.1 \%$ \\
\hline $\begin{array}{l}\text { La Gloria Oil \& Gas } \\
\text { Co. }\end{array}$ & Tyler & Texas & 55,000 & $0.3 \%$ & 55,000 & $0.3 \%$ \\
\hline Lion Oil Co. & El Dorado & Arkansas & 63,000 & $0.4 \%$ & 63,000 & $0.4 \%$ \\
\hline Lunday Thagard & South Gate & California & 8,500 & $0.1 \%$ & 8,500 & $0.1 \%$ \\
\hline \begin{tabular}{|l|} 
Lyondell Citgo \\
Refining Co. Ltd.
\end{tabular} & Houston & Texas & 270,200 & $1.6 \%$ & 270,200 & $1.6 \%$ \\
\hline \multirow{7}{*}{$\begin{array}{l}\text { Marathon Ashland } \\
\text { Petro LLC }\end{array}$} & Canton & Ohio & 73,000 & $0.4 \%$ & \multirow[t]{7}{*}{935,000} & \multirow[t]{7}{*}{$5.5 \%$} \\
\hline & Catlettsburg & Kentucky & 222,000 & $1.3 \%$ & & \\
\hline & Detroit & Michigan & 74,000 & $0.4 \%$ & & \\
\hline & Garyville & Louisiana & 232,000 & $1.4 \%$ & & \\
\hline & Robinson & Illinois & 192,000 & $1.1 \%$ & & \\
\hline & Saint Paul Park & Minnesota & 70,000 & $0.4 \%$ & & \\
\hline & Texas City & Texas & 72,000 & $0.4 \%$ & & \\
\hline $\begin{array}{l}\text { Montana Refining } \\
\text { Co. }\end{array}$ & Great Falls & Montana & 7,000 & $0.0 \%$ & 7,000 & $0.0 \%$ \\
\hline \multirow{4}{*}{$\begin{array}{l}\text { Motiva Enterprises } \\
\text { LLC }\end{array}$} & Convent & Louisiana & 235,000 & $1.4 \%$ & \multirow[t]{4}{*}{879,700} & \multirow[t]{4}{*}{$5.2 \%$} \\
\hline & \begin{tabular}{|l} 
Delaware City \\
\end{tabular} & Delaware & 175,000 & $1.0 \%$ & & \\
\hline & Norco & Louisiana & 219,700 & $1.3 \%$ & & \\
\hline & Port Arthur & Texas & 250,000 & $1.5 \%$ & & \\
\hline \multirow{2}{*}{$\begin{array}{l}\text { Murphy Oil U.S.A. } \\
\text { I nc. }\end{array}$} & Meraux & Louisiana & 95,000 & $0.6 \%$ & \multirow[t]{2}{*}{128,000} & \multirow[t]{2}{*}{$0.8 \%$} \\
\hline & Superior & Wisconsin & 33,000 & $0.2 \%$ & & \\
\hline Navajo Refining Co. & Artesia & New Mexico & 58,000 & $0.3 \%$ & 58,000 & $0.3 \%$ \\
\hline NCRA & McPherson & Kansas & 81,200 & $0.5 \%$ & 81,200 & $0.5 \%$ \\
\hline \begin{tabular}{|l|} 
Paramount \\
Petroleum Corp.
\end{tabular} & Paramount & California & 50,000 & $0.3 \%$ & 50,000 & $0.3 \%$ \\
\hline $\begin{array}{l}\text { PDV Midwest } \\
\text { Refining LLC }\end{array}$ & $\begin{array}{l}\text { Lemont } \\
\text { (Chicago) }\end{array}$ & Illinois & 160,000 & $0.9 \%$ & 160,000 & $0.9 \%$ \\
\hline \multirow[t]{2}{*}{ Petro Star I nc. } & North Pole & Alaska & 18,000 & $0.1 \%$ & \multirow[t]{2}{*}{68,000} & \multirow[t]{2}{*}{$0.4 \%$} \\
\hline & Valdez & Alaska & 50,000 & $0.3 \%$ & & \\
\hline Placid Refining Co. & Port Allen & Louisiana & 48,500 & $0.3 \%$ & 48,500 & $0.3 \%$ \\
\hline \multirow{2}{*}{$\begin{array}{l}\text { Premcor Refg Group } \\
\text { Inc }\end{array}$} & Lima & Ohio & 161,500 & $1.0 \%$ & \multirow[t]{2}{*}{416,500} & \multirow[t]{2}{*}{$2.5 \%$} \\
\hline & Port Arthur & Texas & 255,000 & $1.5 \%$ & & \\
\hline
\end{tabular}




\begin{tabular}{|c|c|c|c|c|c|c|}
\hline Company & Site & State & $\begin{array}{r}\text { Capacity } \\
(b / c d)\end{array}$ & Share & $\begin{array}{r}\text { Company } \\
\text { - Total } \\
\text { (b/cd) } \\
\end{array}$ & $\begin{array}{r}\text { Share } \\
\text { company }\end{array}$ \\
\hline $\begin{array}{l}\text { San J oaquin Refining } \\
\text { Co Inc. }\end{array}$ & Bakersfield & California & 24,300 & $0.1 \%$ & 24,300 & $0.1 \%$ \\
\hline \multirow[t]{7}{*}{ Shell } & Anacortes & Washington & 140,800 & $0.8 \%$ & \multirow[t]{7}{*}{932,800} & \multirow[t]{7}{*}{$5.5 \%$} \\
\hline & Bakersfield & California & 65,000 & $0.4 \%$ & & \\
\hline & Deer Park & Texas & 333,700 & $2.0 \%$ & & \\
\hline & Martinez & California & 154,800 & $0.9 \%$ & & \\
\hline & Saint Rose & Louisiana & 55,000 & $0.3 \%$ & & \\
\hline & \begin{tabular}{|l}
$\begin{array}{l}\text { Saraland } \\
\text { (Mobile) }\end{array}$ \\
\end{tabular} & Alabama & 85,000 & $0.5 \%$ & & \\
\hline & Wilmington & California & 98,500 & $0.6 \%$ & & \\
\hline \multirow[t]{2}{*}{ Silver Eagle Refining } & Evanston & Wyoming & 3,000 & $0.0 \%$ & \multirow[t]{2}{*}{$\begin{array}{ll}19,000 \\
\end{array}$} & \multirow[t]{2}{*}{$0.1 \%$} \\
\hline & Woods Cross & Utah & 11,000 & $0.1 \%$ & & \\
\hline \multirow[t]{3}{*}{ Sinclair Oil Corp. } & $\begin{array}{l}\text { Evansville } \\
\text { (Casper) }\end{array}$ & Wyoming & 22,500 & $0.1 \%$ & \multirow[t]{3}{*}{150,195} & \multirow[t]{3}{*}{$0.9 \%$} \\
\hline & Sinclair & Wyoming & 62,000 & $0.4 \%$ & & \\
\hline & Tulsa & Oklahoma & 65,695 & $0.4 \%$ & & \\
\hline \multirow{3}{*}{$\begin{array}{l}\text { Somerset Refinery } \\
\text { I nc. } \\
\text { Southland Oil Co. }\end{array}$} & Somerset & Kentucky & 5,500 & $0.0 \%$ & 5,500 & $0.0 \%$ \\
\hline & \begin{tabular}{|l} 
Lumberton \\
\end{tabular} & Mississippi & 5,800 & $0.0 \%$ & \multirow[t]{2}{*}{16,800} & \multirow[t]{2}{*}{$0.1 \%$} \\
\hline & Sandersville & Mississippi & 11,000 & $0.1 \%$ & & \\
\hline \multirow[t]{4}{*}{ Sunoco Inc. } & Marcus Hook & Pennsylvania & 175,000 & $1.0 \%$ & 730,000 & $4.3 \%$ \\
\hline & \begin{tabular}{|l|} 
Toledo \\
\end{tabular} & Ohio & 140,000 & $0.8 \%$ & & \\
\hline & Tulsa & Oklahoma & 85,000 & $0.5 \%$ & & \\
\hline & Philadelphia & Pennsylvania & 330,000 & $2.0 \%$ & & \\
\hline Tenby Inc. & Oxnard & California & 2,800 & $0.0 \%$ & 2,800 & $0.0 \%$ \\
\hline \multirow[t]{6}{*}{ Tesoro } & Anacortes & Washington & 115,000 & $0.7 \%$ & \multirow[t]{6}{*}{570,500} & \multirow[t]{6}{*}{$3.4 \%$} \\
\hline & Ewa Beach & Hawaii & 93,500 & $0.6 \%$ & & \\
\hline & Mandan & \begin{tabular}{|l|} 
North \\
Dakota \\
\end{tabular} & 58,000 & $0.3 \%$ & & \\
\hline & Martinez & California & 166,000 & $1.0 \%$ & & \\
\hline & Salt Lake City & Utah & 58,000 & $0.3 \%$ & & \\
\hline & Kenai & Alaska & 80,000 & $0.5 \%$ & & \\
\hline $\begin{array}{l}\text { U.S. Oil \& Refining } \\
\text { Co. }\end{array}$ & Tacoma & Washington & 35,150 & $0.2 \%$ & 35,150 & $0.2 \%$ \\
\hline Ultramar I nc. & Wilmington & California & 80,887 & $0.5 \%$ & 80,887 & $0.5 \%$ \\
\hline United Refining Co. & Warren & Pennsylvania & 65,000 & $0.4 \%$ & 65,000 & $0.4 \%$ \\
\hline
\end{tabular}




\begin{tabular}{|c|c|c|c|c|c|c|}
\hline Company & Site & State & $\begin{array}{r}\text { Capacity } \\
(\mathrm{b} / \mathrm{cd})\end{array}$ & Share & $\begin{array}{r}\text { Company } \\
\text { - Total } \\
\text { (b/cd) }\end{array}$ & $\begin{array}{r}\text { Share } \\
\text { company }\end{array}$ \\
\hline \multirow[t]{12}{*}{ Valero Energy Corp. } & Ardmore & Oklahoma & 85,000 & $0.5 \%$ & \multirow[t]{12}{*}{$1,416,000$} & \multirow[t]{12}{*}{$8.4 \%$} \\
\hline & Benicia & California & 144,000 & $0.9 \%$ & & \\
\hline & Corpus Christi & Texas & 134,000 & $0.8 \%$ & & \\
\hline & Denver & Colorado & 28,000 & $0.2 \%$ & & \\
\hline & Houston & Texas & 83,000 & $0.5 \%$ & & \\
\hline & Krotz Springs & Louisiana & 83,000 & $0.5 \%$ & & \\
\hline & Paulsboro & New Jersey & 167,000 & $1.0 \%$ & & \\
\hline & St. Charles & Louisiana & 155,000 & $0.9 \%$ & & \\
\hline & \begin{tabular}{|l} 
Sunray \\
(McKee)
\end{tabular} & Texas & 155,000 & $0.9 \%$ & & \\
\hline & Texas City & Texas & 215,000 & $1.3 \%$ & & \\
\hline & Three Rivers & Texas & 90,000 & $0.5 \%$ & & \\
\hline & Wilmington & California & 77,000 & $0.5 \%$ & & \\
\hline \multirow[t]{2}{*}{ Williams } & North Pole & Alaska & 227,513 & $1.3 \%$ & \multirow[t]{2}{*}{407,513} & \multirow[t]{2}{*}{$2.4 \%$} \\
\hline & Memphis & Tennessee & 180,000 & $1.1 \%$ & & \\
\hline $\begin{array}{l}\text { Wynnewood } \\
\text { Refining Co. }\end{array}$ & Wynnewood & Oklahoma & 52,500 & $0.3 \%$ & 52,500 & $0.3 \%$ \\
\hline $\begin{array}{l}\text { Wyoming Refining } \\
\text { Co. }\end{array}$ & Newcastle & Wyoming & 12,500 & $0.1 \%$ & 12,500 & $0.1 \%$ \\
\hline $\begin{array}{l}\text { Young Refining } \\
\text { Corp. }\end{array}$ & Douglasville & Georgia & 5,400 & $0.0 \%$ & 5,400 & $0.0 \%$ \\
\hline
\end{tabular}




\section{Appendix B: Employee Tasks for Energy Efficiency}

One of the key steps to a successful energy management program is the involvement of all personnel. Staff may be trained in both skills and the general approach to energy efficiency in day-to-day practices. Personnel at all levels should be aware of energy use and objectives for efficiency. By passing information to everyone, each employee may be able to save energy every day. In addition, performance results should be regularly evaluated and communicated to all personnel, recognizing high performers. Examples of some simple tasks employees can do include the following (Caffal, 1995):

- Report leaks of water (both process water and dripping taps), steam and compressed air and ensure they are repaired quickly.

- Check to make sure the pressure and temperature of equipment is not set too high.

- Carry out regular maintenance of energy consuming equipment.

- Ensure that the insulation on process heating equipment is effective.

- Switch off motors, fans and machines when they are not being used and it does not affect production, quality or safety.

- Switch off unnecessary lights and relying on day lighting whenever possible.

- Use weekend and night setbacks on HVAC in any unused offices or conditioned buildings.

- Look for unoccupied, heated or cooled areas and switch off heating or cooling.

- Check that heating controls are not set too high or cooling controls set too low. In this situation, windows and doors are often left open to lower temperatures instead of lowering the heating.

- Prevent drafts from badly fitting seals, windows and doors, and hence, leakage of cool or warm air. 


\begin{tabular}{|c|c|c|c|c|c|c|c|}
\hline \multicolumn{3}{|c|}{$\frac{\text { Appendix C: Energy Managem }}{\text { ORGANIZATION }}$} & \multicolumn{2}{|c|}{ SYSTEMS MONITORING } & \multicolumn{2}{|c|}{ TECHNOLOGY } & \multirow{2}{*}{$\begin{array}{c}\text { O \& M } \\
\text { Operation \& } \\
\text { Maintenance }\end{array}$} \\
\hline & Accountability & Organization & $\begin{array}{l}\text { Monitoring \& } \\
\text { Targeting }\end{array}$ & $\begin{array}{c}\text { Utilities } \\
\text { Management }\end{array}$ & Reviews & Plans & \\
\hline 0 & $\begin{array}{l}\text { No awareness of } \\
\text { responsibility for } \\
\text { energy usage. } \\
\text { Energy not } \\
\text { specifically } \\
\text { discussed in } \\
\text { meetings. }\end{array}$ & $\begin{array}{l}\text { No energy } \\
\text { manager or } \\
\text { "energy } \\
\text { champion.” }\end{array}$ & $\begin{array}{l}\text { Energy efficiency } \\
\text { of processes on site } \\
\text { not determined. } \\
\text { Few process } \\
\text { parameters } \\
\text { monitored } \\
\text { regularly. }\end{array}$ & $\begin{array}{l}\text { No utilities } \\
\text { consumption } \\
\text { monitoring. }\end{array}$ & $\begin{array}{l}\text { No specific } \\
\text { reviews held. }\end{array}$ & $\begin{array}{l}\text { No energy } \\
\text { improvement } \\
\text { plans published. }\end{array}$ & $\begin{array}{l}\text { No written } \\
\text { procedures for } \\
\text { practices } \\
\text { affecting energy } \\
\text { efficiency. }\end{array}$ \\
\hline 1 & $\begin{array}{l}\text { Operations staff } \\
\text { aware of the } \\
\text { energy efficiency } \\
\text { performance } \\
\text { objective of the } \\
\text { site. }\end{array}$ & $\begin{array}{l}\text { Energy manager } \\
\text { is combined } \\
\text { with other tasks } \\
\text { and roles such } \\
\text { that less than } \\
10 \% \text { of one } \\
\text { person's time is } \\
\text { given to specific } \\
\text { energy } \\
\text { activities. }\end{array}$ & $\begin{array}{l}\text { Energy efficiency } \\
\text { of site determined } \\
\text { monthly or yearly. } \\
\text { Site annual energy } \\
\text { efficiency target } \\
\text { set. Some } \\
\text { significant process } \\
\text { parameters are } \\
\text { monitored. }\end{array}$ & $\begin{array}{l}\text { Utilities (like } \\
\text { power and fuel } \\
\text { consumption) } \\
\text { monitored on } \\
\text { overall site } \\
\text { basis. }\end{array}$ & $\begin{array}{l}\text { Energy only } \\
\text { reviewed as part } \\
\text { of other type } \\
\text { reviews }\end{array}$ & $\begin{array}{l}\text { Energy } \\
\text { improvement } \\
\text { plans published } \\
\text { but based on an } \\
\text { arbitrary } \\
\text { assessment of } \\
\text { opportunities. }\end{array}$ & $\begin{array}{l}\text { No procedures } \\
\text { available to } \\
\text { operating staff. }\end{array}$ \\
\hline 2 & $\begin{array}{l}\text { Energy efficiency } \\
\text { performance } \\
\text { indicators are } \\
\text { produced and } \\
\text { available to } \\
\text { operations staff. } \\
\text { Periodic energy } \\
\text { campaigns. } \\
\text { Intermittent } \\
\text { energy review } \\
\text { meetings. }\end{array}$ & $\begin{array}{l}\text { Energy manager } \\
\text { appointed } \\
\text { giving greater } \\
\text { than } 10 \% \text { of } \\
\text { time to task. } \\
\text { Occasional } \\
\text { training in } \\
\text { energy related } \\
\text { issues. }\end{array}$ & $\begin{array}{l}\text { Weekly trend } \\
\text { monitoring of } \\
\text { energy efficiency } \\
\text { of processes and of } \\
\text { site, monitored } \\
\text { against targets. } \\
\text { Process parameters } \\
\text { monitored against } \\
\text { target. }\end{array}$ & $\begin{array}{l}\text { Weekly } \\
\text { monitoring of } \\
\text { steam/power } \\
\text { balance. }\end{array}$ & $\begin{array}{l}\text { Infrequent } \\
\text { energy review. }\end{array}$ & $\begin{array}{l}\text { Energy } \\
\text { performance } \\
\text { plan published } \\
\text { based on } \\
\text { estimate of } \\
\text { opportunities. }\end{array}$ & $\begin{array}{l}\text { Procedures } \\
\text { available to } \\
\text { operators but not } \\
\text { recently } \\
\text { reviewed. }\end{array}$ \\
\hline
\end{tabular}




\begin{tabular}{|c|c|c|c|c|c|c|c|}
\hline \multicolumn{3}{|c|}{ ORGANIZATION } & \multicolumn{2}{|c|}{ SYSTEMS MONITORING } & \multicolumn{2}{|c|}{ TECHNOLOGY } & \multirow{2}{*}{$\begin{array}{c}\text { O \& M } \\
\text { Operation \& } \\
\text { Maintenance }\end{array}$} \\
\hline & Accountability & Organization & $\begin{array}{c}\text { Monitoring \& } \\
\text { Targeting }\end{array}$ & $\begin{array}{c}\text { Utilities } \\
\text { Management }\end{array}$ & Reviews & Plans & \\
\hline 3 & \begin{tabular}{|l} 
Energy efficiency \\
performance \\
parameter \\
determined for all \\
energy consuming \\
areas. Operations \\
staff advised of \\
performance. All \\
employees aware \\
of energy policy. \\
Performance \\
review meetings \\
held once/month.
\end{tabular} & $\begin{array}{l}\text { Energy manager } \\
\text { in place greater } \\
\text { than } 30 \% \text { of } \\
\text { time given to } \\
\text { task. Ad-hoc } \\
\text { training } \\
\text { arranged. } \\
\text { Energy } \\
\text { performance } \\
\text { reported to } \\
\text { management. }\end{array}$ & $\begin{array}{l}\text { Daily trend } \\
\text { monitoring of } \\
\text { energy efficiency } \\
\text { of processes and } \\
\text { of site, monitored } \\
\text { against target. } \\
\text { Process } \\
\text { parameters } \\
\text { monitored against } \\
\text { targets. }\end{array}$ & $\begin{array}{l}\text { Daily } \\
\text { monitoring of } \\
\text { steam/power. } \\
\text { Steam \& fuel } \\
\text { balances } \\
\text { adjusted daily. }\end{array}$ & $\begin{array}{l}\text { Regular } \\
\text { plant/site energy } \\
\text { reviews carried } \\
\text { out. }\end{array}$ & $\begin{array}{l}\text { A five-year } \\
\text { energy } \\
\text { improvement } \\
\text { plan is published } \\
\text { based on } \\
\text { identified } \\
\text { opportunities } \\
\text { from energy } \\
\text { review. }\end{array}$ & $\begin{array}{l}\text { Procedures } \\
\text { available to } \\
\text { operators and } \\
\text { reviewed in the } \\
\text { last three years. }\end{array}$ \\
\hline 4 & $\begin{array}{l}\text { Energy efficiency } \\
\text { performance } \\
\text { parameter } \\
\text { included in } \\
\text { personal } \\
\text { performance } \\
\text { appraisals. All } \\
\text { staff involved in } \\
\text { site energy targets } \\
\text { and improvement } \\
\text { plans. Regular } \\
\text { weekly meeting to } \\
\text { review } \\
\text { performance. }\end{array}$ & $\begin{array}{l}\text { An energy } \\
\text { manager is in } \\
\text { place giving } \\
\text { greater than } 50 \% \\
\text { time to task. } \\
\text { Energy training } \\
\text { to take place } \\
\text { regularly. } \\
\text { Energy } \\
\text { performance } \\
\text { reported to } \\
\text { management and } \\
\text { actions followed } \\
\text { up. }\end{array}$ & $\begin{array}{l}\text { Same as 3, with } \\
\text { additional } \\
\text { participation in } \\
\text { energy efficiency } \\
\text { target setting. } \\
\text { Process } \\
\text { parameters } \\
\text { trended. }\end{array}$ & $\begin{array}{l}\text { Real time } \\
\text { monitoring of } \\
\text { fuel, steam and } \\
\text { steam/power } \\
\text { balance. } \\
\text { Optimum } \\
\text { balances } \\
\text { maintained. }\end{array}$ & $\begin{array}{l}\text { Site wide energy } \\
\text { studies carried } \\
\text { out at least every } \\
\text { five years with } \\
\text { follow up } \\
\text { actions } \\
\text { progressed to } \\
\text { completion }\end{array}$ & $\begin{array}{l}\text { A ten year } \\
\text { energy } \\
\text { improvement } \\
\text { plan based on } \\
\text { review is } \\
\text { published and } \\
\text { integrated into } \\
\text { the Business } \\
\text { Plan. }\end{array}$ & $\begin{array}{l}\text { Procedures are } \\
\text { reviewed regularly } \\
\text { and updated to } \\
\text { incorporate the } \\
\text { best practices. } \\
\text { Used regularly by } \\
\text { operators and } \\
\text { supervisors. }\end{array}$ \\
\hline
\end{tabular}




\section{Appendix D: Energy Management Assessment Matrix}

\section{ENERGY STAR Guidelines For Energy Management Assessment Matrix}

The U.S. EPA has developed guidelines for establishing and running an effective energy management program based on the successful practices of ENERGY STAR partners.

These guidelines, illustrated in the graphic, are structured on seven fundamental management elements that encompass specific activities.

This Assessment Matrix is designed to help organizations and energy managers compare their energy management practices to those outlined in the Guidelines. The full Guidelines can be viewed on the ENERGY STAR web site - www.energystar.gov

\section{How To Use The Assessment Matrix}

The matrix outlines the key activities identified in the ENERGY STAR Guidelines for Energy Management and three levels of implementation:

- No evidence

- Most elements

- Fully Implemented

Compare your program to the Guidelines by choosing

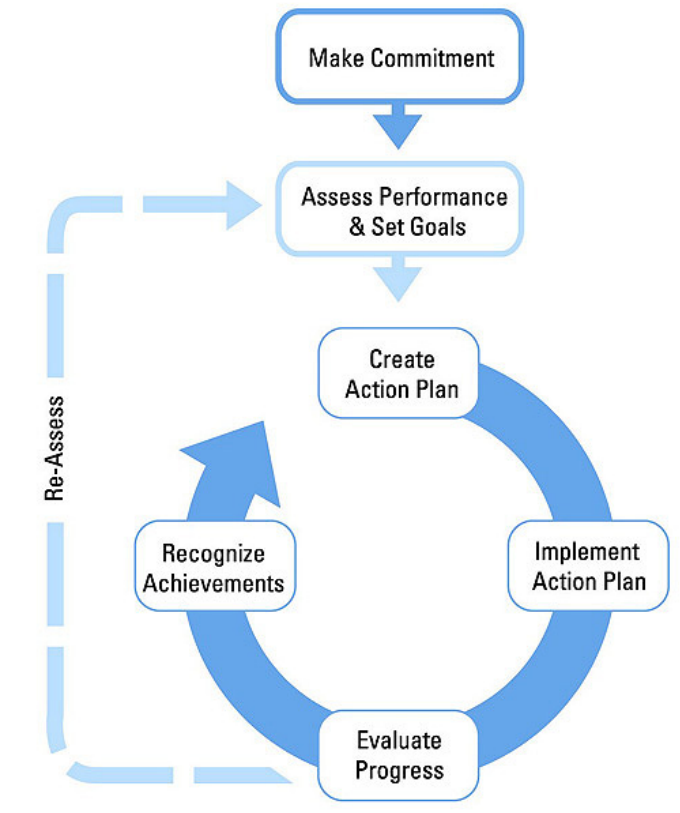
the degree of implementation that most closely matches your organization's program. You can assign yourself a score in order to help identify areas to focus on for improvement.

\section{Interpreting Your Results}

Comparing your program to the level of implementation identified in the Matrix should help you identify the strengths and weaknesses of your program.

The total "score" achieved in the matrix is less important than the process of evaluating your program's practices, identifying gaps, and determining areas for improvement.

The U.S. EPA has observed that organizations fully implementing the practices outlined in the Guidelines achieve the greatest results. Organizations are encouraged to implement the Guidelines as fully as possible.

\section{Resources and Help}

ENERGY STAR offers a variety tools and resources to help organizations strengthen their energy management programs. Here are some next steps you can take with ENERGY STAR:

1. Read the Guidelines sections for the areas where you scored lower.

2. Become an ENERGY STAR Partner, if you are not already.

3. Review ENERGY STAR Tools and Resources.

4. Find more sector-specific energy management information at www.energystar.gov.

5. Contact ENERGY for additional resources. 


\begin{tabular}{|c|c|c|c|c|}
\hline \multicolumn{5}{|l|}{$\begin{array}{l}\text { CHANGE FOR THE } \\
\text { BETTER WITH } \\
\text { ENERGY STAR } \\
\end{array}$} \\
\hline & $\begin{array}{c}0 \text { - Little or no } \\
\text { evidence }\end{array}$ & 1 - Some elements/degree & 2 - Fully implemented & Score \\
\hline \multicolumn{5}{|c|}{ Make Commitment to Continuous Improvement } \\
\hline Energy Director & $\begin{array}{c}\text { No central corporate } \\
\text { resource Decentralized } \\
\text { management }\end{array}$ & $\begin{array}{l}\text { Corporate resource not } \\
\text { empowered }\end{array}$ & $\begin{array}{c}\text { Empowered corporate } \\
\text { leader with senior } \\
\text { management support }\end{array}$ & \\
\hline Energy Team & $\begin{array}{l}\text { No company energy } \\
\text { network }\end{array}$ & Informal organization & $\begin{array}{l}\text { Active cross-functional } \\
\text { team guiding energy } \\
\text { program }\end{array}$ & \\
\hline Energy Policy & No formal policy & $\begin{array}{l}\text { Referenced in environmental } \\
\text { or other policies }\end{array}$ & $\begin{array}{c}\begin{array}{c}\text { Formal stand-alone EE } \\
\text { policy endorsed by senior } \\
\text { mgmt. }\end{array} \\
\end{array}$ & \\
\hline \multicolumn{5}{|c|}{ Assess Performance and Opportunities } \\
\hline Gather and Track Data & $\begin{array}{l}\text { Little metering/no } \\
\text { tracking }\end{array}$ & $\begin{array}{l}\text { Local or partial } \\
\text { metering/tracking/reporting }\end{array}$ & $\begin{array}{l}\text { All facilities report for } \\
\text { central } \\
\text { consolidation/analysis }\end{array}$ & \\
\hline Normalize & Not addressed & $\begin{array}{l}\text { Some unit measures or } \\
\text { weather adjustments }\end{array}$ & $\begin{array}{l}\text { All meaningful adjustments } \\
\text { for corporate analysis }\end{array}$ & \\
\hline Establish baselines & No baselines & Various facility-established & $\begin{array}{c}\text { Standardized corporate } \\
\text { base year and metric } \\
\text { established }\end{array}$ & \\
\hline Benchmark & \begin{tabular}{|c|}
$\begin{array}{c}\text { Not addressed or only } \\
\text { same site historical } \\
\text { comparisons }\end{array}$ \\
\end{tabular} & $\begin{array}{l}\text { Some internal comparisons } \\
\text { among company sites }\end{array}$ & $\begin{array}{c}\text { Regular internal \& external } \\
\text { comparisons \& analyses }\end{array}$ & \\
\hline Analyze & Not addressed & $\begin{array}{l}\text { Some attempt to identify and } \\
\text { correct spikes }\end{array}$ & $\begin{array}{l}\text { Profiles identifying trends, } \\
\text { peaks, valleys \& causes }\end{array}$ & \\
\hline $\begin{array}{l}\text { Technical assessments } \\
\text { and audits }\end{array}$ & Not addressed & Internal facility reviews & $\begin{array}{c}\text { Reviews by multi-functional } \\
\text { team of professionals }\end{array}$ & \\
\hline \multicolumn{5}{|c|}{ Set Performance Goals } \\
\hline Determine scope & No quantifiable goals & $\begin{array}{l}\text { Short term facility goals or } \\
\text { nominal corporate goals }\end{array}$ & $\begin{array}{l}\text { Short \& long term facility } \\
\text { and corporate goals }\end{array}$ & \\
\hline $\begin{array}{l}\text { Estimate potential for } \\
\text { improvement }\end{array}$ & No process in place & $\begin{array}{l}\text { Specific projects based on } \\
\text { limited vendor projections }\end{array}$ & $\begin{array}{c}\text { Facility } \& \text { corporate defined } \\
\text { based on experience }\end{array}$ & \\
\hline Establish goals & Not addressed & $\begin{array}{l}\text { Loosely defined or } \\
\text { sporadically applied }\end{array}$ & $\begin{array}{c}\text { Specific \& quantifiable at } \\
\text { various organizational } \\
\text { levels }\end{array}$ & \\
\hline
\end{tabular}




\begin{tabular}{|c|c|c|c|c|}
\hline \multicolumn{5}{|c|}{ Create Action Plan } \\
\hline $\begin{array}{l}\text { Define technical steps } \\
\text { and targets }\end{array}$ & Not addressed & $\begin{array}{c}\text { Facility-level consideration as } \\
\text { opportunities occur }\end{array}$ & $\begin{array}{l}\text { Detailed multi-level targets } \\
\text { with timelines to close gaps }\end{array}$ & \\
\hline $\begin{array}{l}\text { Determine roles and } \\
\text { resources }\end{array}$ & Not addressed & $\begin{array}{l}\text { Informal interested person } \\
\text { competes for funding }\end{array}$ & $\begin{array}{c}\text { Internal/external roles } \\
\text { defined \& funding identified }\end{array}$ & \\
\hline \multicolumn{5}{|c|}{ Implement Action Plan } \\
\hline $\begin{array}{l}\text { Create a communication } \\
\text { plan }\end{array}$ & Not addressed & $\begin{array}{l}\text { Tools targeted for some } \\
\text { groups used occasionally }\end{array}$ & $\begin{array}{c}\text { All stakeholders are } \\
\text { addressed on regular } \\
\text { basis }\end{array}$ & \\
\hline Raise awareness & No overt effort made & $\begin{array}{c}\text { Periodic references to energy } \\
\text { initiatives }\end{array}$ & $\begin{array}{l}\text { All levels of organization } \\
\text { support energy goals }\end{array}$ & \\
\hline Build capacity & Indirect training only & $\begin{array}{l}\text { Some training for key } \\
\text { individuals }\end{array}$ & $\begin{array}{c}\text { Broad training/certification } \\
\text { in technology \& best } \\
\text { practices }\end{array}$ & \\
\hline Motivate & Occasional mention & $\begin{array}{l}\text { Threats for non-performance } \\
\quad \text { or periodic reminders }\end{array}$ & $\begin{array}{l}\text { Recognition, financial \& } \\
\text { performance incentives }\end{array}$ & \\
\hline Track and monitor & $\begin{array}{l}\text { No system for } \\
\text { monitoring progress }\end{array}$ & Annual reviews by facilities & $\begin{array}{c}\text { Regular reviews \& updates } \\
\text { of centralized system }\end{array}$ & \\
\hline \multicolumn{5}{|c|}{ Evaluate Progress } \\
\hline Measure results & No reviews & Historical comparisons & $\begin{array}{l}\text { Compare usage \& costs } \\
\text { vs. goals, plans, } \\
\text { competitors }\end{array}$ & \\
\hline Review action plan & No reviews & Informal check on progress & $\begin{array}{l}\text { Revise plan based on } \\
\text { results, feedback \& } \\
\text { business factors }\end{array}$ & \\
\hline \multicolumn{5}{|c|}{ Recognize Achievements } \\
\hline $\begin{array}{l}\text { Provide internal } \\
\text { recognition }\end{array}$ & Not addressed & Identify successful projects & $\begin{array}{l}\text { Acknowledge contributions } \\
\text { of individuals, teams, } \\
\text { facilities }\end{array}$ & \\
\hline Get external recognition & Not sought & $\begin{array}{l}\text { Incidental or vendor } \\
\text { acknowledgement }\end{array}$ & $\begin{array}{c}\text { Government/third party } \\
\text { highlighting achievements }\end{array}$ & \\
\hline
\end{tabular}

Total Score 


\section{Appendix E: Support Programs for Industrial Energy Efficiency Improvement}

This appendix provides a list of energy efficiency supports available to industry. A brief description of the program or tool is given, as well as information on its target audience and the URL for the program. Included are federal and state programs. Use the URL to obtain more information from each of these sources. An attempt was made to provide as complete a list as possible; however, information in this listing may change with the passage of time.

\section{Tools for Self-Assessment}

\section{Steam System Assessment Tool}

Description: $\quad$ Software package to evaluate energy efficiency improvement projects for steam systems. It includes an economic analysis capability.

Target Group: $\quad$ Any industry operating a steam system

Format: $\quad$ Downloadable software package (13.6 MB)

Contact: $\quad$ U.S. Department of Energy, Industry Technologies Program

URL: $\quad$ http://www.oit.doe.gov/bestpractices/steam/ssat.html

\section{Steam System Scoping Tool}

Description: Spreadsheet tool for plant managers to identify energy efficiency opportunities in industrial steam systems.

Target Group: $\quad$ Any industrial steam system operator

Format: $\quad$ Downloadable software (Excel)

Contact: $\quad$ U.S. Department of Energy, Industry Technologies Program

URL: $\quad$ http://www.oit.doe.gov/bestpractices/software_tools.shtml\#steamtool

\section{MotorMaster+}

Description:

Target Group:

Format:

Contact:

URL:
Energy efficient motor selection and management tool, including a catalog of over 20,000 AC motors. It contains motor inventory management tools, maintenance log tracking, efficiency analysis, savings evaluation, energy accounting and environmental reporting capabilities.

Any industry

Downloadable Software (can also be ordered on CD)

U.S. Department of Energy, Industry Technologies Program

http://www.oit.doe.gov/bestpractices/software tools.shtml 
ASDMaster: Adjustable Speed Drive Evaluation Methodology and Application

Description: $\quad$ Software program helps to determine the economic feasibility of an adjustable speed drive application, predict how much electrical energy may be saved by using an ASD, and search a database of standard drives.

Target Group: $\quad$ Any industry

Format: $\quad$ Software package (not free)

Contact: $\quad$ EPRI, (800) 832-7322

URL: $\quad$ http://www.epri-peac.com/products/asdmaster/asdmaster.html

AirMaster:+ Compressed Air System Assessment and Analysis Software

Description: Modeling tool that maximizes the efficiency and performance of compressed air systems through improved operations and maintenance practices

Target Group: $\quad$ Any industry operating a compressed air system

Format: Downloadable software

Contact: $\quad$ U.S. Department of Energy, Industry Technologies Program

URL: $\quad$ http://www.oit.doe.gov/bestpractices/software_tools.shtml

Fan System Assessment Tool (FSAT)

Description: The Fan System Assessment Tool (FSAT) helps to quantify the potential benefits of optimizing fan system. FSAT calculates the amount of energy used by a fan system; determines system efficiency; and quantifies the savings potential of an upgraded system.

Target Group: $\quad$ Any user of fans

Format: $\quad$ Downloadable software

Contact: $\quad$ U.S. Department of Energy, Industry Technologies Program

URL: $\quad$ http://www.oit.doe.gov/bestpractices/software_tools.shtml

Pump System Assessment Tool (PSAT)

Description: $\quad$ The tool helps industrial users assess the efficiency of pumping system operations. PSAT uses achievable pump performance data from Hydraulic Institute standards and motor performance data from the MotorMaster + database to calculate potential energy and associated cost savings.

Target Group: $\quad$ Any industrial pump user

Format: Downloadable software

Contact: $\quad$ U.S. Department of Energy, Industry Technologies Program

URL: $\quad$ http://www.oit.doe.gov/bestpractices/steam/psat.html 
ENERGY STAR Portfolio Manager

Description: Online software tool helps to assess the energy performance of buildings by providing a 1-100 ranking of a building's energy performance relative to the national building market. Measured energy consumption forms the basis of the ranking of performance.

Target Group: $\quad$ Any building user or owner

Format: Online software tool

Contact: U.S. Environmental Protection Agency,

URL: http://www.energystar.gov/index.cfm?c=business.bus_index

\section{Optimization of the Insulation of Boiler Steam Lines - 3E Plus}

Description:

Downloadable software to determine whether boiler systems can be optimized through the insulation of boiler steam lines. The program calculates the most economical thickness of industrial insulation for a variety of operating conditions. It makes calculations using thermal performance relationships of generic insulation materials included in the software.

Target Group: $\quad$ Energy and plant managers

Format: Downloadable software

Contact: $\quad$ U.S. Department of Energy, Industry Technologies Program

URL: $\quad$ http://www.oit.doe.gov/bestpractices/software_tools.shtml 


\section{Assessment and Technical Assistance}

\section{Industrial Assessment Centers}

Description: Small- to medium-sized manufacturing facilities can obtain a free energy and waste assessment. The audit is performed by a team of engineering faculty and students from 30 participating universities in the United States and assesses the plant's performance and recommends ways to improve efficiency.

Target Group: $\quad$ Small- to medium-sized manufacturing facilities with gross annual sales below $\$ 75$ million and fewer than 500 employees at the plant site.

Format:

A team of engineering faculty and students visits the plant and prepares a written report with energy efficiency, waste reduction and productivity recommendations.

Contact: $\quad$ U.S. Department of Energy, Industry Technologies Program

URL: $\quad$ http://www.oit.doe.gov/iac/

Plant-Wide Audits

Description:

Target Group:

Format:

Contact:

URL:
An industry-defined team conducts an on-site analysis of total energy use and identifies opportunities to save energy in operations and in motor, steam, compressed air and process heating systems. The program covers $50 \%$ of the audit costs.

Large plants

Solicitation (put out regularly by DOE)

U.S. Department of Energy, Industry Technologies Program

http://www.oit.doe.gov/bestpractices/plant_wide_assessments.shtml

\section{Manufacturing Extension Partnership (MEP)}

Description: $\quad$ MEP is a nationwide network of not-for-profit centers in over 400 locations providing small- and medium-sized manufacturers with technical assistance. A center provides expertise and services tailored to the plant, including a focus on clean production and energy efficient technology.

Target Group: $\quad$ Small- and medium-sized plants

Format: $\quad$ Direct contact with local MEP Office

Contact: $\quad$ National Institute of Standards and Technology, (301) 975-5020

URL: $\quad$ http://www.mep.nist.gov/ 
Small Business Development Center (SBDC)

Description: $\quad$ The U.S Small Business Administration (SBA) administers the Small Business Development Center Program to provide management assistance to small businesses through 58 local centers. The SBDC Program provides counseling, training and technical assistance in the areas of financial, marketing, production, organization, engineering and technical problems and feasibility studies, if a small business cannot afford consultants.

Target Group: $\quad$ Small businesses

Format: $\quad$ Direct contact with local SBDC

Contact: $\quad$ Small Business Administration, (800) 8-ASK-SBA

URL: $\quad$ http://www.sba.gov/sbdc/

ENERGY STAR - Selection and Procurement of Energy Efficient Products for Business

Description: ENERGY STAR identifies and labels energy efficient office equipment. Look for products that have earned the ENERGY STAR. They meet strict energy efficiency guidelines set by the EPA. Office equipment included such items as computers, copiers, faxes, monitors, multifunction devices, printers, scanners, transformers and water coolers.

Target Group: $\quad$ Any user of labeled equipment.

Format: Website

Contact: $\quad$ U.S. Environmental Protection Agency

URL: $\quad$ http://www.energystar.gov/index.cfm?c=business.bus_index 


\section{Training}

\section{Best Practices Program}

Description: The Best Practices Program of the Office for Industrial Technologies of U.S. DOE provides training and training materials to support the efforts of the program in efficiency improvement of utilities (compressed air, steam) and motor systems (including pumps). Training is provided regularly in different regions. One-day or multi-day trainings are provided for specific elements of the above systems. The Best Practices program also provides training on other industrial energy equipment, often in coordination with conferences. A clearinghouse provides answers to technical questions and on available opportunities: 202-5862090 or http://www.oit.doe.gov/clearinghouse/

Target Group: $\quad$ Technical support staff, energy and plant managers

Format:

Contact:

URL: Various training workshops (one day and multi-day workshops) U.S. Department of Energy, Industry Technologies Program http://www.oit.doe.gov/bestpractices/training/

ENERGY STAR Description:

Target Group:

Format:

Contact:

URL:
As part of ENERGY STAR's work to promote superior energy management systems, energy managers for the companies that participate in ENERGY STAR are offered the opportunity to network with other energy managers in the partnership. The networking meetings are held monthly and focus on a specific strategic energy management topic to train and strengthen energy managers in the development and implementation of corporate energy management programs.

Corporate and plant energy managers

Web-based teleconference

Climate Protection Partnerships Division, U.S. Environmental Protection Agency http://www.energystar.gov/ 


\section{Financial Assistance}

Below the major federal programs are summarized that provide assistance for energy efficiency investments. Many states also offer funds or tax benefits to assist with energy efficiency projects.

\section{Industries of the Future - U.S. Department of Energy}

Description: Collaborative R\&D partnerships in nine vital industries. The partnership consists of the development of a technology roadmap for the specific sector and key technologies, and cost-shared funding of research and development projects in these sectors.

Target Group: Nine selected industries: agriculture, aluminum, chemicals, forest products, glass, metal casting, mining, petroleum and steel.

Format: Solicitations (by sector or technology)

Contact: $\quad$ U.S. Department of Energy, Industry Technologies Program

URL: $\quad$ http://www.eere.energy.gov/industry/technologies/industries.html

Inventions \& Innovations (I\&I)

Description: $\quad$ The program provides financial assistance through cost-sharing of 1) early development and establishing technical performance of innovative energy-saving ideas and inventions (up to \$75,000) and 2) prototype development or commercialization of a technology (up to \$250,000). Projects are performed by collaborative partnerships and must address industry-specified priorities.

Target Group: $\quad$ Any industry (with a focus on energy intensive industries)

Format: Solicitation

Contact: $\quad$ U.S. Department of Energy, Industry Technologies Program

URL: $\quad$ http://www.eere.energy.gov/inventions/

National Industrial Competitiveness through Energy, Environment and Economics (NICE $\left.{ }^{3}\right)$

Description: Cost-sharing program to promote energy efficiency, clean production and economic competitiveness in industry through state and industry partnerships (large and small business) for projects that develop and demonstrate advances in energy efficiency and clean production technologies. Applicants must submit project proposals through a state energy, pollution prevention or business development office. Nonfederal cost share must be at least $50 \%$ of the total cost of the project.

Target Group: $\quad$ Any industry

Format: $\quad$ Solicitation

Contact: $\quad$ U.S. Department of Energy, Industry Technologies Program

URL: $\quad$ http://www.eere.energy.gov/wip/program/nice3.html 


\section{Small Business Administration (SBA)}

Description: The Small Business Administration provides several loan and loan guarantee programs for investments (including energy efficient process technology) for small businesses.

Target Group: $\quad$ Small businesses

Format:

Direct contact with SBA

Contact:

Small Business Administration

URL:

http://www.sba.gov/ 


\section{State and Local Programs}

Many state and local governments have general industry and business development programs that can be used to assist businesses in assessing or financing energy efficient process technology or buildings. Please contact your state and local government to determine what tax benefits, funding grants, or other assistance they may be able to provide your organization. This list should not be considered comprehensive but instead merely a short list of places to start in the search for project funding. Below we summarize selected programs earmarked specifically for support of energy efficiency activities.

\section{California - Public Interest Energy Research (PIER)}

Description: PIER provides funding for energy efficiency, environmental, and renewable energy projects in the state of California. Although there is a focus on electricity, fossil fuel projects are also eligible.

Target Group: $\quad$ Targeted industries (e.g., food industries) located in California

Format: $\quad$ Solicitation

Contact: $\quad$ California Energy Commission, (916) 654-4637

URL: $\quad$ http://www.energy.ca.gov/pier/funding.html

California - Energy Innovations Small Grant Program (EISG)

Description: EISG provides small grants for development of innovative energy technologies in California. Grants are limited to \$75,000.

Target Group: $\quad$ All businesses in California

Format: $\quad$ Solicitation

Contact: $\quad$ California Energy Commission, (619) 594-1049

URL: $\quad$ http://www.energy.ca.gov/research/innovations/index.html

\section{Indiana - Industrial Programs}

Description: The Energy Policy Division of the Indiana Department of Commerce operates two industrial programs. The Industrial Energy Efficiency Fund (IEEF) is a zero-interest loan program (up to $\$ 250,000$ ) to help Indiana manufacturers increase the energy efficiency of manufacturing processes. The fund is used to replace or convert existing equipment, or to purchase new equipment as part of a process/plant expansion that will lower energy use. The Distributed Generation Grant Program (DGGP) offers grants of up to $\$ 30,000$ or up to $30 \%$ of eligible costs for distributed generation with an efficiency over $50 \%$ to install and study distributed generation technologies such as fuel cells, micro turbines, cogeneration, combined heat \& power and renewable energy sources. Other programs support can support companies in the use of biomass for energy, research or building efficiency.

Target Group: $\quad$ Any industry located in Indiana

Format: Application year-round for IEEF and in direct contact for DGGP

Contact: Energy Policy Division, (317) 232-8970.

URL: http://www.in.gov/doc/businesses/EP_industrial.html 


\section{Iowa - Alternate Energy Revolving Loan Program}

Description: $\quad$ The Alternate Energy Revolving Loan Program (AERLP) was created to promote the development of renewable energy production facilities in the state.

Target Group: $\quad$ Any potential user of renewable energy

Format: $\quad$ Proposals under $\$ 50,000$ are accepted year-round. Larger proposals are accepted on a quarterly basis.

Contact: $\quad$ Iowa Energy Center, (515) 294-3832

URL: $\quad$ http://www.energy.iastate.edu/funding/aerlp-index.html

New York - Industry Research and Development Programs

Description: The New York State Energy Research \& Development Agency (NYSERDA) operates various financial assistance programs for New York businesses. Different programs focus on specific topics, including process technology, combined heat and power, peak load reduction and control systems.

Target Group: $\quad$ Industries located in New York

Format: $\quad$ Solicitation

Contact: $\quad$ NYSERDA, (866) NYSERDA

URL: $\quad$ http://www.nyserda.org/programs/Commercial_Industrial/default.asp?i=2

\section{Wisconsin - Focus on Energy}

Description: $\quad$ Energy advisors offer free services to identify and evaluate energysaving opportunities, recommend energy efficiency actions, develop an energy management plan for business; and integrate elements from national and state programs. It can also provide training.

Target Group: $\quad$ Industries in Wisconsin

Format: $\quad$ Open year round

Contact:

Wisconsin Department of Administration, (800) 762-7077

URL:

http://focusonenergy.com/page.jsp?pageId=4 